\title{
Determinants of treatment defaulting among tuberculosis patients in Khartoum State, Sudan
}

Citation for published version (APA):

Ali, A. O. A. (2021). Determinants of treatment defaulting among tuberculosis patients in Khartoum State, Sudan. [Doctoral Thesis, Maastricht University]. Maastricht University.

https://doi.org/10.26481/dis.20210420aa

Document status and date:

Published: 01/01/2021

DOI:

10.26481/dis.20210420aa

Document Version:

Publisher's PDF, also known as Version of record

\section{Please check the document version of this publication:}

- A submitted manuscript is the version of the article upon submission and before peer-review. There can be important differences between the submitted version and the official published version of record.

People interested in the research are advised to contact the author for the final version of the publication, or visit the DOI to the publisher's website.

- The final author version and the galley proof are versions of the publication after peer review.

- The final published version features the final layout of the paper including the volume, issue and page numbers.

Link to publication

\footnotetext{
General rights rights.

- You may freely distribute the URL identifying the publication in the public portal. please follow below link for the End User Agreement:

www.umlib.nl/taverne-license

Take down policy

If you believe that this document breaches copyright please contact us at:

repository@maastrichtuniversity.nl

providing details and we will investigate your claim.
}

Copyright and moral rights for the publications made accessible in the public portal are retained by the authors and/or other copyright owners and it is a condition of accessing publications that users recognise and abide by the legal requirements associated with these

- Users may download and print one copy of any publication from the public portal for the purpose of private study or research.

- You may not further distribute the material or use it for any profit-making activity or commercial gain

If the publication is distributed under the terms of Article $25 \mathrm{fa}$ of the Dutch Copyright Act, indicated by the "Taverne" license above, 


\title{
Determinants Of Treatment Defaulting Among Tuberculosis Patients In Khartoum State, Sudan
}

\author{
Dissertation \\ to obtain the degree of Doctor at Maastricht University, \\ on the authority of the Rector Magnificus Prof.dr. Rianne M. Letschert \\ in accordance with the decision of the Board of Deans, \\ to be defended in public on \\ April Tuesday 20, 2021 at 10:00 hours
}

by

Ahmed O.A Ali 
Supervisors

Prof Dr M.H.Prins

Assessment Committee

1. Prof. dr. L.J.M. Smits, (Chair);

2. Dr. A.W.A. Lensing, Bayer AG, Germany

3. Prof. dr. J.A.W. Teijink,

4. Prof. dr. H. ten Cate,

5. Prof. dr. S. Middeldorp, University of Amsterdam 


\section{Contents}

Chapter 1 General introduction 3

Chapter 2 Patient characteristics associated with non-adherence to

Tuberculosis treatment: a systematic review

Chapter 3 Patient non adherence to tuberculosis treatment in Sudan: Socio demographic factors influencing non adherence to tuberculosis therapy in Khartoum State.

Chapter 4 Disease- and treatment-related factors associated with

tuberculosis treatment default in Khartoum State, Sudan:

a case control study

Chapter 5 Patient knowledge and behavioral factors leading to nonadherence to tuberculosis treatment in Khartoum State, Sudan

Chapter 6 Barriers Leading to Treatment Default among Tuberculosis

Patients in Khartoum State, Sudan: a qualitative study

Chapter 7 Mobile health to improve adherence to tuberculosis treatment in

Khartoum state, Sudan

Chapter 8 General discussion

The impact of the research

Summary

Appendices

Appendix 1

206

Appendix 2

Acknowledgements 
Chapter 1 General introduction 


\section{General Introduction}

Tuberculosis is a disease that has been around since the dawn of humankind [1,2]. In 1882, Robert Koch (3) first discovered and described mycobacterium tuberculosis (MTB), the bacteria that causes TB in humans. More than a century later, in 1993, the World Health Organization (WHO) declared TB infection to be global public health problem [4,5]. TB continues to cause high morbidity and mortality rates, and is classified among the top ten causes of global mortality, particularly in developing countries (6).

Since then, many efforts have been undertaken by experts in international organisations, for example the World Health Organisation (WHO) and the International Union against Tuberculosis and Lung Disease (IUATLD), to tackle this health crisis. Based on an expert evaluation of the National TB Control Programme (NTCP), the WHO launched the "Directly Observed Treatment; Short-course (DOTS)" strategy in 1994 as the essential, most cost-effective means of tuberculosis control. The targets for success set by the WHO for the NTCP were to achieve a detection rate of smear positive TB cases of $70 \%$ and a cure rate of $85 \%$ in the detected cases (7-9). The success of this strategy later underpinned the development and implementation of the "Stop TB Strategy" (2006-2015), put in place to accelerate the global expansion of tuberculosis care and control (10). This was incorporated in the subsequent "End TB Strategy", launched by the WHO as a post-2015 global TB strategy. This post-2015 framework consists of three pillars and components, the first of which focuses on integrated, patient-centred care and prevention, and is based on the DOTS treatment strategy. The goal of this strategy is to end the global tuberculosis epidemic by the year 2030, and the overall vision is of a world that will be free of TB disease, with zero deaths and zero suffering due to tuberculosis $(11,12)$. 


\section{TB in Khartoum State}

TB continues to be a major public health problem in Sudan, particularly in Khartoum State, despite the fact that there has been a reduction in tuberculosis-related mortality, and a decline in incidence and prevalence (13).

Sudan ranks the $3^{\text {rd }}$ of the 10 highest burden countries in the Eastern Mediterranean region. It alone carries about $15 \%$ of TB burden in the region. In 2010, the estimated annual risk for TB in Sudan was 1.8\%, with an estimated incidence rate of 119/100,000 population (37,072 new cases for a population of 30.894 million). The prevalence of all TB cases in Sudan was estimated to be 209/100,000 population, with an overall death rate - including HIV infected TB cases - of 24/100,000 population annually. In 2018, the total number of reported cases of TB in Sudan was 20117 with a total incidence rate of 71/100.000 population; a multidrug-resistant TB (MDR-TB) incidence of 2.6/100.000 population; a TB incidence rate among people living with HIV of 2.3/100.000, and a mortality rate of 17/100.000 population (14-17).

Tuberculosis in Khartoum State remains a major public health problem. The total number of TB cases detected in 2010 was 6670; an incidence rate of 119/100.000 population (population of the state was 5.558.647 in the year 2010). The annual risk for TB was 1.8\%, hence the programme was able to detect 2196 new smear positive cases (83.5\% of the target) and achieve a cure rate of $48.4 \%$ from the detected cases. Non-adherence was $12 \%$ (the same as in 2009). The treatment failure rate was $1.0 \%$, up slightly from 2009 (0.7\%). The case fatality rate was $2.0 \%$, which is higher than in $2009(1.3 \%)$. This may be due to the increased incidence of HIV, the emergence of multi-drug resistance to $\mathrm{TB}$, treatment failure, and the high default rate (18). The treatment success rate increased from 66\% in 2011 to reach $81.0 \%$ and $84.0 \%$ in 2017 and 2018, respectively (of all registered new smear positive cases). These figures come close to the target set $(85 \%)(19,20)$. The treatment outcomes 
are illustrated in Figures 1-3 (18-20). In 2018, around 50\% of detected TB patients had new smear positive pulmonary TB (PTB), 35\% had smear negative PTB, and $15 \%$ had extra pulmonary TB (EPTB). Five percent of these cases were among children. The prevalence of multidrug resistant/ rifampicin resistant(RR) was $2.6 / 100.000$ population $(17,19,20)$. The incidence of TB in Khartoum State is similar to the national incidence estimates reported by the National Tuberculosis Control Programme ( NTCP) in 2011, but it is higher than that reported in 2018, as mentioned above $(19,20)$.

The estimated prevalence of multi drug resistant Tuberculosis ( MDRTB) and TB among HIV patients remains unclear as the NTCP does not have a well-established system in place to detect these patients. This is due to the fact that laboratory investigation is not implemented on a routine basis for HIV and drug resistant TB (i.e. TB that is resistant to rifampicin and isoniazid) (20). 
Figure 1: Prevalence of TB cases in Khartoum State 2010-2018 (18-20)

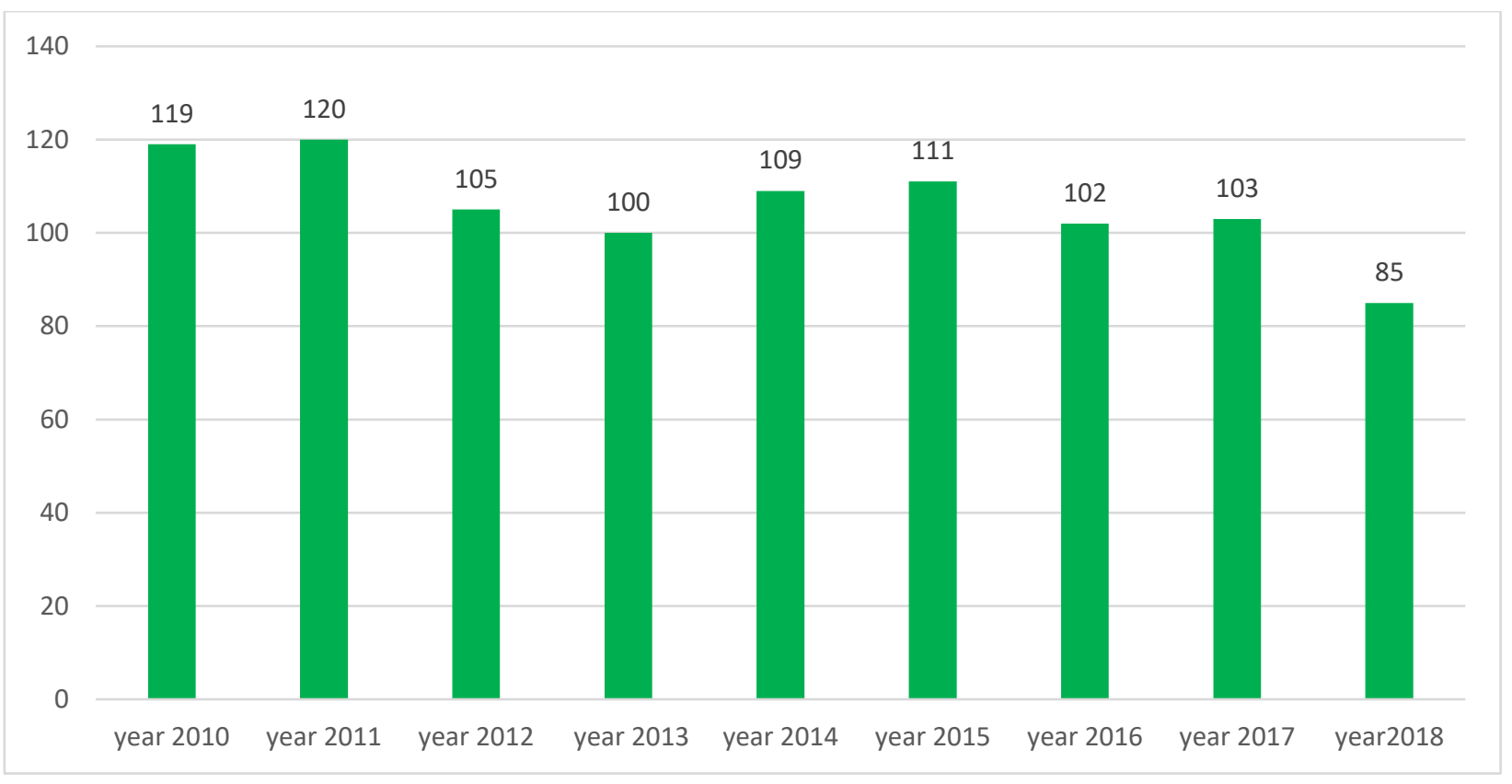

Figure 2: Outcomes of TB treatment in Khartoum State 2010-2018 (18-20)

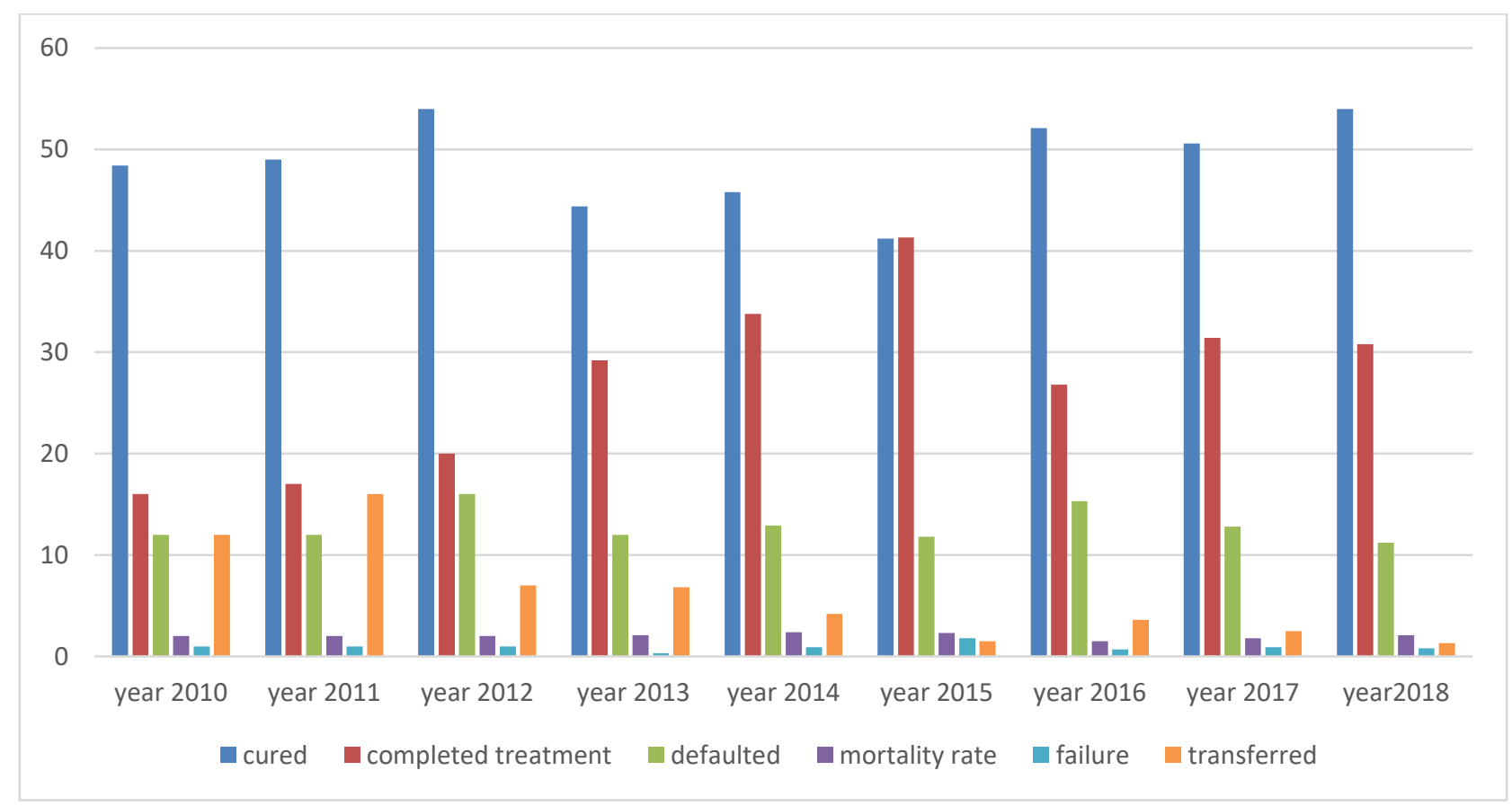


Figure 3: TB prevalence among patients living with HIV disease in Khartoum State 2010-2018 (18-20)

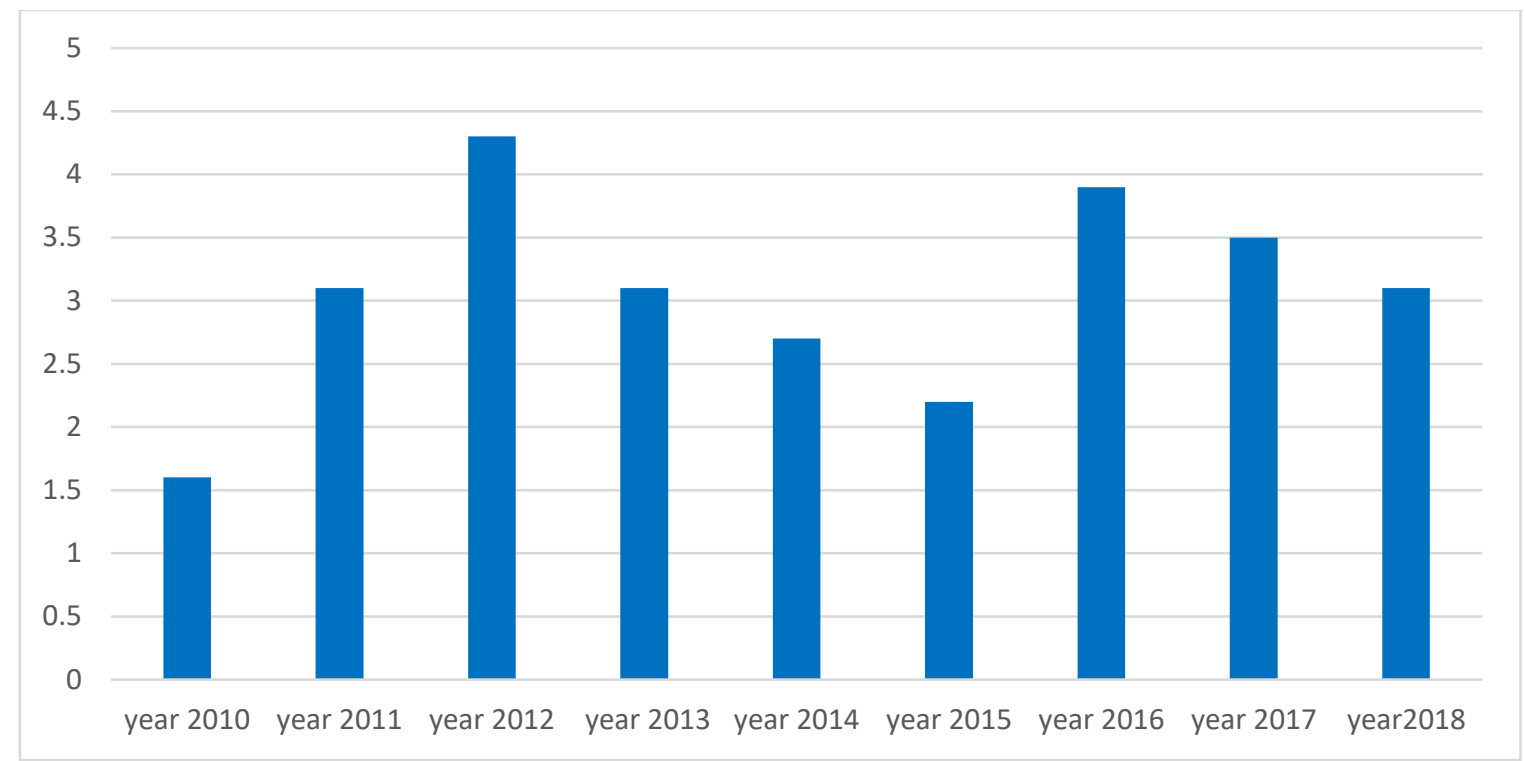

There are many organisms which can infect the lungs, including bacteria, viruses, and other parasites. However, Mycobacterium TB remains the most chronic infectious disease, and may require a treatment period exceeding six months (in contrast to other infections which may only require treatment for a few days) $(21,22)$. Furthermore, for a TB patient to be considered non-infectious, s/he should be on regular treatment for a period of more than 2 weeks (23). In some cases, a patient's health condition may require hospital admission, and absence from work, resulting in a loss of up to $30 \%$ of annual household income, or the loss of a job. Furthermore, when an individual suffers from TB, s/he may not be able to perform routine household activities such as preparing food. In some societies, TB patients may not be able to get married. Hence, TB infection can have a social, psychological and financial impact on patients, families, communities and countries (24). 
TB shows high morbidity and mortality, and has proven difficult to eliminate, despite the fact that it is both curable and preventable $(6,25,26)$. Many professionals reiterate that poor compliance associated with TB treatment remains a challenge for the national TB control programmes in developing countries and in Sudan, including Khartoum State $(27,28)$. Treatment compliance is as crucial as the early detection of disease for achieving a high cure rate (26). Despite all of the efforts taken by the TB control programme, there is still a high TB treatment default rate (14\%) in Khartoum State (29), as compared to the WHO benchmark (of less than 3\%) (30). Irregular, interrupted or incomplete TB treatment increases the risk of disease spread, treatment failure, relapse of disease, acquisition of drugresistant TB, prolonged infectiousness, and death $(27,28)$.

It has been observed that the ratio of TB cases among males to females is $1: 1$ at a young age in Sudan. This ratio increases to 2:1 among males after the age of 50 years. This finding reflects the complexity of the sociodemographic factors influencing TB treatment compliance. One study in Sudan found that, in more than $80 \%$ of TB cases, the family income was less than 100 dollar per month. Moreover, $66 \%$ of TB patients were illiterate or had received less than 6 years of schooling (15). Health is no longer considered simply as a biomedical problem; rather, it is influenced by social, cultural, physiological, economic and political factors that determine the decisions of the individuals concerned $(31,32)$. Other influential factors have also been proposed, including exposure, accessibility of TB services for diagnosis and medical treatment, stigma, behavioural factors, patient knowledge, beliefs, patient movement or change of address during the treatment course, and the receptiveness of healthcare providers $(33,34)$.

Poverty, poor nutrition, illiteracy and lack of knowledge represent major factors associated with noncompliance to treatment for TB among displaced individuals and refugees who live in camps, where TB medical services are provided in clinics managed by 
non-governmental organizations. These clinics are not fully equipped in terms of labs, trained health personnel, and the availability of medication for DR TB (18, 33-36).

Since 1993, the Ministry of Health (MOH) in Khartoum State has therefore adopted the implementation of TB treatment under the DOTS programme, in order to offer the services (TB diagnosis and medication) free of charge. The purpose of the DOTS strategy is to enhance the accessibility of services through primary health care centres (PHCC) (37). However, there are still some challenges facing the implementation of the DOTS programme, such as the inequity of health services utilization, especially in rural areas (18).

Default from TB treatment may occur during the course of the patient's referral pathway from one TB health unit to another. Treatment default can mainly be attributed to lack of reporting and close follow-up, as well as to an ineffective default tracing system. Problems with this system include a lack of transportation and communication methods, as the tracing team depends on land line telephones and irregular home visits (38).

Accordingly, NTCP policy makers have been urged to pay more attention to obstacles facing TB treatment adherence and not merely the treatment factors. In order for this to happen, it is necessary to address the social and behavioural factors influencing treatment adherence. It is also important to increase patient (and family) awareness of and knowledge about TB. In addition, it is necessary to enhance the current capacity of TB clinics, which means focusing on the workforce, the building venue, equipment, medical supplies, communication methods, transportation, and health care provider training (to improve communication skills as well as attitudes/behaviours towards TB patients). Moreover, the default tracing system should be improved by encouraging the use of active communication methods and technology such as text messages, phone calls and home visits, as well as incentives, and increasing transportation facilities. Lastly, there is a need to strengthen the coordination efforts between governmental sectors, charity associations and non- 
governmental organisations in order to streamline the socioeconomic support provided to families and patients, alongside the provision of treatment services.

In Khartoum state, despite the well-established infrastructure, and the availability of treatment for recommended regimens, the most serious challenge facing the control program is the high default rate, which, as mentioned earlier, stands at approximately 14\% (29). Only a few studies have addressed this problem and these studies have mainly focused on sociodemographic and treatment-related factors (39). In order to achieve a higher rate of treatment compliance among TB patients, further in-depth research needs to be carried out to identify the particular factors, which determine treatment default in Khartoum State. The results of this research could then be used to make recommendations to policy makers and health care providers with the aim of reducing treatment default and improving treatment adherence. We hope the results of this research will be of value to the TB control programme in Khartoum State, Sudan, and also relevant to other countries with similar health situations. We hope that this thesis will serve as resource document for the design of interventions targeted at achieving the objectives of these TB programmes.

\section{Population of Khartoum State}

Sudan it is the third-largest country in the continent of Africa. Located in the north east of Africa, Sudan is surrounded by Egypt, Libya, Chad, Central African Republic, South Sudan, Ethiopia, Eretria and the Red Sea. The surface area of Sudan is 1,882,000 km2, and it lies between latitudes $8^{\circ}$ and $23^{\circ} \mathrm{N}$. According to the last census taken in 2008, the population of Sudan is over 30.894.000. In 2018, the total population was estimated at 41.984.514 with an annual growth rate of $2.49 \%$; a birth rate of 33.0/1000; a life expectancy of 65 years (40-42), and a population density of 22.69/km2 in 2016 (43).

The country is composed of 18 states. Khartoum is the capital of Sudan and is located at the confluence of the Blue Nile and the White Nile. Although Khartoum is the smallest 
state in the country, with an area of $28.1165 \mathrm{~km} 2$, it is the most populous state, with the population estimated at 7,687,542 $(20,44)$.

\section{The National TB Control Programme(NTCP) in Khartoum State:}

The National Tuberculosis Programme (NTP) was established in Sudan in 1974, and was based upon a system of specialist Chest Units situated in hospitals. With the support of the WHO and the International Union Against Tuberculosis and Lung Disease (IUATLD), the programme was reviewed and reformed in 1993, when it fully adopted the WHO promoted DOTS strategy (37).

The TB control programme was established in Khartoum State in 1993. TB services are delivered in primary health care along with all other routine health services. The services are provided by TB health units in hospitals, health centres, non- governmental clinics and private clinics. The decentralized healthcare system in Khartoum is divided into seven districts and 19 health areas. Its health facilities include 52 hospitals, 242 health centres, 185 NGOs centres, 235 dispensaries and 365 primary health care units. TB patients receive their treatment in 53 TB health units distributed all over the state [17]. A registered nurse is designated for treatment and follow-up (continuation of treatment) in the primary health care unit, which is the basic unit of management of the program and also the unit of reporting. The healthcare team also includes a medical assistant, a laboratory technician, and a clerk. As mentioned earlier, the program follows the DOTS strategy which consists of passive case detection, ongoing government political and financial commitment to TB control, access to a regular uninterrupted drug supply, the use of short-course chemotherapy, standardized evaluation and monitoring of case detection and individual treatment outcomes, in addition to overall evaluation of TB control programme performance $(17,45)$. 


\section{Map of Sudan (46)}

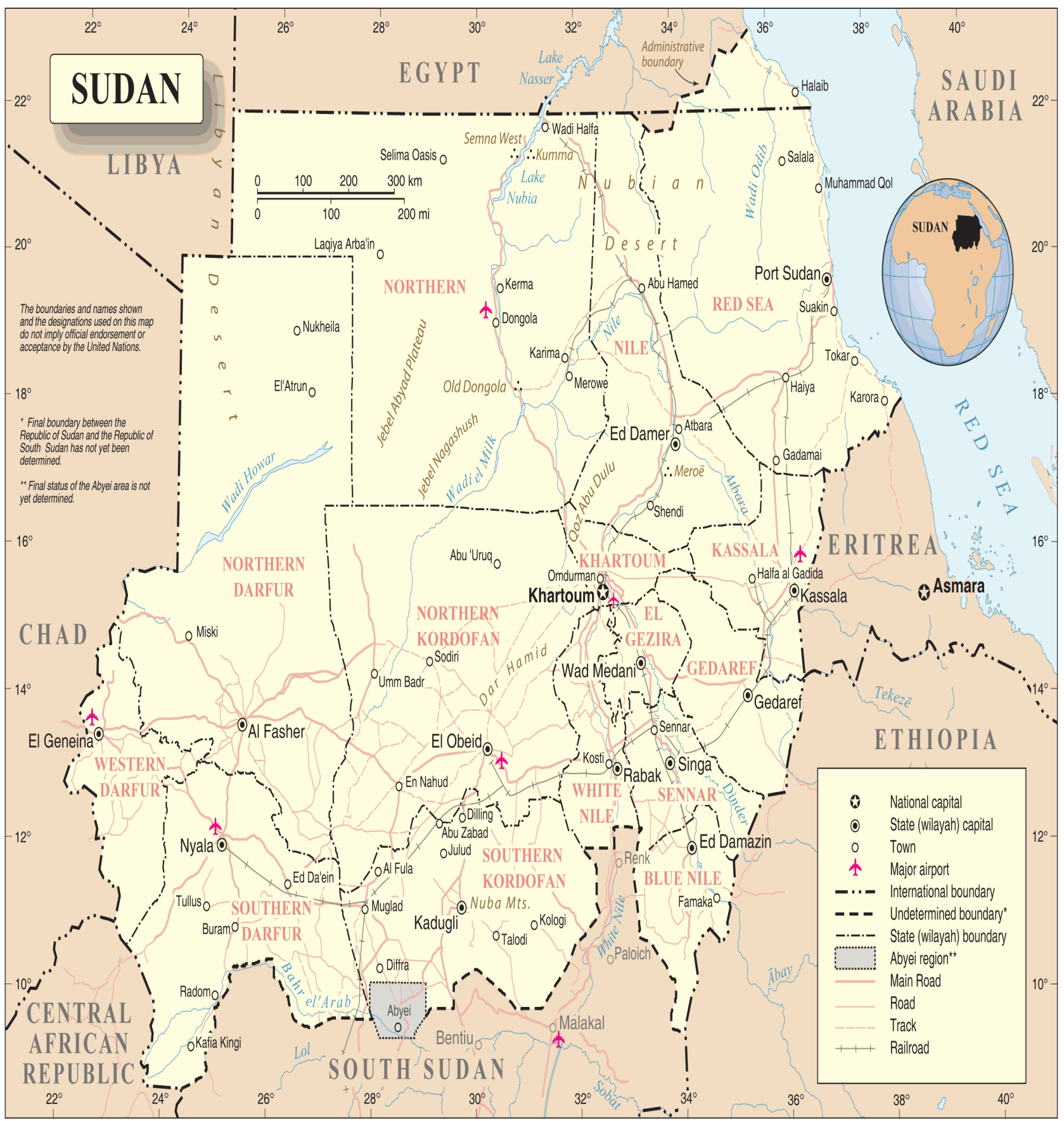




\section{Symptoms and signs of Tuberculosis:}

Tuberculosis (TB) is caused by bacteria (Mycobacterium tuberculosis) whose principle reservoir is humans. TB most often affects the lungs, occurring in about $80 \%$ of TB cases. TB may affect organs other than the lungs (this is called Extra-Pulmonary Tuberculosis), such as pleura, lymph nodes, abdomen, genitourinary tract, skin, joints, bones, and meninges. TB is mainly spread from person to person through the air. When people with lung TB cough, sneeze or spit, they propel the TB germs into the air. Bovine TB is spread by the ingestion of unpasteurized cow's milk. A person needs to inhale only a few of these germs to become infected. Of those who become infected, 10-12\% may develop tuberculosis disease. Common symptoms of active lung TB are cough with sputum and occasionally blood, chest pains, weakness, weight loss, fever and night sweats (15).

\section{Treatment of tuberculosis}

The treatment of drug-susceptible tuberculosis and the type of patient care provided is of importance in the context of the "End TB Strategy". The use of a 6-month rifampicinbased regimen $2 \mathrm{HRZE} / 4 \mathrm{HR}$ remains the recommended TB treatment option. Moreover, the use of fixed daily dosing (rather than thrice-weekly dosing) is the recommended dosing frequency for all patients with pulmonary $\mathrm{TB}$, in both the intensive and continuation phases of therapy. The drugs used for TB treatment include: Rifampicin (R); Isoniazid (INH), Ethambutol (E), Ppyrazinamide (Z), and Streptomycin (47).

\section{Multidrug-resistant TB (MDR-TB):}

Resistance to TB drugs is a formidable obstacle to effective TB care and prevention globally. Multidrug-resistant TB (MDR-TB) is multifactorial and is fuelled by improper treatment of patients, poor management of supply and quality of drugs, and airborne transmission of bacteria in public places. Case management is therefore difficult and the challenge is 
compounded by the catastrophic economic and social costs that patients incur while seeking help and while receiving treatment (48).

\section{Objectives of the thesis:}

The overall objective of this study was to identify the determinants of treatment default among TB patients in Khartoum State, so that relevant suggestions and recommendations can be made with the aim of reducing treatment default among tuberculosis patients.

The following specific objectives were identified:

- To identify the factors which influence treatment default among TB patients registered at TB health units in Khartoum state.

- To identify patient-related determinants of treatment default among TB patients (including sociodemographic factors, disease- and treatment-related factors, behavioural factors, knowledge about TB, and awareness of available TB services).

- To explore the views of health care providers and TB patients about the factors that prevent TB treatment adherence.

- To explore the magnitude of TB treatment default in Khartoum State and to identify the response of defaulting patient to the default tracing method carried out by the TB programme.

- To assess the use of mobile phones in improving adherence and decreasing the default rate among patients receiving TB medication under the DOTS programme.

- To provide advice and recommendations from the study findings to strengthen the current TB control programme in Khartoum State and to inform and improve future interventions. 


\section{Outline of the thesis}

This thesis investigates and describes the determinant factors leading to TB treatment default that need intervention by a TB control programme.

Chapter 2 provides a systematic review of the patient characteristics associated with non-adherence to tuberculosis treatment. This study will increase existing knowledge about treatment default (and the factors affecting it) and help to promote adherence to TB treatment. The aim is to reinforce the surveillance system of TB control activities and to assist health care system designers, health service providers, patients, families and the community, who are all working towards the goal of eliminating TB at state, national and international levels.

Chapter 3 describes patients' non adherence to TB treatment in Sudan, zeroing in on the socio-demographic factors influencing non adherence to tuberculosis therapy in Khartoum State. Chapter 4 outlines the disease- and treatment-related factors associated with TB treatment default in Khartoum State. Chapter 5 investigates patient knowledge about TB and behavioural factors leading to non- adherence to TB treatment in Khartoum State. Chapter 6 presents the results of a qualitative study and explores the barriers leading to treatment default among TB patients in Khartoum State. Chapter 7 describes the results of an intervention study which investigated the use of mobile phones to improve adherence to tuberculosis treatment in Khartoum state. Finally, Chapter 8 presents a summary and discussion of the findings presented in the preceding chapters, and provides a foundation for future studies to build on. 


\section{References:}

1-Kanai I. Introduction to Tuberculosis and Mycobacterium. South East- Asian Medical Information Centre Publication. International Medical Foundation of Japan. 1990; 60:3-5.

2. Smith I. Mycobacterium tuberculosis Pathogenesis and Molecular Determinants of Virulence. Clinical Microbiology Reviews; 16(3): 463-496.

3.Martini M, Besozzi G, Barberis I. The never-ending story of the fight against tuberculosis: from Koch's Bacillus to Global Control Programs. J PREV MED HYG 2018; 59: E241-E247.

4. World Health Organization. TB - A Global Emergence. Geneva:World Health Organization; 1994.

5. World Health Organization. Global Tuberculosis Control 2010.

(WHO/HTM/TB/2010.7) Geneva: WHO, 2010.

6. World Health Organization. Global Tuberculosis Report 2018.

https://books.google.com.sa/books/about/Global_Tuberculosis_Report_2018.htm

7. Thomas R F, John A S.Promoting Adherence to Treatment for Tuberculosis: the Importance of Direct Observation. Bulletin of the World Health Organization.2007; \{ HYPERLINK"https://www.who.int/bulletin/volumes/85/5/en/" \o "Volume 85, Number 5, May2007, 325-420"

8. World Health Organization. What is DOTS? A Guide to Understanding the WHO-Recommended TB Control Strategy Known as DOTS.

WHO/CDS/CPC/TB/99.270. Geneva, WHO, 1999.

9. WHO Tuberculosis Programme: framework for effective tuberculosis control. Geneva, World Health Organization, 1994 (WHO/TB/94.179)

10. World Health Organization. The Stop TB strategy: Building on and -Enhancing DOTS to meet the TB-related Millennium Development Goals. WHO/HTM/TB/2006.368. WHO, 2006. 
11. World Health Organization. Global Strategy and Targets forTtuberculosis Prevention, Care and Control after 2015. 2013; EB134/12.

http://apps.who.int/gb/ebwha/pdf_files/EB134/B134_12-en.pdf?ua=1

12. World Health Organization. The End TB Strategy.2018. $\mathrm{WHO} / \mathrm{CDS} / \mathrm{TB} / 2018.29$

13. World Health Organization, Regional Office Eastern Mediterranean. TB in Sudan http://www.emro.who.int/sdn/programmes/stop-tb-sudan.html

14. World Health Organization, Regional Office Eastern Mediterranean. top tuberculosis. http://www.emro.who.int/tuberculosis/epidemiological-situation/epidemiologicalsituation.html

15. Federal Ministry of Health. General Directorate of Primary Health Care, Sudan. National Tuberculosis Control Programme. 2011.

16. Federal Ministry of Health. Sudan National TB Management Guideline 2018.

2019/07/Sudan-National-TB-management-Guideline-March.2019-1.pdf

17. World Health Organization. Sudan Tuberculosis Profile.2018.

https://www.who.int $>$ tb $>$ country $>$ data $>$ profiles

http://www.who.int/tb/data/

18. Preventive medicine department Ministry of Health Khartoum State, Sudan. Yearly Integrated Analysis Report for Year 2009. 2010.

19. Preventive medicine department Ministry of Health Khartoum State, Sudan. Yearly Integrated Analysis Report for Year 2011.

20. Preventive Medicine Department Ministry of Health Khartoum State, Sudan. Yearly Integrated Analysis Report for Year 2012,2013, 2014,2015,2016,2017,2018. 
21. World Health Organization. WHO Guidelines on Tuberculosis Infection Prevention and Control Update 2019.2019.

WHO/CDS/TB/2019.1

22.World Health Organization. Revised WHO Classification and Treatment of Childhood Pneumonia at Health Facilities. 2014

WHO/FWC/MCA/14.8

23. Kevin S. Dick M. How Long are TB Patients Infectious?. JAMC. 2000; 163 (2):157158.

24. World health organization. The Economic Impact of Tuberculosis.2000.

WHO/CDS/STB/2000.5

25. The Global Fund to Fight AIDS, Tuberculosis and Malaria. HIV/AIDS, Tuberculosis, and Malaria: the Status and Impact of the Three Diseases [online].2005.

26. Chaulk CP; Kazandjian VA. Directly Observed Therapy for Treatment Completion of Pulmonary Tuberculosis: Consensus Statement of the Public Health Tuberculosis Guidelines Panel. The Journal of the American Medical Association 1998;279:943-8.

27. Menzies R, Rochert I, Vissandjee B. Factors Associated with Compliance in Treatment of Tuberculosis .Tuber\& and Lung Disease. 1993Jun; 74(3):32-1.

28. Jasmer RM, Seaman CB, Gonzalez LC, Kawamura LM, Osmond DH, Daley CL. Tuberculosis Treatment Outcomes: Directly Observed Therapy Compared with SelfAdministered Therapy. American Journal of Respiratory and Critical Care Medicine. 2004;170(5):561-6.

29. Suleiman M M A, Sodemann M. Evaluation of Tuberculosis Control Programme in Khartoum State for the Year 2006. Scandinavian Journal of Public Health. 2009;37:101-8. 30. World Health Organization.WHO Tuberculosis Programme.Framework for Effective Tuberculosis Control. Geneva, Switzerland, WHO /TB/94.1994:179. 
31. World Health Organization. What are the Main Factors that Influence the Implementation of Disease Prevention and Health Promotion Programmes in Children and Adolescents?. 2005. http://www.euro.who.int/_data/assets/pdf_file/0010/74674/E86766.pdf 32. Quilala D. Knowledge, Attitudes and Practices (KAP) of Public School Teachers in Ilocos Sur Regarding Tuberculosis. Philippines Journal of Internal Medicine 2005;43:15967.

33. Muture B, Keraka M, Kimuu P, Kabiru E, Ombeka V, Oguya F. Factor9s Associated with Default from Treatment Among Tuberculosis Patients in Nairobi Province, Kenya: A case control study. BMC Public Health. 2011;11:696:1-10.

34. Kate C C, Janet M B, Sarah E R , and Daniel P C. Movement of Tuberculosis Patients and the Failure to Complete Antituberculosis Treatment. . American Journal of Respiratory and Critical Care medicine .1998; 157: 1249-52.

35. World Health Organization. Tuberculosis Control in Refuges Situations on Inter Agency Field Manual.1997.

36. Eyasu E, Getenet B, Getu B, Zegeye B, Gemeda A. Factors Associated with Unsuccessful Treatment Outcome in Tuberculosis Patients Among Refugees and Their Surrounding Communities in Gambella Regional State, Ethiopia.Plos One. 2018;13(10). .https://doi.org/10.1371/journal.pone.0205468

37. El Sony AI, Baraka O, Enarson DA,Bjune G. Tuberculosis Control in Sudan Against Seemingly Insurmountable Odds. International Journal of Tuberculosis and Lung Disease 2000;4:657-64.

38. Ahmed AOA, Martin HP. Barriers leading to treatment default among tuberculosis patients in Khartoum State, Sudan: a qualitative study. Clinical and Medical Investigations.2018; Volume 3(1): 1-8. 
39. Ahmed AOA, Martin HP. Disease and Treatment-Related Factors Associated with Tuberculosis Treatment Default in Khartoum State, Sudan: a Case-Control Study. Eastern Mediterranean Health Journal.2017;23(6):408-418.

40. http://www.presidency.gov.sd/page/general-info

41.UNFPA Sudan.2019https://www.unfpa.org/data/transparency-portal/unfpa-sudan

42. The World Bank. Crude Birth Rate.2019.

https://data.worldbank.org/indicator/SP.DYN.CBRT.IN?locations=SD

43. World Bank.Sudan - Population Density (People Per Sq. Km).2016.

https://tradingeconomics.com/sudan/population-density-people-per-sq-km-wb-data.html.

44. Sudan University of Science and Technology. 2019.

http://www.sustech.edu/khartoum_state

45. World Health organization. What is DOTS?: A Guide to Understanding the WHORecommended TB Control Strategy Known as DOTS.1999.

46.United Nation. Map of Sudan. 2012.

https://www.un.org/Depts/Cartographic/map/profile/sudan.pdf

47. World Health Organization. Treatment of Tuberculosis, Guidelines for Treatment of Susceptible Tuberculosis and Patient Care Update.2017.

48. World Health Organization. Companion Handbook to the WHO Guidelines for the Programmatic Management of Drug-Resistant Tuberculosis.2014.

WHO/HTM/TB/2014.11. 
Chapter 2 Patient characteristics associated with non-adherence to Tuberculosis treatment: a systematic review

\author{
Ahmed Osman A Ali \\ Martin H. Prins
}

Journal of Tuberculosis Research. 2020: 8: 73-92 


\section{Abstract}

Background: A high level of adherence to treatment is essential for cure and prevention of tuberculosis (TB) treatment resistance.

Methods: A Systematic review of 53 studies addressing the patient characteristics associated with TB medication non-adherence was performed. The publications were identified by searching the PubMed, World Health Organization (WHO), and Centers for Disease Control and Prevention (CDC) database, EmBase, Scopus database Arts, humanities, Social Science database and Google scholar. Only English language publications were eligible. Potentially eligible studies were retrieved and the full articles were assessed. The potentially eligible studies were included if they concerned patients treated for tuberculosis, reported non-adherence and reported on potential risk factors associated with non-adherence.

Results: Factors that were most frequently consistently and statistically significantly related to non-adherence to tuberculosis treatment were: family income, patient movement and changing address or giving wrong address, tuberculosis relapse or multidrug-resistant TB (MDRTB), during intensive phase of treatment, history of default, treatment regimen(long course), response to treatment, homeless, stigma, seeking traditional healers, staff receptiveness, lack of directly observed therapy short course (DOTS), poor knowledge or lack of health education, side effects of drugs, feeling better, alcohol intake and lack of family and social support.

Conclusions: Non- adherence to tuberculosis treatment was influenced by several factors.

\section{Keywords}

Tuberculosis, non-adherence, adherence, defaulter, compliance. 


\section{Introduction:}

Tuberculosis (TB) is among the top ten causes of global mortality [1-4]. It is estimated that approximately one-third of the world's population (approximately two billion people)is infected with tuberculosis bacillus[5-7]. In 2015, globally 10.4 million new cases of TB and 1.8 million deaths from TB occurred, of which 1.4 million among HIV-negative people and 0.4 million deaths were in HIV-positive people and thus officially classified as HIV deaths in the International Statistical Classification of Diseases[8-10]. Approximately $80 \%$ of TB cases are found in 22 countries; the highest incidence rates being found in Africa and SouthEast Asia[11].

TB has a high morbidity and mortality rate despite its status as a treatable disease[12,13]. A high level of adherence to treatment is essential for cure and to avoid development of resistance $[14,15]$. Thus, completion of antituberculosis treatment is the foremost priority of tuberculosis (TB) control programs. Treatment that is taken irregular, interrupted for two months or longer or is incomplete increases the risk of treatment failure, relapse of disease, acquisition of drug-resistant TB, death, and prolonged infectiousness [1621]. In turn, treatment failure and relapse can increase transmission of TB. Poor adherence to treatment is common despite various interventions aimed at improving treatment completion [22]. Non-adherence to TB medication is a major barrier to its local and global control and worsen the treatment outcome. In addition, defaulting increases the risk of drug resistance, relapse and death, and may prolong infectiousness. The objective of this systematic review was to identify the patient characteristics that are consistently associated with TB medication non-adherence. This knowledge could be helpful for health care providers and health policy makers to improve treatment adherence. The patient characteristics that we studied were: socio-demographic factors; disease related factors; treatment and services related factors; behavioral factors and social factors. 


\section{Methods:}

This systematic review was conducted to answer the question: which patient characteristics are consistently and statistically significantly associated with TB treatment non-adherence. The study reviewed publications found on risk factors associated with defaulting tuberculosis treatment that were published in English between 1990 to 2017. The publications were identified by searching the PubMed database, WHO database, and CDC database, EmBase, Scopus database, Arts, humanities, Social Science database and google scholar. Using the key words 'tuberculosis', 'mycobacterium tuberculosis', 'adherence' ,'non adherence', 'defaulting', 'risk factors', 'compliance', 'determinant factors', 'outcome of tuberculosis treatment', 'predictors', leading', 'impact', 'noncompliance', 'Anti tuberculosis treatment', and 'anti tuberculosis therapy'. Because of resource limitations, papers published in other languages were not considered. Additional reports were identified by manually reviewing the references of the studies found.

The potentially eligible studies were included if the following criteria were all met: it concerned patients treated for tuberculosis (see definition below), it reported on adherence and non adherence, it reported on potential risk factors associated with adherence and non adherence, if the type of study is observation (cohort, case-control, cross-sectional), RCT and community survey, if it is a quantitative study or combined quantitative and qualitative, and if there is association ( $\mathrm{p}$ value, odds ratio or relative risk and 95\% confidence interval, or $\mathrm{p}$ value, odds ratio or relative risk, or $\mathrm{p}$ value). The papers were excluded if they did not meet the above criteria, and if only an abstract was available. Selected articles were reviewed for information on the country of study, sample size, population source, type of the study, the statistical association, and risk factors e.g age, sex, and other associated factors.

For purpose of data review simple definition were used according to those of the World Health organization publication(WHO, 2013) [23-24]. 
A case of tuberculosis was defined as a patient in whom tuberculosis has been bacteriologically confirmed, or has been diagnosed by a clinician.

A bacteriologically confirmed TB case is one from whom a biological specimen is positive by smear microscopy, culture or WHO-approved rapid diagnostics (WRD) (such as Xpert MTB/RIF). All such cases should be notified, regardless of whether TB treatment has started.

A clinically diagnosed TB case is one who does not fulfil the criteria for bacteriological confirmation but has been diagnosed with active TB by a clinician or other medical practitioner who has decided to give the patient a full course of TB treatment. This definition includes cases diagnosed on the basis of X-ray abnormalities or suggestive histology and extrapulmonary cases without laboratory confirmation. Clinically diagnosed cases subsequently found to be bacteriologically positive (before or after starting treatment) should be reclassified as bacteriologically confirmed.

Pulmonary tuberculosis (PTB) refers to any bacteriologically confirmed or clinically diagnosed case of TB involving the lung parenchyma or the tracheobronchial tree. Miliary TB is classified as PTB because there are lesions in the lungs. Tuberculous intra-thoracic lymphadenopathy (mediastinal and/or hilar) or tuberculous pleural effusion, without radiographic abnormalities in the lungs, constitutes a case of extrapulmonary TB. A patient with both pulmonary and extrapulmonary TB should be classified as a case of PTB. Extrapulmonary tuberculosis (EPTB) refers to any bacteriologically confirmed or clinically diagnosed case of TB involving organs other than the lungs, e.g. pleura, lymph nodes, abdomen, genitourinary tract, skin, joints and bones, meninges.

Potentially eligible studies were excluded if they did not report on potential risk factors associated with adherence and non adherence, if no full articles available or if the 
review. Potentially eligible studies were retrieved and the full articles were assessed. Results are reported according to the PRISMA guidelines for systematic reviews[25].

Data was extracted by A.A.Ali. For the purpose of data extraction a simple definition for treatment adherence and nonadherence was used according to that of the World Health organization publication (WHO, 2002)[22,26]. Non - adherence (or Defaulter): A patient whose treatment was interrupted for 2 or more consecutive months.

The following five categories of risk factors for TB treatment non-adherence were considered:

1-Sociodemogaphic factors including; age, sex, ethnicity, marital status, educational level , occupation, employment status, family income, nationality, and residential locality, religion, patients moving or changing address, family size and house size [11,27-40].

2-Disease related factors including; type of tuberculosis(first time to develop tuberculosis, relapse, multi- drug resistant tuberculosis), sputum smear result, severity of disease , and site of tuberculosis[41-51].

3- The treatment and services related factors including; treatment regimen, Time of defaulting, directly observation therapy short course(DOTS), drugs availability, drug cost, response to treatment, side effects of drugs, distance of residence from treatment center, waiting time, travelling time, travelling cost, satisfaction with treatment and services, staff receptiveness towards the patients, history of default, treatment (in patient or out-patient), type of clinic(governmental or private), hospital referral, and difficulties facing tracing system for defaults [31,42,52-61].

4-Selected behavioral factors including; smoking, alcohol intake, IVDU and HIV status, homelessness, prison and immigrant $[19,45,62-66]$. 
5- Other factors influencing defaulting including; presence or absence of social support such as family support, health education and patient knowledge, stigma, chronic diseases, traditional treatment, feeling better, and need incentive[13,67-76].

When possible we extracted odds ratios (ORs), relative risks (RRs), and their 95\% confidence interval. Otherwise the direction of the association and statistical significance was used. The relationship was considered consistent if the variable was reported in 3 studies or more to be statistically significantly related with non-adherence to tuberculosis treatment and more often statistically significantly related to non-adherence than none related. Ethics approval was not required for this systematic review.

\section{Results:}

The database searching resulted in a total of 2131 identified citations. About 981 records remained after removal of duplication. Out of these 894 were excluded because they did not focus on the TB treatment and risk factors. Of the 87 abstracts that were potentially eligible, 34 were excluded after the review of the full paper or abstract (see Figure 1). Hence 53 eligible articles were finally included.

Of these 53 eligible studies, 21 were conducted in Africa, 19 in Asia, five in North America, four in Europe and four in South America.

The study design included 26 cohort studies, 17 case control studies, eight crosssectional studies, and two surveys. The main characteristics of each study are reported in table-1.

The factors associated with non- adherence to tuberculosis treatment are given in table (2a-e). Factors that were most frequently, consistently and statistically significantly related to tuberculosis treatment non-adherence were; low family income reported odds ratio(OR: 1.61 to 11.24$)$, patient moving or giving wrong address reported relative risk( RR:2.36 to5.5), tuberculosis relapse or multidrug resistant (MDR) TB (OR 1.61 to 12), intensive 
phase of treatment(OR:1.78 to117.21), history of default (OR 1.09 to8.2), long course treatment regimen (OR:1.096 to 6.9), response to treatment(OR: 2.4 to 9.9), side effect of drugs(OR:1.1 to 13.3), alcohol intake(OR:1.3 to 4.9) homeless (OR: 2.0 to 3.2), stigma(OR: 2.0 to 5.0 ), seeking traditional healers( OR:1.9 to 5.7) ,staff receptiveness (OR: 1.7 to 12.3 ), lack of DOTS (OR: 1.42 to 2.29),poor knowledge or lack of health education(OR: 1.88 to 8.67 ), lack family and social support (OR:2.14-3.23) and feeling better (OR:5.28 to 21.0).

Factors frequently but not consistently related to tuberculosis treatment nonadherence were: male, residential locality, distance to tuberculosis treatment unit, HIV status, IVDU, prison, and smoking.

All studies reported the default rates. The reported default rates ranged between $3 \%$ and $55.7 \%$. These default rates varied substantially among the studies as either cumulative or incremental percentages of all patients. Also it varied according to regimen of treatment, age, sex, ethnicity, and residential locality.

All the papers included in the systematic synthesis had reported the number of patients (the sample size) participated in the individual study. The total number of the participant subjects in all articles was 165842.

Ninety eight percent of the studies included in the systematic review showed a significant effect of the 17 related factors on TB treatment default.

The number of studies showed increased risk of TB treatment default for each of the 17 significant variables varied from 5 to 16 studies: 5/52 for homeless and seeking traditional healers; $6 / 52$ for feeling better; 7/52 for response to treatment and stigma; 8/52 for low family income, patient moving or giving wrong address, and lack of family and social support ; 11/52 for long course treatment regimen, lack of DOTS, and side effects of drugs; 12/52 for intensive phase of treatment and alcohol intake;13/52 for tuberculosis 
relapse or multidrug resistant (MDR) TB, staff receptiveness and history of default; and $16 / 52$ for poor knowledge or lack of health education and counseling. 
Figure I: Study flow diagram:

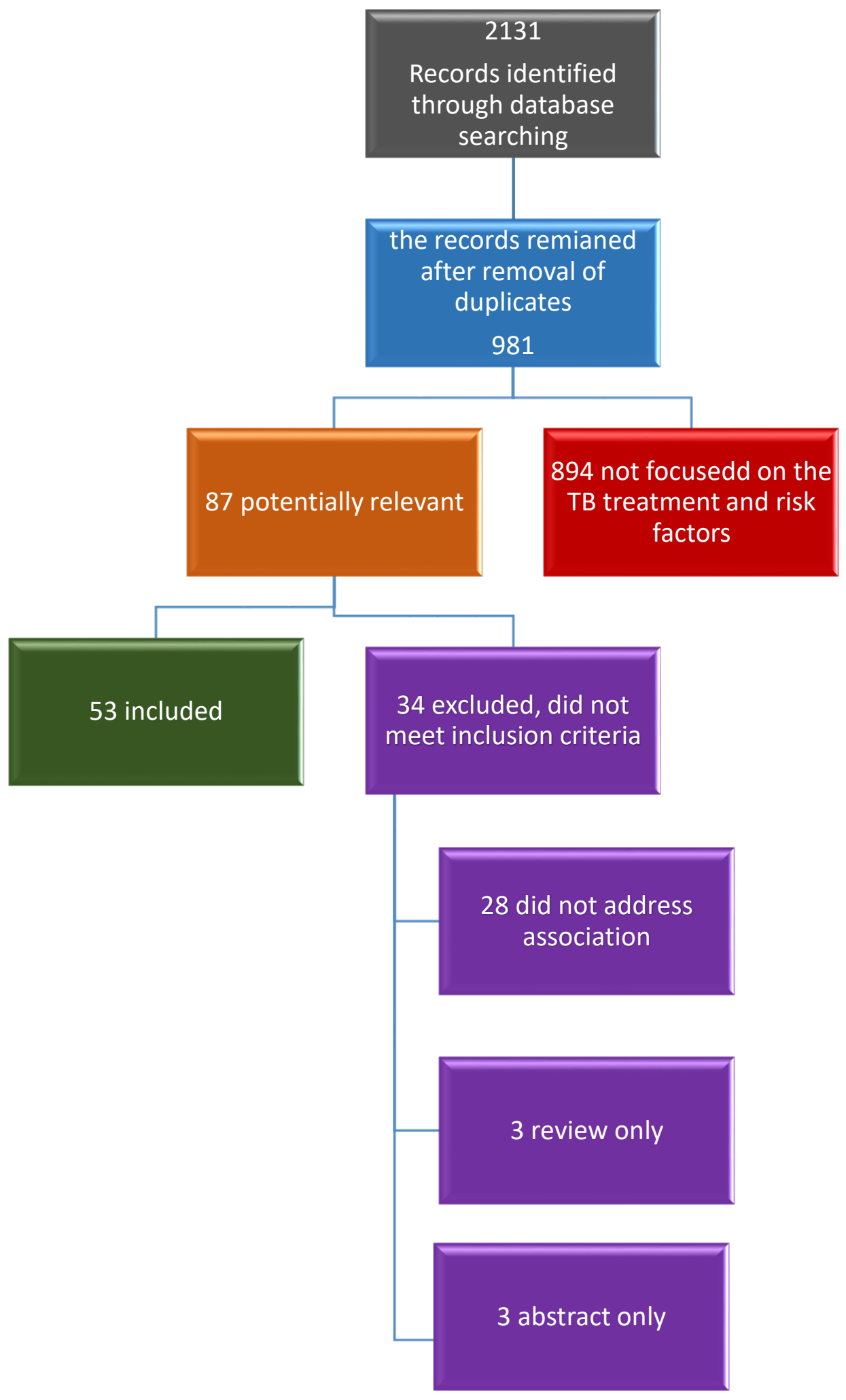

31 
Table (1): The design of the studies (Patient characteristics associated with non-adherence to tuberculosis treatment)

\begin{tabular}{|c|c|c|c|c|c|c|}
\hline NO & Author & Country & $\mathbf{N}$ & $\begin{array}{l}\text { Default } \\
\text { rate }\end{array}$ & Study type & Population \\
\hline 1 & $\begin{array}{l}\text { VAN DER Werf TS } \\
(1990)(15)\end{array}$ & Ghana & 569 & 10 & $\begin{array}{l}\text { Retrospective } \\
\text { cohort study }\end{array}$ & $\begin{array}{l}\text { Sputum-smear positive pulmonary tuberculosis (PTB) patients } \\
\text { registered between } 1984 \text { and } 1987 \text { in a rural ambulatory non- } \\
\text { supervised service program in Agogo Hospital in the hills of } \\
\text { Ashanti, Ghana, }\end{array}$ \\
\hline 2 & $\begin{array}{l}\text { Chuah SY } \\
(1991)(17)\end{array}$ & Malaysia & 227 & 33 & $\begin{array}{l}\text { Retrospective } \\
\text { cohort study }\end{array}$ & Tuberculosis patients in Perak started treatment in 1982. \\
\hline 3 & $\begin{array}{l}\text { Menzies R } \\
(1993)(18)\end{array}$ & Canada & 352 & 16 & $\begin{array}{l}\text { Retrospective } \\
\text { cohort study }\end{array}$ & $\begin{array}{l}\text { Adult Tuberculosis patients treated at the tuberculosis clinic of } \\
\text { Montreal Chest Hospital in 1987-1988. }\end{array}$ \\
\hline 4 & $\begin{array}{l}\text { Me'ndez A P (1997) } \\
(66)\end{array}$ & USA & 184 & 48 & $\begin{array}{l}\text { Retrospective } \\
\text { cohort study }\end{array}$ & $\begin{array}{l}\text { All patients in New York City with a first-time positive culture } \\
\text { for Mycibacterium tuberculosis in April } 1991 \text { were selected }\end{array}$ \\
\hline 5 & $\begin{array}{l}\text { Ngamvithayapong, J } \\
(1997)(22)\end{array}$ & Thailand & 412 & 26 & $\begin{array}{l}\text { Prospective } \\
\text { cohort }\end{array}$ & $\begin{array}{l}\text { (i)blood donors who had indicated a desire to know their HIV } \\
\text { test result; (ii) persons attending the hospital's anonymous } \\
\text { counselling and testing clinic; (iii) patients attending the } \\
\text { hospital's outpatient clinics for other illnesses but found to be } \\
\text { HIV-infected, and (iv) female commercial sex workers }\end{array}$ \\
\hline 6 & $\begin{array}{l}\text { Jochem K } \\
(1997)(24)\end{array}$ & Nepal & 693 & 14.8 & $\begin{array}{l}\text { Prospective } \\
\text { cohort study }\end{array}$ & New cases of Smear positive tuberculosis patients. \\
\hline 7 & $\begin{array}{l}\text { William J } \\
(1997)(20)\end{array}$ & USA & 294 & 18 & $\begin{array}{l}\text { Retrospective } \\
\text { cohort study }\end{array}$ & All patients treated with outpatient DOT from 1984 to 1994 \\
\hline 8 & $\begin{array}{l}\text { KATE C. } \\
(1998)(67)\end{array}$ & USA, & 2,576 & 5.5 & Cohort study & $\begin{array}{l}\text { Adult patients at least( } 15 \mathrm{yr} \text { of age }) \text { reported as having TB in } \\
\text { California during } 1993 \text {. }\end{array}$ \\
\hline 9 & $\begin{array}{l}\text { Comolet T M } \\
(1998)(27)\end{array}$ & Madagascar & 149 & 25.5 & $\begin{array}{l}\text { Case-control } \\
\text { study }\end{array}$ & Sputum positive tuberculosis patient \\
\hline 10 & $\begin{array}{l}\text { Tanguis, H G } \\
(2000)(62)\end{array}$ & Spain & 2201 & 13.1 & Cohort study & HIV-infected with TB patients between 1987 and 1996 \\
\hline
\end{tabular}


Table (1): The design of the studies (Patient characteristics associated with non-adherence to tuberculosis treatment)

\begin{tabular}{|c|c|c|c|c|c|c|}
\hline NO & Author & Country & $\mathbf{N}$ & $\begin{array}{l}\text { Default } \\
\text { rate }\end{array}$ & Study type & Population \\
\hline 11 & $\begin{array}{l}\text { Borgdorff MW J. } \\
2000)(63)\end{array}$ & Netherland & 7529 & 10 & Cohort study & Tuberculosis patient in the Netherlands in the period 1993-1997 \\
\hline 12 & $\begin{array}{l}\text { El-Sony A I } \\
(2002)(13)\end{array}$ & Sudan & 1797 & 16.9 & cross-sectional study & $\begin{array}{l}\text { All persons aged } 15-49 \text { years with respiratory symptoms seen in } \\
\text { the general health services from March } 1998 \text { to March 2000, from } \\
\text { eight states in Sudan }\end{array}$ \\
\hline 13 & Tekle B(2002) (76) & Ethiopia & 1367 & 11.3 & A case control study & New tuberculosis patients on DOTS \\
\hline 14 & $\begin{array}{l}\text { Edginton ME } \\
(2002)(29)\end{array}$ & $\begin{array}{l}\text { South } \\
\text { Africa }\end{array}$ & 303 & 5.6 & A descriptive study & $\begin{array}{l}\text { TB patients and community members in the rural Tintswalo } \\
\text { district ofthe Northern Province of South Africa registered with } \\
\text { tuberculosis in the } 18 \text {-month period }\end{array}$ \\
\hline 15 & Santha, T(2002)(41) & India & 676 & 17 & A community survey & $\begin{array}{l}\text { All tuberculosis patients registered from May } 1999 \text { through April } \\
2000\end{array}$ \\
\hline 16 & $\begin{array}{l}\text { Chan-Yeung } \\
\text { M(2003), (53) }\end{array}$ & $\begin{array}{l}\text { China,Hong } \\
\text { Kong }\end{array}$ & 5757 & 8 & $\begin{array}{l}\text { Nested case- control } \\
\text { study }\end{array}$ & $\begin{array}{l}\text { Patients registered for antituberculous drug therapy in 1996in } \\
\text { Hong Kong }\end{array}$ \\
\hline 17 & $\begin{array}{l}\text { Sophia V, (2003) } \\
(54)\end{array}$ & India, & 483 & 25 & Case control study & $\begin{array}{l}\text { New and re-treatment smear positive patients followed up till } \\
\text { treatment outcome from March to December } 1999 \text { and March } \\
1999 \text { to September } 2000 \text {. }\end{array}$ \\
\hline 19 & $\begin{array}{l}\text { Chang K C(2004) } \\
\text { (31) }\end{array}$ & $\begin{array}{l}\text { China,Hong } \\
\text { Kong }\end{array}$ & 408 & 8.5 & $\begin{array}{l}\text { Nested case-control } \\
\text { study }\end{array}$ & $\begin{array}{l}\text { All tuberculosis patients registered at the Government } \\
\text { chest clinics from } 1 \text { January } 1999 \text { to } 31 \text { March } 1999 \text {, }\end{array}$ \\
\hline 20 & Hill PC(2005), (42) & Gambia, & 301 & 25.2 & $\begin{array}{l}\text { Prospective cohort } \\
\text { study }\end{array}$ & $\begin{array}{l}\text { New cases of TB aged }>15 \text { years who started their treatment } \\
\text { between } 16 \text { October } 2002 \text { and } 26 \text { November } 2003 \text {. }\end{array}$ \\
\hline 21 & $\begin{array}{l}\text { Pandit, N S.K. } \\
\text { (2006) (70) }\end{array}$ & India & 274 & 6.2 & Cross sectional study & $\begin{array}{l}\text { All the patients who registered for DOT treatment during last } \\
\text { quarter (Oct-Nov-Dec) 2002, in Anand district, state Gujarat, } \\
\text { India }\end{array}$ \\
\hline 22 & $\begin{array}{l}\text {.Daniel OJ (2006) } \\
(64)\end{array}$ & Nigeria & 774 & 23 & $\begin{array}{l}\text { Retrospective cohort } \\
\text { study }\end{array}$ & $\begin{array}{l}\text { Adult Tuberculosis patients age } 15 \text { years and above registered for } \\
\text { anti-TB treatment DOTS between January 1997-December } 2003 \text {, } \\
\text { Sagamu, Nigeria }\end{array}$ \\
\hline
\end{tabular}


Table (1): The design of the studies (Patient characteristics associated with non-adherence to tuberculosis treatment)

\begin{tabular}{|c|c|c|c|c|c|c|}
\hline NO & Author & $\begin{array}{l}\text { Countr } \\
\text { y and } \\
\text { area }\end{array}$ & $\mathbf{N}$ & $\begin{array}{l}\text { Default } \\
\text { rate }\end{array}$ & Study type & Population \\
\hline 23 & $\begin{array}{l}\text { Estifanos B S (2007) } \\
\text { (32) }\end{array}$ & $\begin{array}{l}\text { Ethiopi } \\
\text { a }\end{array}$ & $\begin{array}{l}40 \\
4\end{array}$ & 20 & $\begin{array}{l}\text { Prospective cohort } \\
\text { study }\end{array}$ & Smear-positive tuberculosis patients in Hossana Hospital \\
\hline 24 & $\begin{array}{l}\text { Gelmanova IY } \\
(2007)(43)\end{array}$ & Russia & $\begin{array}{l}23 \\
7\end{array}$ & 8.8 & $\begin{array}{l}\text { Retrospective cohort } \\
\text { study }\end{array}$ & $\begin{array}{l}\text { Detected, smear and/or culture-positive adult TB patients } \\
\text { initiating therapy in a DOTS programme in Tomsk between } 1 \\
\text { January and } 31 \text { December } 2001\end{array}$ \\
\hline 25 & $\begin{array}{l}\text { Fahrettin T } \\
(2008)(44) \\
\end{array}$ & Turkey & $\begin{array}{l}58 \\
6 \\
\end{array}$ & 5.1 & $\begin{array}{l}\text { Retrospective cohort } \\
\text { study }\end{array}$ & $\begin{array}{l}\text { Adult pulmonary tuberculosis patient age more than } 15 \text { years in } \\
\text { Istanbul Eyup tuberculosis Dispensary between year } 1999-2004\end{array}$ \\
\hline 26 & Franke M F(2008) (50) & Peru & $\begin{array}{l}67 \\
1\end{array}$ & 10 & Retrospective cohort & Patients with multi drug resistant TB disease \\
\hline 27 & $\begin{array}{l}\text { Kapella B K } \\
(2009)(71)\end{array}$ & $\begin{array}{l}\text { Thailan } \\
\text { d }\end{array}$ & $\begin{array}{l}99 \\
5\end{array}$ & 40 & Cohort study & $\begin{array}{l}\text { Registered TB treatment (non Thai)from } 1 \text { October } 2004 \text { to } 31 \\
\text { September } 2006 .\end{array}$ \\
\hline 28 & $\mathrm{Xu} \mathrm{L} \mathrm{(2010)} \mathrm{(33)}$ & China, & $\begin{array}{l}50 \\
1\end{array}$ & 9 & $\begin{array}{l}\text { A patient-based } \\
\text { study survey }\end{array}$ & $\begin{array}{l}\text { Rural smear-positive pulmonary TB patients registered with the } \\
\text { county TB dispensaries at study sites who completed treatment } \\
\text { during the period October } 2006 \text { to September } 2007 \text {. }\end{array}$ \\
\hline 29 & Kliiman K(2010) (65) & Estonia & $\begin{array}{l}11 \\
07\end{array}$ & 9.4 & $\begin{array}{l}\text { a retrospective } \\
\text { cohort study }\end{array}$ & $\begin{array}{l}\text { Patients with culture-confirmed pulmonary TB who started } \\
\text { treatment during } 2003-2005\end{array}$ \\
\hline 30 & Samuel A B (2010) (72) & Ghana & $\begin{array}{l}16 \\
5\end{array}$ & 55.7 & Cross-sectional study & $\begin{array}{l}\text { TB patients who had registered in New Juaben District from } \\
\text { January } 2003 \text { to December } 2005 \text { (TB Registry) and had fully } \\
\text { completed their treatment during the time of the study }\end{array}$ \\
\hline 31 & Muture BN (2011) (45) & Kenya & $\begin{array}{l}197 \\
8\end{array}$ & 16.7 & A Case-Control study & $\begin{array}{l}\text { TB patients (adults and children) registered during the period January } \\
2005 \text { to March } 2007\end{array}$ \\
\hline 32 & Kelly E D(2011) (51) & $\begin{array}{l}\text { Morocc } \\
\text { o }\end{array}$ & 291 & 13 & $\begin{array}{l}\text { A retrospective cohort } \\
\text { study }\end{array}$ & Patients with smear- or culture-positive pulmonary tuberculosis \\
\hline 33 & Finlay A (2012) (46) & $\begin{array}{l}\text { South } \\
\text { Africa }\end{array}$ & $\begin{array}{l}316 \\
5\end{array}$ & 12 & $\begin{array}{l}\text { Retrospective case } \\
\text { control study }\end{array}$ & $\begin{array}{l}\text { Adult persons } \geq 18 \text { years old enrolled in treatment under DOTS at } \\
\text { public health facilities in South Africa between January } 1 \text { and December } \\
31,2002 \text {. }\end{array}$ \\
\hline 34 & Culqui D R(2012), (56) & Peru & 789 & 5 & $\begin{array}{l}\text { An unmatched - case- } \\
\text { control study }\end{array}$ & $\begin{array}{l}\text { Patients diagnosed with tuberculosis from } 2004 \text { to } 2005 \text { who completed } \\
\text { treatment until September } 2006 \text { in Peru }\end{array}$ \\
\hline
\end{tabular}


Table (1): The design of the studies (Patient characteristics associated with non-adherence to tuberculosis treatment):

\begin{tabular}{|c|c|c|c|c|c|c|}
\hline NO & Author & $\begin{array}{l}\text { Countr } \\
\text { y and } \\
\text { area }\end{array}$ & $\mathbf{N}$ & $\begin{array}{l}\text { Default } \\
\text { rate }\end{array}$ & Study type & Population \\
\hline 35 & Garrido MDS(2012) (60) & Brazilia & 11321 & 10 & Case control study & TB patients from 2005-2010 in the Amazonas State. \\
\hline 36 & $\frac{\text { Tamhane }}{(75)} \mathrm{A}(2012)$ & India & 150 & 29 & $\begin{array}{l}\text { Cross-sectional } \\
\text { study }\end{array}$ & $\begin{array}{l}\text { Newly diagnosed sputum smear-positive pulmonary tuberculosis (TB) } \\
\text { patients. }\end{array}$ \\
\hline 37 & Nezenega ZS(2013) (61) & Ethiopia & 531 & 26 & $\begin{array}{l}\text { Cross sectional } \\
\text { study }\end{array}$ & $\begin{array}{l}\text { TB patients on anti TB treatment in } 11 \text { public health centers and one } \\
\text { hospital of Sidama zone }\end{array}$ \\
\hline 38 & Lalor M K(2013) (49) & $\begin{array}{l}\text { Uzbekis } \\
\tan \end{array}$ & 710 & 20 & $\begin{array}{l}\text { A retrospective } \\
\text { cohort }\end{array}$ & $\begin{array}{l}\text { Multi and extensively drug-resistant tuberculosis patients who started } \\
\text { treatment between } 2003 \text { and } 2008 \text { and thus had finished approximately } 2 \\
\text { years of treatment by the end of } 2010 \text {. }\end{array}$ \\
\hline 39 & Slama K(2013) (39) & $\begin{array}{l}\text { Morocc } \\
\text { o }\end{array}$ & 320 & 33.8 & Case-control study & $\begin{array}{l}\text { TB patients (new cases or relapsed) who were enrolled in treatment for TB } \\
\text { between } 1 \text { January } 2009 \text { and } 31 \text { December } 2010\end{array}$ \\
\hline 40 & Alobu I(2014), (35) & Nigeria & 1668 & 9.9 & $\begin{array}{l}\text { A retrospective } \\
\text { Cohort Study }\end{array}$ & $\begin{array}{l}\text { Adult tuberculosis patients treated during } 2011 \text { and } 2012 \text { in two large health } \\
\text { facilities in Elbony state }\end{array}$ \\
\hline 41 & Vasudevan K(2014) (59) & India & 564 & 5.9 & $\begin{array}{l}\text { Retrospective } \\
\text { cohort study }\end{array}$ & TB patients registered at RNTCP in Puducherry, Southern India. \\
\hline 42 & Cherkaoui I(2014) (48) & Moroco & 277 & 3 & Case-control study & $\begin{array}{l}\text { Adult patients with definite or probable pulmonary or extrapulmonary TB } \\
\text { who either defaulted from TB treatment (cases) or successfully completed it } \\
\text { (controls) were enrolled. }\end{array}$ \\
\hline 43 & Abdelhadi. A.A(2015) (36) & Sudan & 306 & 11 & Case control study & Pulmonary TB patient \\
\hline 44 & Lackey B(2015) (38) & Peru & 1233 & 10 & $\begin{array}{l}\text { A Cohort } \\
\text { Study }\end{array}$ & $\begin{array}{l}\text { New adult smear-positive cases of pulmonary TB in a high-Incidence Area } \\
\text { of Lima district }\end{array}$ \\
\hline 45 & Roy N (2015), (55) & India & 158 & 15 & $\begin{array}{l}\text { A case-control } \\
\text { study }\end{array}$ & $\begin{array}{l}\text { New sputum-positive (NSP) tuberculosis (TB) patients in Darjeeling } \\
\text { District, West Bengal, India from August'2011 to December'2011. }\end{array}$ \\
\hline 46 & Basa S(2015), (74) & India & 550 & 7.5 & $\begin{array}{l}\text { Cross sectional } \\
\text { study }\end{array}$ & $\begin{array}{l}\text { TB patients registered under DOTS from January to June } 2005 \text { and to study } \\
\text { the reasons for default in Mayurbhanj district, Orissa, India. }\end{array}$ \\
\hline 47 & Thelma E.(2016) (37) & $\begin{array}{l}\text { Philippi } \\
\text { nes }\end{array}$ & 273 & 38 & Case-control study & $\begin{array}{l}\text { More than } 18 \text { years of age with confirmed MDR or rifampin-resistant TB } \\
\text { for whom treatment was initiated during July } 1 \text {-December } 31,2012\end{array}$ \\
\hline
\end{tabular}


Table (1): The design of the studies (Patient characteristics associated with non-adherence to tuberculosis treatment):

\begin{tabular}{|c|c|c|c|c|c|c|}
\hline NO & Author & $\begin{array}{l}\text { Country } \\
\text { and area }\end{array}$ & $\mathbf{N}$ & $\begin{array}{l}\text { Default } \\
\text { rate }\end{array}$ & Study type & Population \\
\hline 48 & $\begin{array}{l}\text { Saibannavar A (2016), } \\
\text { ( 47) }\end{array}$ & India & 411 & 6 & $\begin{array}{l}\text { A retrospective } \\
\text { cohort study }\end{array}$ & TB defaulters patients \\
\hline 49 & Ahmed A(2016),(57) & Sudan & 315 & 14 & Case control study & $\begin{array}{l}\text { Tuberculosis patients registered at tuberculosis centers at all provinces in } \\
\text { Khartoum state from May } 2010 \text { to May } 2011 .\end{array}$ \\
\hline 50 & $\begin{array}{l}\text { Ahmed OAA(2016), } \\
(58)\end{array}$ & Sudan & $\begin{array}{l}31 \\
5\end{array}$ & 14 & $\begin{array}{l}\text { Case control } \\
\text { study }\end{array}$ & $\begin{array}{l}\text { Tuberculosis patients registered at tuberculosis centers at all provinces in } \\
\text { Khartoum state from May } 2010 \text { to May } 2011 \text {. }\end{array}$ \\
\hline 51 & .Kigozi G(2017) (34) & $\begin{array}{l}\text { South } \\
\text { Africa }\end{array}$ & $\begin{array}{l}11 \\
03 \\
94\end{array}$ & 7.2 & $\begin{array}{l}\text { A retrospective } \\
\text { cohort study }\end{array}$ & $\begin{array}{l}\text { Pulmonary TB cases older than } 15 \text { years of age with a recorded pre- } \\
\text { treatment smear result registered in the ETR.Net electronic register }\end{array}$ \\
\hline 52 & $\begin{array}{l}\text { El -Muttalut M } \\
\text { (2017), (40) }\end{array}$ & Sudan & $\begin{array}{l}36 \\
6\end{array}$ & 16.4 & $\begin{array}{l}\text { A cross-sectional } \\
\text { study }\end{array}$ & TB patient in Kassala State \\
\hline 53 & $\begin{array}{l}\text { Hashim EA } \\
(2017),(73)\end{array}$ & Sudan & $\begin{array}{l}16 \\
0\end{array}$ & 21.3 & $\begin{array}{l}\text { Case-control } \\
\text { study }\end{array}$ & $\begin{array}{l}\text { Pulmonary tuberculosis treatment Al-muglad rural hospital, Al-Muglad } \\
\text { locality, West Kordofan state in Western Sudan. }\end{array}$ \\
\hline
\end{tabular}


Table 2 a : Socio-demographic factors consistently associated with non-adherence:

\begin{tabular}{|c|c|c|c|c|}
\hline No & $\begin{array}{l}\text { Socio - } \\
\text { demographic } \\
\text { factors }\end{array}$ & $\begin{array}{l}\text { Factors } \\
\text { associated \& } \\
\text { statistically } \\
\text { significant }\end{array}$ & $\begin{array}{l}\text { Factors } \\
\text { associated but } \\
\text { not statistically } \\
\text { significant }\end{array}$ & Factors not associated \\
\hline 1 & Age & $\begin{array}{l}15,32,34,71,35,36,4 \\
7,74,48,49,60\end{array}$ & $\begin{array}{l}67,41,54,42,46,37 \\
38,40\end{array}$ & $\begin{array}{l}17,18,22,20,27,, 62,63,53,3 \\
1,70,64,43,33,72,45,39,73, \\
55,56,57,58,50,51,65, \\
75,66\end{array}$ \\
\hline 2 & Gender & $\begin{array}{l}15,17,22,27,41,53,5 \\
4,64,72,45,34,47, \\
74,56,51\end{array}$ & $\begin{array}{l}20,63,44,46,38 \\
48,75\end{array}$ & $\begin{array}{l}18,, 62,31,42,32,43,71,33 \\
37,39,40,49,55,57,58 \\
50,60,65,66\end{array}$ \\
\hline 3 & Ethnicity & 47 & $20,63,54,66$ & $17,31,42,72,46$ \\
\hline 4 & Marital status & 22,47 & 45 & $\begin{array}{l}15,31,32,44,71,33,46,36 \\
38,39,40,73,49,55,56 \\
57,51,75\end{array}$ \\
\hline 5 & Educational level & $46,36,38,40,47,60$ & $\begin{array}{l}15,27,45,48,57, \\
50,75\end{array}$ & $\begin{array}{l}22,41,54,70,32,44,33,72,39 \\
, 55,56,65,66,76\end{array}$ \\
\hline 6 & Occupation & $17,47,48,57$ & 72 & $\begin{array}{l}69,41,31,42,32,71,33,36 \\
37,40\end{array}$ \\
\hline 7 & Employment status & $73,74,65$ & 48,75 & $54,43,45,46,39,49,55,76$ \\
\hline 8 & Family income & $\begin{array}{l}62,33,72,45,40,73 \\
, 47,56\end{array}$ & $54,39,48,66$ & $32,37,57,75,76$ \\
\hline 9 & Nationality, & 63 & 20,46 & $18,36,57$ \\
\hline 10 & Residential locality & $27,40,57,58,50,65$ & $20,45,35,34,37$ & $17,63,31,32,71,48,60$ \\
\hline 11 & Religion & 59 & & $27,72,46,47,56,57$ \\
\hline 12 & $\begin{array}{l}\text { Patients moving or } \\
\text { changing address }\end{array}$ & $\begin{array}{l}67,27,54,71,45,46 \\
73,57\end{array}$ & 49,75 & - \\
\hline 13 & Family size & & 48 & $45,57,75$ \\
\hline 14 & House size & 50 & & $45,39,57$ \\
\hline
\end{tabular}


Table 2 b: Behavioral factors consistently associated with non-adherence:

\begin{tabular}{|l|l|l|l|l|}
\hline No & $\begin{array}{l}\text { Behavioral } \\
\text { factors }\end{array}$ & $\begin{array}{l}\text { Factors associated } \\
\text { \& statistically } \\
\text { significant }\end{array}$ & $\begin{array}{l}\text { Factors associated } \\
\text { but not statistically } \\
\text { significant }\end{array}$ & $\begin{array}{l}\text { Factors not } \\
\text { associated }\end{array}$ \\
\hline 1 & Smoking & $31,39,48$ & $41,37,38,55$ & $49,58,51,75$ \\
\hline 2 & Alcohol intake & $\begin{array}{l}20,67,41,45,46,37,39, \\
73,, 74,55,60,65\end{array}$ & 43,66 & $\begin{array}{l}27,62,31,49, \\
58,51,65\end{array}$ \\
\hline 3 & IVDU & $67,43,38,56,50,66$ & 51 & $\begin{array}{l}20,62,71,37, \\
58\end{array}$ \\
\hline 4 & HIV status & $45,34,38,60$ & $67,62,31,64,66$ & $\begin{array}{l}20,63,13,71, \\
58\end{array}$ \\
\hline 5 & Homelessness & $20,67,62,63,66$ & 65 & $49,38,71$ \\
\hline 6 & Prison & $67,63,65$ & 62,38 & \\
\hline 7 & Immigrant & 63,74 & 22 & \\
\hline
\end{tabular}


Table 2 c: Treatment and services related factors consistently associated with non-adherence: :

\begin{tabular}{|c|c|c|c|c|}
\hline No & $\begin{array}{l}\text { Treatment and services } \\
\text { related }\end{array}$ & $\begin{array}{c}\text { Factors associated } \\
\& \text { statistically } \\
\text { significant }\end{array}$ & $\begin{array}{l}\text { Factors associated } \\
\text { but not } \\
\text { statistically } \\
\text { significant }\end{array}$ & $\begin{array}{l}\text { Factors not } \\
\text { associated }\end{array}$ \\
\hline 1 & $\begin{array}{l}\text { Treatment regimen(long } \\
\text { course) }\end{array}$ & $\begin{array}{l}18,24,13,54,72,35 \\
74,49,59,50,66\end{array}$ & & $17,67,71,47$ \\
\hline 2 & $\begin{array}{l}\text { Time of defaulting (intensive } \\
\text { phase or continuation phase }\end{array}$ & $\begin{array}{l}17,18,53,54,31,42,64 \\
45,36,59,61,76\end{array}$ & $41,37,48$ & \\
\hline 3 & DOTS & $\begin{array}{l}15,62,21,70,53,33,35, \\
74,48,60,66\end{array}$ & & 31 \\
\hline 4 & Drugs availability & 29,61 & 72 & \\
\hline 5 & Drug cost & 68,75 & & 70 \\
\hline 6 & Response to treatment & $24,20,29,54,42,43,66$ & 50 & \\
\hline 7 & Side effects of drug & $\begin{array}{l}29,31,70,43,72,37 \\
74,48,55,56,76\end{array}$ & $22,54,46,45$ & $15,20,27,39$ \\
\hline 8 & $\begin{array}{l}\text { Distance of residence from } \\
\text { treatment center }\end{array}$ & $15,29,32,33,72,47,74$ & 45,57 & $\begin{array}{l}17,22,54,37 \\
73,48,50,76\end{array}$ \\
\hline 9 & Waiting time & 29,61 & 45 & $70,46,58$ \\
\hline 10 & Travelling time & $27,42,39$ & 37,57 & $15,70,43,73,75$ \\
\hline 11 & Travelling cost & 29,42 & 32,57 & 15,70 \\
\hline 12 & $\begin{array}{l}\text { Satisfaction with treatment and } \\
\text { services }\end{array}$ & 73,61 & & 58 \\
\hline 13 & Staff receptiveness & $\begin{array}{l}18,27,29,33,72,46,37 \\
73,74,55,58,75,61\end{array}$ & 45 & \\
\hline 14 & History of default & $\begin{array}{l}18,41,53,54,31,45,46, \\
70,71,72,73,76\end{array}$ & 51 & 65 \\
\hline 15 & $\begin{array}{l}\text { Treatment (in patient or out- } \\
\text { patient) }\end{array}$ & 22,31 & & 46 \\
\hline 16 & $\begin{array}{l}\text { Type of clinic(governmental or } \\
\text { private) }\end{array}$ & & 35 & \\
\hline 17 & Hospital referral & 17 & & \\
\hline 18 & $\begin{array}{l}\text { Difficulties facing tracing } \\
\text { system for defaults }\end{array}$ & 55 & & \\
\hline 19 & $\begin{array}{l}\text { access health-care services } \\
\text { within office hours }\end{array}$ & 56 & & \\
\hline 20 & $\begin{array}{l}\text { Too many patients when } \\
\text { visiting health center }\end{array}$ & 58 & & \\
\hline 22 & health center appearance & 58 & & 76 \\
\hline
\end{tabular}


Table $2 \mathrm{~d}$ : Disease related factors consistently associated with non-adherence:

\begin{tabular}{|c|c|c|c|c|}
\hline No & $\begin{array}{l}\text { Disease related } \\
\text { factors }\end{array}$ & $\begin{array}{l}\text { Factors } \\
\text { associated \& } \\
\text { statistically } \\
\text { significant }\end{array}$ & $\begin{array}{l}\text { Factors } \\
\text { associated but } \\
\text { not statistically } \\
\text { significant }\end{array}$ & $\begin{array}{l}\text { Factors not } \\
\text { associated }\end{array}$ \\
\hline 1 & $\begin{array}{l}\text { Type of tuberculosis } \\
\text {-first time to develop TB } \\
\text { - relapse } \\
\text { - multi- drug resistant }\end{array}$ & $\begin{array}{l}67,62,41,53,43, \\
44,46,34,38,39 \\
, 49,65,66\end{array}$ & & $63,71,45,37$ \\
\hline 2 & Severity of disease & 22,51 & & $15,17,53,66$ \\
\hline 3 & Sputum smear result & $18,24,35,50,51$ & 63,34 & $\begin{array}{l}15,17,13,53,31,64,43, \\
37,60,65,66\end{array}$ \\
\hline 4 & Site of tuberculosis & 35 & $17,41,48,57$ & $53,44,39,66$ \\
\hline
\end{tabular}

Table 2 e: Other (miscellaneous) factors consistently associated with nonadherence:

\begin{tabular}{|l|l|l|l|l|}
\hline No & $\begin{array}{l}\text { Other factors } \\
\text { influencing } \\
\text { defaulting }\end{array}$ & $\begin{array}{l}\text { Factors associated } \\
\text { \& statistically } \\
\text { significant }\end{array}$ & $\begin{array}{l}\text { Factors associated but } \\
\text { not statistically } \\
\text { significant }\end{array}$ & $\begin{array}{l}\text { Factors not } \\
\text { associated }\end{array}$ \\
\hline 1 & social support & $\begin{array}{l}29,72,37,74,48,57, \\
58,76\end{array}$ & & \\
\hline 2 & Health education, & $18,27,29,54,70,72,45$, & 42 & 36 \\
& $\begin{array}{l}46,37,39,48,55,56, \\
\text { counseling and patient } \\
\text { knowledge }\end{array}$ & $\begin{array}{l}4,75,76 \\
22,29,70,72,46,36,73\end{array}$ & 45,58 & \\
\hline 3 & Stigma & 53,60 & 38,50 & $31,71,48$ \\
\hline 4 & Chronic diseases & $72,45,46,74,75$ & 41 & \\
\hline 5 & Traditional treatment & $46,36,39,40,74,48$ & & \\
\hline 6 & Feeling better & 46 & 37 & \\
\hline 7 & Need incentive & & & \\
\hline
\end{tabular}




\section{Discussion:}

The results of this systematic review show that family income, moving of patient or giving wrong address, tuberculosis relapse or MDR TB, intensive phase of treatment, history of default, long course treatment regimen, response to treatment, homeless, stigma, seeking traditional healers, staff receptiveness, DOTS, poor knowledge or lack of health education were consistently and statistically significantly related to tuberculosis treatment non-adherence. Surprisingly some frequently cited factors which were traditionally thought to be related to tuberculosis treatment non-adherence appeared to be not consistently associated with nonadherence, these include age, sex, marital status, occupation, employment status, level of education.

The most important methodological aspect of this systematic review that requires explanation is the use of a qualitative approach, i.e. counting statistical results of the patient characteristics related to non-adherence to tuberculosis treatment. Ideally, numerical results of individual studies are combined. However, when reviewing eligible studies it was discovered that in most of these primary studies only numerators were given if a factor was statistically significant related to non-adherence. Hence, only including the results of a characteristic if full numerical data was given had the potential to lead to an extreme bias. Since studies dating back to 1990 were included we assumed that it was unlikely to get full responses of all authors. Hence, we resorted to, admittedly a less optimal qualitative approach.

Some other methodological aspects of this systematic review require attention: First of all, we attempted to identify all relevant articles published up to date of this review and found a large number of relevant references. However, due to language restriction and lack of resources we only included articles in the English language. Secondly, data extraction was hampered by unclear methodology and 
definitions in many relevant studies. In addition, many relevant factors for nonadherence were not taken into account in many studies. Thirdly, the majority of articles included in this study were conducted in developing countries; the findings are therefore most applicable to countries with low resources which carry the greatest burden of TB disease and where urgent interventions are needed to improve adherence to tuberculosis treatment. However, our findings may also be applicable to more developed countries. Fourthly, our review took many types of risk factors (social and biomedical) for non - adherence to TB treatment into account while many individual articles solely have focused on the factors related to health services provision.

Overall we trust that the factors identified as consistently related to TB treatment non-adherence are of truly associated with non- adherence. For the potential risk factors for non-adherence that were not consistently associated a numerical approach in large data set of new studies might still show an association. However, it is likely that these associations are of little importance.

Exploration of the factors associated with non-adherence to tuberculosis treatment deserves some attention. Some of these factors identified can be changed and solved. These include factors associated with patient behavior: moving of patient or giving wrong address, homeless, stigma and seeking traditional healers, and factors related to treatment services: not on DOTS, long course treatment regimen, staff receptiveness and poor knowledge or lack of health education .Other factors related to non- adherence are difficult to change as they are not of patients or the treating physician control. Most of these factors are related to the treatment and the system of services provision and include: low family income, tuberculosis relapse or MDR TB, intensive phase of treatment, history of default and response to 
treatment. Hence, the presence of these factors might guide to the targeting of extra attempts to stimulate treatment adherence.

The doctor-patient-relationship offers good environment for communication giving patients comfort in expressing the obstacles they face during treatment course. This enables treating doctors and health worker staff to analyze patients' problems and provide advice, counseling and health education regarding type of disease, side effect of drug, duration of treatment, implementation of DOT short course program. Moreover, it will enable health care workers to be more flexible with patients in giving them choices and options that maintain their autonomy in treatment compliance and to overcome obstacles related to health services provision.

The doctors and health worker staff receptiveness and their effort in counseling and health education provision increases awareness of patients and their families and the whole community about Tuberculosis. The social support positively affects the patients' knowledge to counteract the feeling of guilt and shame (stigma). This will be reflected on patients' compliance with tuberculosis medication instead of seeking traditional medicine. Patients' compliance assists the tuberculosis control program to achieve high cure rates and decrease the MDR prevalence in the community.

This synthesis suggests that governmental and nongovernmental organizations need to give more attention to support poor patients financially and offer accommodation for the homeless. Another cost effective suggestion is to consider even distribution of health services to improve its availability, accessibility and affordability to all tuberculosis patients. This, combined with good referral system from health unit to hospital, will result in reduction of the cost of travelling, waiting time at tuberculosis clinic, and patient movement. Besides, good counseling to patients would encourage them to give their correct address and to report any 
change of address to health worker staffs and therefore improve adherence to tuberculosis treatment.

The review findings are important for the policy makers, medical practitioners, health worker staff and researchers to study the patient context as a whole (social, behavioral factors, believes and knowledge) and not to ignore their experience and opinion in treatment course. This will make the health care consumer share the responsibility of the treatment process and will combat non-adherence. Moreover, it helps in creating good relationship between the patients, health care providers and the whole community. This new approach in thinking will improve tuberculosis treatment adherence and will reinforce the surveillance system of tuberculosis control program at state, national and international levels.

In addition to the findings of this systematic review we believe that further studies are needed to be conducted to deeply understand different aspects of tuberculosis disease and its treatment (social and biomedical) aspects which is a complex process. These studies should include the experience of policy makers, the health personnel working in the field, nongovernmental organizations, patient support groups and the community leaders. Moreover, the patients' knowledge about tuberculosis for example, patient satisfaction with health services provision and staff receptiveness. This will substantially help the health care system planners in developing good future strategy to improve treatment adherence among tuberculosis patients. 


\section{Conclusions:}

Non adherence to tuberculosis treatment is a complex dynamic process which was influenced by multiple factors. Identifying and understanding the nature of these factors facilitates development of appropriate and effective intervention plans.

The relationship between the identifiable variables and TB treatment default is important for the knowledge of policy makers and clinicians dealing with TB patients. Despite the fact that association of these variables with increased risk of TB treatment default had been reported in many individual studies, it had not received attention in terms of planning, training, guidelines, and research. This systematic review attempts to alter the current situation with the aim to increase Knowledge about treatment default and to promote adherence to TB treatment.

The results of our review can help to find out the consistently statistically related factors to TB default treatment and assist the health care system designers, health service providers including clinicians, nurses, counselors, patients, families, and the community leading to high adherence to tuberculosis treatment, reinforcing the surveillance system of tuberculosis control program hence achieving the goal of tuberculosis elimination at state, national and international levels.

\section{Acknowledgements}

We would like to thank our Colleagues at $\mathrm{MOH}$ Khartoum State and TB control Programme.

\section{Conflicts of interest}

The authors declare no conflicts of interest regarding the publication of this paper. 


\section{References:}

[1] World Health Organization (2000) The World Health Report about Health Systems Improving Performance. Geneva.

[2] Murray, C.J. and Lopez, A.D. (1997) Mortality by Cause for Eight Regions of the World: Global Burden of Disease Study. The Lancet , 349, 1269-1276. https://doi.org/10.1016/S0140-6736(96)07493-4

[3] Jasmin, J., Anju, K. and Renu, B. (2003) Factors Associated with Drug Resistance in Pulmonary Tuberculosis. Indian Journal of Chest and Allied Sciences , 45, 105-109.

[4] Suleiman, M.M.A. and Sodemann, M. (2009) Evaluation of tuberculosis control programme in Khartoum State for the Year 2006. Scandinavian Journal of Public Health , 37, 101-108. https://doi.org/10.1177/1403494808097172

[5] World Health Organization (WHO) (2008) Stop TB Partnership. Tuberculosis Facts. Geneva.

[6] Getahun, H., Gunneberg, C., Granich, R. and Nunn, P. (2010) HIV infectionAssociated Tuberculosis: the Epidemiology and the Response. Clinical Infectious Diseases , 50, S201-S207. https://doi.org/10.1086/651492

[7] World Health Organization (WHO) (2008) Global Tuberculosis Control, Surveillance, Planning and Financing 2008.

[8] World Health Organization (WHO) (2004) Guidelines for HIV Surveillance among Tuberculosis Patients. 2nd Edition, Geneva.

[9] World Health Organization (WHO) (2011) Global Tuberculosis Control.

[10] Lonnroth, K., Castro, G.K., Chakaya, J.M., Chauhan, L.S., Floy, K., Glaziou, P. and Raviglione, M.C. (2010) Tuberculosis Control and Elimination 2010-50: Cure, Care, and Social Development. The Lancet , 375, 1814-1829. https://doi.org/10.1016/S0140-6736(10)60483-7 
[11] Maher, D. and Raviglione, M. (2005) Global Epidemiology of Tuberculosis. Clinics in Chest Medicine , 26, 167-182. https://doi.org/10.1016/j.ccm.2005.02.009 [12] Kyobutungi, C., Ziraba, A.K., Ezeh, A. and Ye, Y. (2008) The Burden of Disease Profile of Residents of Nairobi's Slums: Results from a Demographic Surveillance System. Population Health Metrics , 6, Article No. 1. https://doi.org/10.1186/1478-7954-6-1

[13] El-Sony, A.I., Khamis, A.H., Enarson, D.A., Baraka, O., Mustafa, S.A. and Bjune, G. (2002) Treatment Results of DOTS in 1797 Sudanese Tuberculosis Patients with or without HIV Co-Infection. International Journal of Tuberculosis and Lung Disease , 6, 1058-1066.

[14] Sloan, J.P. and Sloan, M.C. (1981) An Assessment of Default and NonCompliance in Tuberculosis Control in Pakistan. Transactions of the Royal Society of Tropical Medicine and Hygiene, 75, 717-718. https://doi.org/10.1016/0035-9203(81)90161-9

[15] Van Der Werf, T.S., Dade, G.K. and Van Der Mark, T.W. (1990) Patient Compliance with Tuberculosis Treatment in Ghana: Factors Influencing Adherence to Therapy in a Rural Service Programme. Tubercle , 71, 247-252. https://doi.org/10.1016/0041-3879(90)90036-8 [16] California Department of Health Services/California Tuberculosis Controllers association Joint Guidelines. Guidelines for the Treatment of Active Tuberculosis Disease.2003.

[17] Chuah, S.Y. (1991) Factors Associated with Poor Patient Compliance with Anti-Tuberculosis Therapy in Northwest Perak, Malaysia. Tubercle ; 72, 261-264. https://doi.org/10.1016/0041-3879(91)90051-S

[18] Menzies, R., Rochert, I. and Vissandjee, B. (1993) Factors Associated with Compliance in Treatment of Tuberculosis. Tuber\& and Lung Disease , 74, 32-37. https://doi.org/10.1016/0962-8479(93)90066-7 
[19] Wilkinson, D. (1994) High-Compliance Tuberculosis Treatment Programme in a Rural Community. The Lancet , 343, 647-648.

https://doi.org/10.1016/S0140-6736(94)92640-9

[20] William, J.B., Cohn, D.L., Rietmeijer, C.A., Judson, F.N., Sbarbaro, J.A. and Reves, R.R. (1997) Noncompliance with Directly Observed Therapy for Tuberculosis: Epidemiology and Effect on the Outcome of Treatment. Chest, 111, 1168-1173.

https://doi.org/10.1378/chest.111.5.1168

[21] Jasmer, R.M., Seaman, C.B., Gonzalez, L.C., Kawamura, L.M., Osmond, D.H. and Daley, C.L. (2004) Tuberculosis Treatment Outcomes: Directly Observed Therapy Compared with Self-Administered Therapy. American Journal of Respiratory and Critical Care Medicine, 170, 561-566. https://doi.org/10.1164/rccm.200401-095OC

[22] Ngamvithayapong, J., Uthaivoravit, W., Yanai, H., Akarasewi, P. and Sawanpanyalert, P. (1997) Adherence to Tuberculosis Preventive Therapy among HIV-Infected Persons in Chiang Rai, Thailand. AIDS, 11, 107-112. https://doi.org/10.1097/00002030-199701000-00016

[23] World Health Organization () Definitions and Reporting Framework for Tuberculosis - 2013 Revision (updated December 2014 and January 2020).

[24] Jochem, K., Fryatt, R.J., Harper, I., White, A., Luitel, H. and Dahal, R. (1997) Tuberculosis Control in Remote Districts of Nepal Comparing Patient-Responsible Short-Course Chemotherapy with Long-Course Treatment. International Journal of Tuberculosis and Lung Disease , 1, 502-508.

[25] Moher, D., Liberati, A., Tetzlaff, J. and Altman, D.G. (2009) Preferred Reporting Items for Systematic Reviews and Meta-Analyses: The PRISMA Statement. BMJ,339, b2535. 
[26] Awofeso, N. (2008) Anti-Tuberculosis Medication Side-Effects Constitute Major Factor for Poor Adherence to Tuberculosis Treatment. Bulletin of the World Health Organization, 86, A-D. https://doi.org/10.2471/BLT.07.043802

[27] Comolet, T.M., Rakotomalala, R. and Rajaonarioa, H. (1998) Factors Determining Compliance with Tuberculosis Treatment in an Urban Environment, Tamatave,Madagascar. International Journal of Tuberculosis and Lung Disease , 11, 891-897.

[28] Kruyt, M.L., Kruyt, N.D., Boeree, M.J., Harries, A.D., Salaniponi, F.M. and van Noord, P.A. (1999) True Status of Smear-Positive Pulmonary Tuberculosis Defaulters in Malawi. Bulletin of the World Health Organization, 77, 386-391. [29] Edginton, M.E., Sekatane, C.S. and Goldstein, S.J. (2002) Patients' Beliefs: Do They Affect Tuberculosis Control? A Study in a Rural District of South Africa. International Journal of Tuberculosis and Lung Disease , 6, 1075-1082.

[30] Sanou, A., Dembele, M., Theobald, S. and Macq, J. (2004) Access and Adhering to Tuberculosis Treatment: Barriers Faced by Patients and Communities in Burkina Faso. International Journal of Tuberculosis and Lung Disease , 8, 14791483.

[31] Chang, K.C., Leung, C.C. and Tam, C.M. (2004) Risk Factors for Defaulting from Anti-Tuberculosis Treatment under Directly Observed Treatment in Hong Kong.International Journal of Tuberculosis and Lung Disease , 8, 1492-1498.

[32] Shargie, E.B. and Lindtjorn, B. (2007) Determinants of Treatment Adherence among Smear-Positive Pulmonary Tuberculosis Patients in Southern Ethiopia. PLoS Medicine , 4, e37. https://doi.org/10.1371/journal.pmed.0040037

[33] Xu, L., Gai, R., Wang, X., Liu, Z., Cheng, J., Zhou, C., et al . (2010) SocioEconomic Factors Affecting the Success of Tuberculosis Treatment in Six Counties 
of Shandong Province, China. International Journal of Tuberculosis and Lung Disease , 14, 440-446.

[34] Kigozi, G., Heunis, C., Chikobvu, P.C., Botha, S. and Rensburg, D. (2017) Factors Influencing Treatment Default among Tuberculosis Patients in a High Burden Province of South Africa. International Journal of Infectious Diseases , 54, 95-102.

https://doi.org/10.1016/j.ijid.2016.11.407

[35] Alobu, I., Oshi, S.N., Oshi, D.C. and Ukwaja, K.N. (2014) Risk Factors of Treatment Default and Death among Tuberculosis Patients in a Resource-Limited Setting. Asian Pacific Journal of Tropical Medicine , 7, 977-984.

https://doi.org/10.1016/S1995-7645(14)60172-3

[36] Abdelhadi, M.A., Talal, E., Mahdi, T.E., Mohammed, A., Soghaier, M.A., Awadalla, H.M., Ahmed, A.E. and Khalid, F.A. (2015) Factors Associated with Default from Treatment among Tuberculosis Patients in Kassala State, Sudan 2013. Journal of Public Health and Epidemiology, 7, 183-188.

https://doi.org/10.5897/JPHE2015.0740

[37] Thelma, E.T., Anna, M.C.G. Garfin, Kurbatova E V, Mangan JM, Chi R O, et al . (2016) Factors Associated with Loss to Follow-Up during Treatment for Multidrug- Resistant Tuberculosis, the Philippines, 2012-2014. Emerging Infectious Diseases, 22, 491-502. https://doi.org/10.3201/eid2203.151788

[38] Lackey, B., Seas, C., Stuyft, P.V. and Otero, L. (2015) Patient Characteristics Associated with Tuberculosis Treatment Default: A Cohort Study in a HighIncidence Area of Lima, Peru. PLoS ONE, 10, e0128541. https://doi.org/10.1371/journal.pone.0128541 
[39] Slama, K., Tachfouti, N., Obtel, M. and Nejjari, C. (2013) Factors Associated with Treatment Default by Tuberculosis Patients in Fez, Morocco. Eastern Mediterranean Health Journal , 19, 687-693. https://doi.org/10.26719/2013.19.8.687 [40] El-Muttalut, M. and Elnimeiri, M.K. (2017) Factors Contributing to NonCompliance with Treatment among Tuberculosis Patients, Kassala State, Sudan 2016. International Scholars Journals , 6, 332-338.

[41] Santha, T., Garg, R., Frieden, T.R., Chandrasekaran, V., Subramani, R., Gopi, P.G., et al . (2002) Risk Factors Associated with Default, Failure and Death among Tuberculosis Patients Treated in a DOTS Programme in Tiruvallur District, South India, 2000. International Journal of Tuberculosis and Lung Disease , 6, 780-788. [42] Hill, P.C., Stevens, W., Hill, S., Bah, J., Donkor, S.A., Jallow, A., et al . (2005) Risk Factors for Defaulting from Tuberculosis Treatment: A Prospective Cohort Study of 301 Cases in The Gambia. International Journal of Tuberculosis and Lung Disease $, 9,1349-1354$.

[43] Gelmanova, I.Y., Keshavjee, S., Golubchikova, V.T., Berezina, V.I., Strelis, A.K., Yanova, G.V., et al . (2007) Barriers to Successful Tuberculosis Treatment in Tomsk, Russian Federation: Non-Adherence, Default and the Acquisition of Multidrug Resistance. Bull World Health Organ, 85, 703-711. https://doi.org/10.2471/BLT.06.038331

[44] Talay, F., Kumbetli, S. and Altin, S. (2008) Factors Associated with Treatment Success for Tuberculosis Patients: A Single Center's Experience in Turkey. Japanese Journal of Infectious Diseases , 61, 25-30.

[45] Muture, B., Keraka, M., Kimuu, P., Kabiru, E., Ombeka, V. and Oguya, F. (2011) Factors Associated with Default from Treatment among Tuberculosis Patients in Nairobi Province, Kenya: A Case Control Study. BMC Public Health , 11, Article No. 696. https://doi.org/10.1186/1471-2458-11-696 
[46] Finlay, A., Lancaster, J., Holtz, T.H., Weyer, K., Miranda, A. and van der Walt, M. (2012) Patient- and Provider-Level Risk Factors Associated with Default from Tuberculosis Treatment, South Africa, 2002: A Case-Control Study. BMC Public Health , 12, Article No. 56. https://doi.org/10.1186/1471-2458-12-56

[47] Saibannavar, A. and Desai, S. (2016) Risk Factors Associated with Default among Smear Positive TB Patients under RNTCP in Western Maharashtra. Journal of Dental and Medical Sciences , 15, 50-56.

[48] Cherkaoui, I., Sabouni, R., Ghali, I., Kizub, D., Alexander, C., et al . (2014) Treatment Default amongst Patients with Tuberculosis in Urban Morocco: Predicting and Explaining Default and Post-Default Sputum Smear and Drug Susceptibility Results. PLoS ONE, 9, e93574.

https://doi.org/10.1371/journal.pone.0093574

[49] Lalor, M.K., Greig, J., Allamuratova, S., Althomsons, S., Tigay, Z., et al . (2013) Risk Factors Associated with Default from Multi- and Extensively DrugResistant Tuberculosis Treatment, Uzbekistan: A Retrospective Cohort Analysis. PLoS ONE, 8,e78364. https://doi.org/10.1371/journal.pone.0078364 [50] Franke, M.F., Appleton, S.C., Bayona, J., Arteaga, F., Palacios, E., Llaro, K., et al .(2008) Risk Factors and Mortality Associated with Default from MultidrugResistant Tuberculosis Treatment. Clinical Infectious Diseases , 46, 1844-1851. https://doi.org/10.1086/588292

[51] Kelly, E.D., Ouafae, L., Iraqi, G., Janine, K., Elmessaoud, M.D., Imad, C. and Rajae,E. (2011) Risk Factors for Tuberculosis Treatment Failure, Default, or Relapse and Outcomes of Retreatment in Morocco. BMC Public Health , 11, Article No. 140.

https://doi.org/10.1186/1471-2458-11-140 
[52] Centers for Disease Control and Prevention MMWR (1998) Acquired Multidrug-Resistant Tuberculosis-Buenaventura, Colombia, 1998. JAMA, 280, 1653.

https://doi.org/10.1001/jama.280.19.1653-JWR1118-3-1

[53] Yeung, M.C., Noertjojo, K., Leung, C.C., Chan, S.L. and Tam, C.M. (2003) Prevalence and Predictors of Default from Tuberculosis Treatment in Hong Kong. Hong Kong Med Journal , 9, 263-268.

[54] Vijay, S., Balasangameswara, V.H., Jagannatha, P.S., Saroja, V.N. and Kumar, P. (2003) Defaults among Tuberculosis Patients Treated under DOTS in Bangalore City: A Search for Solution. Indian Journal of Tuberculosis , 50, 185-195.

[55] Roy, N., Basu, M., Das, S., Mandal, A., Dutt, D. and Dasgupta, S. (2015) Risk Factors Associated with Default among Tuberculosis Patients in Darjeeling District of West Bengal, India. Journal of Family Medicine and Primary Care , 4, 388-394. https://doi.org/10.4103/2249-4863.161330

[56] Culqui, D.R., Munayco, E.C.V., Grijalva, C.G., Cayla, J.A., Horna-Campos, O., Alva, Ch.K. and Suarez, O.L.A. (2012) Factors Associated with the NonCompletion of Conventional Anti-Tuberculosis Treatment in Peru. Archivos de Bronconeumologia ,48, 150-155. https://doi.org/10.1016/j.arbres.2011.12.008 [57] Ali, A.O.A. and Prins, M.H. (2016) Patient Non Adherence to Tuberculosis Treatment in Sudan: Socio Demographic Factors Influencing Non Adherence to Tuberculosis Therapy in Khartoum State. Pan African Medical Journal , 25, No. 80. https://doi.org/10.11604/pamj.2016.25.80.9447

[58] Ali, A.O.A. and Prins, M.H. (2016) Patient Knowledge and Behavioral Factors Leading to Non-Adherence to Tuberculosis Treatment in Khartoum State, Sudan. Journal of Public Health and Epidemiology , 8, 316-325. 
[59] Vasudevan, K., Jayakumar, N. and Gnanasekaran, D. (2014) Smear Conversion, Treatment Outcomes and the Time of Default in Registered Tuberculosis Patients on RNTCP DOTS in Puducherry, Southern India. Journal of Clinical and Diagnostic Research , 8, No. 10. https://doi.org/10.7860/JCDR/2014/8421.4984 [60] Marlucia, S.G., Maria, L.P., Tomas, M.P., Alexandra, B.S., Leni, S.M., et al . (2012) Factors Associated with Tuberculosis Treatment Default in an Endemic Area of the Brazilian Amazon: A Case Control-Study. PLoS ONE, 7, e39134. https://doi.org/10.1371/journal.pone.0039134

[61] Nezenega, Z.S., Gacho, Y.H. and Tafere, T.E. (2013) Patient Satisfaction on Tuberculosis Treatment Service and Adherence to Treatment in Public Health Facilities of Sidama Zone, South Ethiopia. BMC Health Services Research, 13, Article No. 110. https://doi.org/10.1186/1472-6963-13-110 [62] Tanguis, H.G., Cayla, J.A., Garcia de Olalla, P.G., Jansa, J.M. and Brugal, M.T. (2000) Factors Predicting Non-Completion of Tuberculosis Treatment among HIVInfected Patients in Barcelona (1987-1996). International Journal of Tuberculosis and Lung Disease , 4, 55-60.

[63] Borgdorff, M.W., Veen, J., Kalisvaart, N.A., Broekmans, J.F. and Nagelkerke, N.J.D.(2000) Defaulting from Tuberculosis Treatment in the Netherlands:Rates, Risk Factors and Trend in the Period 1993-1997. European Respiratory Journal , 16, 209-213. https://doi.org/10.1034/j.1399-3003.2000.16b05.x

[64] Daniel, O.J., Oladapo, O.T. and Alausa, O.K. (2006) Default from Tuberculosis Treatment Programme in Sagamu, Nigeria. Nigerian Journal of Medicine, 15, 63-67. https://doi.org/10.4314/njm.v15i1.37119

[65] Kliiman, K. and Altraja, A. (2010) Predictors and Mortality Associated with Treatment Default in Pulmonary Tuberculosis. International Journal of Tuberculosis and Lung Disease , 14, 454-463. 
[66] Pablos-Mendez, A., Knirsch, C.A., Barr, R.G., Lerner, B.H. and Frieden, T.R. (1997) Nonadherence in Tuberculosis Treatment: Predictors and Consequences in New York City. The American Journal of Medicine , 102, 164-170.

https://doi.org/10.1016/S0002-9343(96)00402-0

[67] Cummings, K.C., Mohle-Boetani, J., Royce, S.E. and Chin, D.P. (1998) Movement of Tuberculosis Patients and the Failure to Complete Anti Tuberculosis Treatment. American Journal of Respiratory and Critical Care Medicine , 157, 12491252.

https://doi.org/10.1164/ajrccm.157.4.9708058

[68] Uplekar, M., Juvekar, S., Morankar, S., Rangan, S. and Nunn, P. (1998) Tuberculosis Patients and Practitioners in Private Clinics in India. International Journal of Tuberculosis and Lung Disease , 2, 324-329.

[69] Gelaw, M., Genebo, T., Dejene, A., Lemma, E. and Eyob, G. (2001) Attitude and Social Consequences of Tuberculosis in Addis Ababa, Ethiopia. East African Medical Journal , 78, 382-388. https://doi.org/10.4314/eamj.v78i7.9014 [70] Pandit, N. and Choudhary, S.K. (2006) A Study of Treatment Compliance in Directly Observed Therapy for Tuberculosis. Indian Journal of Community Medicine, 31, 241-243.

[71] Kapella, B.K., Anuwatnonthakate, A., Komsakorn, S., Moolphate, S., Charusuntonsri, P., Limsomboon, P., et al . (2009) Directly Observed Treatment Is Associated with Reduced Default among Foreign Tuberculosis Patients in Thailand. International Journal of Tuberculosis and Lung Disease , 13, 232-237.

[72] Samuel, A.B., Tomoko, K., Tomoko, T. and Nobuyuki, H. (2010) Factors Contributing to Tuberculosis (TB) Defaulter Rate in New Juaben Municipality in the Eastern Region of Ghana. Journal of the National Institute of Public Health , 59, 291-297. 
[73] Hashim, E.A. and Mohamed, E.Y. (2017) Risk Factors for Default from Tuberculosis (TB) Treatment in Patients Attending a Rural Sudanese Hospital. EC Pulmonology and Respiratory Medicine , 3, 177-182.

[74] Basa, S. and Venkatesh, S. (2015) Study on Default and Its Factors Associated among Tuberculosis Patients Treated under DOTS in Mayurbhanj District, Odisha. Journal of Health Research and Reviews, 2, 25-28.

https://doi.org/10.4103/2394-2010.158125

[75] Ashutosh, T., Girish, A., Sten, H.V., Connie, L.K., Alka, K. and Nalini, S. (2012) Pulmonary Tuberculosis in Mumbai, India: Factors Responsible for Patient and Treatment Delays. International Journal of Preventive Medicine , 3, 569-580. [76] Tekle, B., Mariam, D.H. and Ali, A. (2002) Defaulting from DOTS and Its Determinants in Three Districts of Arsi Zone in Ethiopia. International Journal of Tuberculosis and Lung Disease , 6, 573-579. 
Chapter 3 Patient non adherence to tuberculosis treatment in Sudan: Socio demographic factors influencing non adherence to tuberculosis therapy in Khartoum State

Ahmed Osman A Ali

Martin H. Prins

Pan African Medical Journal. 2016; 25(80) 


\begin{abstract}
:
Despite the Treatment pulmonary TB patients, defaulting from treatment may remain the major challenge to control TB. In addition, it increases the risk of drug resistance, relapse, and death and may prolong infectiousness. Our objective was to identify determinants of treatment defaulting among TB patients in Khartoum State, Sudan.
\end{abstract}

\title{
Methods:
}

We conducted a case control study where the patients defaulting from treatment were considered as 'cases' and those completing treatment as 'controls' between May 2010 to May 2011.

\section{Results:}

There were 2727 TB patients who attended TB treatment clinics during study period. Out of these 2399 patients $(86 \%)$ had continued their treatment while 328 patients (14\%) had interrupted it. 105 cases were traced and interviewed. In addition 210 patients who had continued their treatment were included (controls). In the multivariate analysis the variables that remained in the model were: residential locality (rural area) (OR 2.58; 95\% CI 1.4 -4.67), patients moving or changing address(OR 5.47; 95\% CI 2.90- 10.35), absence of family support (OR 2.14; $95 \%$ CI 1.12 - 4.11), and occupation (blue collar work) (OR 2.38; 95\% CI 1.39 -4.10).

\section{Conclusions:}

The results of this study conclude some socio-demographic factors influence defaulting of TB treatment. We believe that the findings are applicable to current situation of TB management and control in Sudan and other developing countries

Key words: Tuberculosis, non-adherence, adherence, defaulter, compliance. 


\section{Introduction}

Tuberculosis (TB) as a disease has been known ever since the dawn of man's history [1]. In 1993 the World Health Organization (WHO) declared that TB was the major global public health problem [2]. It is estimated that one-third of the world's population (approximately two billion people) have been affected by the mycobacterium tuberculosis[3-5].The WHO estimates that currently about 9.4 million new TB cases occur each year and that approximately 1.8 million deaths annually are related to $\mathrm{TB}[6-7]$.

In 2010, it was estimated that in Sudan there were 209 cases of active TB per 100.000 of populace with an annual incidence of new cases of 119/100.000, resulting in approximately 37.000 new cases each year in Sudan. Hence, Sudan shoulders about $15 \%$ of $\mathrm{TB}$ burden in the Eastern Mediterranean Region and has the second highest active TB prevalence of the countries in this region. In addition, the estimated death rate related to TB, including HIV infected TB patients, was 24/100.000 per year [8].

Treatment of active pulmonary TB patients remains the most effective strategy to stop the spread of the disease $[9,10]$. Defaulting from treatment may remain the major challenge to control TB. In addition, it increases the risk of drug resistance, relapse, and death and may prolong infectiousness [11-15]. Non-compliance with therapy is considered a priority for researchers because it remains unclear how to identify patients at risk for non-compliance, or how to effectively intervene with such patients [16]. The high rate of patient defaulting TB treatment in Khartoum State makes the identification of risk factors leading to this default essential. The present study was conducted to identify determinants of treatment defaulting among TB patients. Such information could help to put forward suggestions and recommendations that can lead to reduction of TB treatment defaulting. 


\section{Methods}

This was an observational case control study where the patients defaulting from treatment were considered as 'cases' and those completing treatment as 'controls'.

\section{Setting}

This study was conducted in Khartoum State. In 1993, the Ministry of Health in Khartoum State established a tuberculosis control program. The decentralized healthcare system in Khartoum is divided into seven districts and 19 health areas. Its health facilities include 43 hospitals, 147 health centers, 185 NGOs centers, 235 dispensaries and 365 primary health care units. TB services are delivered in primary health care along with all other routine health services. A registered nurse is designated responsible for treatment and follow up for continuation of treatment in the primary health care unit. This primary health care unit is the basic unit of management of the program and also the unit of reporting. Personnel at the primary health care unit responsible for tuberculosis services include a medical assistant, a laboratory technician and a clerk. The program provides care through the DOTS strategy (Directly Observed Treatment with Short course chemotherapy) as recommended by WHO. TB patients receive their treatment through 53 TB treatment units distributed all over the state[17].

\section{Population}

The reference population for this study comprised all tuberculosis patients registered at tuberculosis centers at all provinces in Khartoum state from May 2010 to May 2011. The data collection was done from $1^{\text {th }}$ of May 2011 to $15^{\text {th }}$ of July 2011.

The inclusion criteria for both cases and controls were; patients age more than 15 years and clinically and laboratory diagnosed as tuberculosis, registered at the treatment units in Khartoum States. Cases were those patients identified as TB treatment defaulting during the data collection period. Following identification of 
each case (defaulter) without exclusion criteria, the next 2 subsequent patients without exclusion criteria, who came for treatment or follow up, without defaulting, in the same TB treatment unit or the near one in the same area, were taken as control into the study. The patients were excluded from the study if they were: too ill for interview, had a psychiatric illness, or gave incorrect address and could not be traced. The following definitions were applied according to the World Health Organization (WHO, 2002). Treatment default: an interruption of TB treatment for two or more consecutive months during the intended treatment period. Pulmonary TB: a patient with tuberculosis disease involving the lung parenchyma. Extra-pulmonary TB: a patient with tuberculosis of organs other than the lungs (e.g. pleura, lymph nodes, abdomen, genitourinary tract, skin, joints and bones, meninges). Diagnosis should be based on a culture-positive specimen, histological evidence or strong clinical evidence consistent with active extra-pulmonary disease, followed by a decision by a clinician to treat with a full course of anti-tuberculosis chemotherapy. A patient in whom both pulmonary and extra-pulmonary TB has been diagnosed was classified as pulmonary $\mathrm{TB}[18-20]$.

\section{Data Collection}

Information on disease related factors and treatment related factors were retrieved from patients' medical records. In addition, a face to face interview was held, using a standardized questionnaire by trained interviewers to elicited information on the various factors possibly associated with treatment defaulting.

The following variables were collected: socio-demographic factors including; age, sex, ethnicity, marital status, educational level, occupation, employment status, family income, nationality, residential locality, distance of residence from treatment center, religion, patients moving or changing address, family size, house size, means 
of transport to the health center, travelling cost to health centre, waiting time, family support and site of tuberculosis[9,11,21-28].

Before the start of data collection the interviewers had been trained on how to interview the respondents, and had been given instructions on how to fill the questionnaire. After that, pretesting was conducted by interviewing few patients. Based on the pretesting results the questionnaire was used without any major changes.

\section{Statistics}

The sample size was calculated according to Fleiss J.L(1981) [29] using a two sided type one error of 0.05 and a power of $80 \%$ and the ability to detect an odds ratio of 2.0 with a exposure frequency of $30 \%$ in the control group and a ratio of cases to controls of 1:2. This yielded a sample size of 105cases and 210 controls.

Data were reviewed for consistency and completeness. Data analysis was performed in SPSS(Statistical package of Social Sciences) version 16. The Demographic characteristics of cases and controls were compared using $\chi^{2}$ test for qualitative variables and student's t tests for continuous variables. Univariate and multivariate analysis were conducted. Descriptive statistics were calculated for all dependent variables. Logistic regression was used to calculate the odds ratio and its $95 \%$ confidence interval. Variables that were related to treatment default with a pvalue less than 0.20 were entered in a multivariate model, using a backward approach $[30,31]$.

\section{Ethical Considerations}

Ethical approval was obtained from Ministry of Health Khartoum State ' ethical Committee. Permission was granted by public committee leaders in the localities through official letters. Informed verbal consent was secured from every eligible patient included in this study before the interview. Privacy and 
confidentially was maintained. Prior to the arrival of the data collection team the respondents had been informed regarding all relevant aspects of the study, including the purpose of the study, interview process and potential benefits. The interviewers introduced themselves to respondents and outlined the scope of interview and its approximate length to the potential respondents at the beginning of each interview. the respondents had been informed that the participation was entirely voluntary, and that privacy and confidentially will be maintained during data processing and reporting. Potential respondents also were informed that they had the right to refuse to participate, or to end the interview at any time.

\section{Results}

\section{Patients}

There were 2727 TB patients who attended TB treatment clinics during study period. Out of these 2399 patients $(86 \%)$ had continued their treatment while 328 patients (14\%) had interrupted it. Out of these, 185 patients had defaulted prior to the data collection period. Hence, 143 patients were potentially eligible as cases. Of these 15 had given a wrong address and 12 had moved out of Khartoum State and could not be interviewed. A further 11patients refused the interview. Hence, 105 cases were traced and interviewed. In addition 210 patients who had continued their treatment were included (controls). The demographic and TB characteristics are given in table 1a and table $1 \mathrm{~b}$. Cases and controls were of similar age, but cases lived

more often in a village and at a greater distance from the TB center. Also, they were more often illiterate, had less family support and were more liable to give a wrong address or to move during treatment period without informing the treatment center.

\section{Risk factors for defaulting}

In the univariate analysis the socio demographic factors found statistically significant $(\mathrm{p}<0.05)$ related to TB patient treatment default were: educational level 
(illiterate), distance to health center, residential locality (rural area), patients moving or changing address, time to clinic >60minutes, no family support and, occupation (blue collar work) Table 2.

In the multivariate analysis the variables that remained in the model were: residential locality (rural area), patients moving or changing address, absence of family support and occupation (blue collar work). The adjusted odds ratios with their corresponding 95\% confidence intervals are given in Table 3.

\section{Discussion}

The results of present study showed that $14 \%$ of TB patients in Khartoum State were treatment defaulters. Also we identified several factors associated with TB treatment default which included: educational level (illiterate), distance to health center (more than 5 kilometer), type of residential area (village), moving, absence of family support, and occupation (blue collar work). Surprisingly, the traditional factors thought to be related to TB treatment default (e.g. age, religion, family income, family size, house size and travelling cost) were found not statistically associated with default in this study.

The findings of this study are similar to results in developing countries with low resources in Africa and Asia which carry the highest burden of TB[22-28]. We observed that patients moving or giving wrong address were more likely to default their TB treatment. These findings are similar to results of other studies in developing (Uganda, South Africa) and developed countries (USA) [21,26,28]. However, in a recent study in Malaysia, changing of residence was not associated with TB default[22].

We could confirm that rural residence, distance to health center (more than five kilometers), educational level (illiteracy), and absence of family support were strongly associated with TB default. Hence the influence of these factors on 
defaulting TB treatment is well recognized as mentioned by Tatek in (Ethiopia), [23] Bernard N Muture in (Kenya) [9] and Samuel A (Ghana) [25]. However our findings were in contrast to those reported by Nyi and Chuah from Malysia the rural residence, distance to health center, and educational level were not associated with TB treatment default[11,22].

The present study showed no significant association between TB treatment default and the following socio-demographic factors: age, sex, ethnicity, marital status, nationality, means of transport to the health center, waiting time, religion, family income, family size, house size, travelling cost the and site of tuberculosis. These findings are similar to those reported by Nyi from Malaysia, but differ from those reported by Jaggarajamma K. in India, Connoly C. in South Africa and Kelly E Dooley in Morocco where age (older more than 45 years/younger less than 45 years) and female sex were related to TB treatment default.

The results of this study might help the policy maker in Khartoum state, Sudan and developing countries in planning and policy development to strengthen TB control programs in general. Attention for and exploring of the factors that are-even with the DOTS-approach - still strongly associated with TB treatment default could be done.

An important issue seems health education and counseling provided by health workers for TB patients including their families. These efforts should encourage patients and their families to adhere to TB treatment and also help to ensure family support during the treatment period.

Changing address and moving to other place continues to be a challenge for TB treatment adherence. TB patients and their families should give their home addresses and be informed to notify the health personnel's if they move. Possibly, 
recording of the address of a (more distant) family member living at a different location could be used to increase tracking ability of the health care workers.

This study showed that those who lived in the rural areas or if the distance of their residences is more than five kilometers from the TB treatment centre were more than two times likely of being non compliance to TB treatment than those lived in urban areas or their residence is less than 5 kilometers to TB treatment centers. Hence, the Provision of health services and accessibility in the rural areas and near to residence of TB patient will enhance the patients compliance to treatment. For those who had no work or of low socioeconomic status. They need more attention from the governmental and nongovernmental organizations to support TB patients financially and socially. Overall the results of present study raise very important issues on TB default and socio-demographic predictors factors in Sudan since there were no previous details studies on this field. This results can help in decreasing the TB treatment default. Hence, decreasing treatment failure, multi drugs resistant, treatment relapse and spreading of tuberculosis in the community.

There are some methodological aspects of this study need attention: firstly, this study was conducted in Khartoum State, capital of Sudan which is the most populated state in Sudan. The population in this state could be safely stated to represent the whole country as most of the inhabitants are drawn from various parts of Sudan. Hence, the results of this study apply to other parts of Sudan. In addition, the TB patients included in this study were selected from all tuberculosis treatment units (health centers and hospitals) in the state. By this fact, the generalization of the study findings to total tuberculosis population in the state and Sudan could be done and seems logical. 
Secondly, the recall bias was minimized by reviewing the patient medical records and cross checking for each study variables, and avoiding rush questioning during interview period.

Thirdly, the reliability and sensitivity of information gathered from each subject could not be counterchecked. Although questions about sensitive issues were carefully tackled using a warm approach and ensuring strict and uninterrupted communications, so as to maximize the validity of the responses obtained.

Fourthly, possible confounders were taken into consideration in the design (by restricting the diagnosis criteria) and by using logistic regression.

Lastly, the major problem we faced during this study was how to reach the defaulting patients (cases) for this study. This problem was tackled stepwise. Firstly, their medical records were traced and identified and all contact information was reviewed. Then, study personnel used the following sequence of contact attempts: calls - first to the patient and thereafter to known family members or friends - and home visits - first to patient and thereafter to known family members or friends. Interestingly, it appeared during the study that many of the defaulting patients did not have access to mobile telephones, a risk factor not previously described. The interviewers made an average of three attempts to contact each defaulter before deciding that a defaulter was a non-respondent. Due to the proportion of defaulters who could not be traced and retrieved, the generalizability of the findings to the whole population of patients with tuberculosis should be done with caution.

\section{Conclusions:}

The results of this study conclude some socio-demographic factors (rural residence, occupation(blue colour work), those without family support and those moving or change their address during treatment period) influence defaulting of TB 
treatment. We believe that the findings are applicable to current situation of TB management and control in Sudan and other developing countries.

\section{What is known about this topic?}

- TB is a major health problem in Sudan.

- defaulting from treatment remain the major challenge to control TB disease.

- Defaulting from treatment increases the risk of drug resistance, relapse, and death and may prolong infectiousness

\section{What this study adds}

- This study provides valuable information on risk factors leading to TB treatment default in Sudan.

- The current study confirms the high default rate in Khartoum state which mentioned in previous studies.

- Special attention should be given to TB patients and their families and patients address to enhance treatment compliance.

\section{Competing interests}

The authors declare no competing interests.

\section{Authors' contributions}

Ahmed.A.O.A initiated study concept, design, data collection, analysis and wrote the first draft of manuscript. Martin H. Prins contributed and supervised study design, results, discussion and the approved the final manuscript.

\section{Acknowledgments}

We would like to thank our Colleagues at $\mathrm{MOH}$ Khartoum State and TB control Programme. We are further grateful to all TB coordinators and health care workers at TB units for their cooperation. 
Table 1. Demographic and social characteristics of the study population.

\begin{tabular}{|c|c|c|c|}
\hline Socio-demographic factors & $\begin{array}{l}\text { Cases } \\
\mathrm{N}=105\end{array}$ & $\begin{array}{l}\text { Control } \\
\mathrm{N}=210\end{array}$ & P-value \\
\hline Age - mean (SD*) & $32.8(14.4)$ & $34.6(14.9)$ & 0.339 \\
\hline Between 15 and 30 years & $56(53.3 \%)$ & $100(47.6 \%)$ & \\
\hline Over 30 years & $49(46.7 \%)$ & $110(52.4)$ & \\
\hline Sex & & & 0.98 \\
\hline Male & $74(70.5 \%)$ & $128(60.9 \%)$ & \\
\hline Female & $31(29.5 \%)$ & $82(39.1 \%)$ & \\
\hline Site of tuberculosis & & & 0.39 \\
\hline Pulmonary & $92(87.6 \%)$ & $180(85.7 \%)$ & \\
\hline Extra-pulmonary & $13(12.4 \%)$ & $30(14.3 \%)$ & \\
\hline Type of residential area & & & 0.001 \\
\hline City & $64(61.0 \%)$ & $169(80.5 \%)$ & \\
\hline Village & $41(39.0 \%)$ & $41(19.5 \%)$ & \\
\hline Distance to clinic & & & 0.005 \\
\hline Between 1 and 5 kilometers & $35(33.3 \%)$ & $105(50.0 . \%)$ & \\
\hline More than 5 kilometers & $70(66.7 \%)$ & $105(50.0 . \%)$ & \\
\hline Patient moving or giving wrong address & & & 0.001 \\
\hline Yes & $41(39.0 \%)$ & $23(11.0 \%)$ & \\
\hline No & $64(61.0 \%)$ & $187(89.0 \%)$ & \\
\hline Inform clinic when moving & & & 0.002 \\
\hline Yes & $7(17.1 \%)$ & $10(43.5 \%)$ & \\
\hline No & $34(82.9 \%)$ & $13(56.5 \%)$ & \\
\hline Type of transport to get to clinic & & & 0.103 \\
\hline On foot or by bicycle & $7(6.7 \%)$ & $25(11.9 \%)$ & \\
\hline With car or public transport & $98(93.3 \%)$ & $185(88.1 \%)$ & \\
\hline Transportation cost & & & 0.06 \\
\hline Less than 3 Sudanese pound(SD) & $61(58.1 \%)$ & $101(48.1 \%)$ & \\
\hline 3 Sudanese pound(SD) or more & $44(41.9 \%)$ & $109(51.9 \%)$ & \\
\hline Time to clinic & & & 0.048 \\
\hline Up to 60 minutes & $83(79 \%)$ & $184(87.6 \%)$ & \\
\hline More than 60minutes & $22(21 \%)$ & $26(22.4 \%)$ & \\
\hline
\end{tabular}

$* \mathrm{SD}=$ Standard deviation 
Table 1: Demographic and social characteristics of the study population.

\begin{tabular}{|c|c|c|c|}
\hline Socio-demographic factors & $\begin{array}{l}\text { Cases(Non-adherence) } \\
105(33,3 \%)\end{array}$ & $\begin{array}{l}\text { Control(adherence) } \\
210(66.7 \%)\end{array}$ & P-value \\
\hline Marital status & & & 0.178 \\
\hline Single & $50(47.6 \%)$ & $87(41.4 \%)$ & \\
\hline Married & $55(51.4)$ & $123(58.6)$ & \\
\hline Family size & & & 0.484 \\
\hline Less than 4 members & $17(16.2 \%)$ & $36(17.1 \%)$ & \\
\hline 4 members or more & $88(83.8 \%)$ & $174(82.9 \%)$ & \\
\hline House size(room number) & & & 1.00 \\
\hline Less than 3rooms & $41(39 \%)$ & $82(39 \%)$ & \\
\hline 3 rooms or more & $64(61 \%)$ & $128(61 \%)$ & \\
\hline Family income $=($ mean, SD $)$ & $(1.14,0.447)$ & $(1.24,0.575)$ & 0.07 \\
\hline Less than 1000 Sudanese pound(SP) & $93(88.6 \%)$ & $171(81.4 \%)$ & \\
\hline $1000(\mathrm{SP})$ or more & $12(11.4 \%)$ & $39(18.6 \%)$ & \\
\hline Family support & & & 0.001 \\
\hline Those with family support & $73(69.5 \%)$ & $180(85.7 \%)$ & \\
\hline Those without family support & $32(30.5 \%)$ & $30(14.3 \%)$ & \\
\hline Occupation & & & 0.001 \\
\hline Blue collar work & $66(62.9 \%)$ & $91(43.3 \%)$ & \\
\hline White work & $39(37.1 \%)$ & $119(56.7 \%)$ & \\
\hline Nationality & & & 0.523 \\
\hline Sudanese & $98(93.3 \%)$ & $197(93.8 \%)$ & \\
\hline Non-Sudanese & $7(6.7 \%)$ & $13(6.2 \%)$ & \\
\hline Educational level & & & 0.005 \\
\hline Illiterate & $24(22.9 \%)$ & $23(11 \%)$ & \\
\hline Literate & $81(77.1 \%)$ & $187(89 \%)$ & \\
\hline Religion & & & 0.370 \\
\hline Muslim & $95(90.1 \%)$ & $196(92.3 \%)$ & \\
\hline Non muslim & $10(9.9 \%)$ & $14(7.7 \%)$ & \\
\hline
\end{tabular}


Table 2: Socio-demographic factors associated with TB treatment default

\begin{tabular}{|c|c|c|}
\hline Socio-demographic factor & Odds ratio $(\mathrm{OR})$ & $95 \%$ C.I \\
\hline \multicolumn{3}{|l|}{ Age group } \\
\hline Between 15 and 30 years vs. Over 30 years & 0.80 & $0.50-1.27$ \\
\hline \multicolumn{3}{|l|}{ Sex } \\
\hline Male vs. Female & 1.53 & $0.93-2.53$ \\
\hline \multicolumn{3}{|l|}{ Site of tuberculosis } \\
\hline Pulmonary vs. Extra-pulmonary & 1.18 & $0.60-2.37$ \\
\hline \multicolumn{3}{|l|}{ Residential locality } \\
\hline Village vs. City & 2.64 & $1.57-4.44$ \\
\hline \multicolumn{3}{|l|}{ Distance } \\
\hline More than 5 kilometers vs Between 1 and 5 kilometers & 2.000 & $1.23-3.26$ \\
\hline \multicolumn{3}{|l|}{ Patient movement } \\
\hline Patient moving or giving wrong address vs. Those not moved & 5.21 & $2.90-9.34$ \\
\hline \multicolumn{3}{|l|}{ Inform clinic when moving } \\
\hline $\begin{array}{l}\text { Those not informed the clinic vs. } \\
\text { Those Inform clinic when moving }\end{array}$ & 6.31 & $1.98-20.11$ \\
\hline \multicolumn{3}{|l|}{ Type of transport to get to clinic } \\
\hline On foot or by bicycle vs With car or public transport & 1.89 & $0.80-4.53$ \\
\hline \multicolumn{3}{|l|}{ Transportation cost } \\
\hline Cheap vs Expensive & 0.67 & $0.42-1.10$ \\
\hline \multicolumn{3}{|l|}{ Time to clinic } \\
\hline More than 60 minutes vs Up to 60 minutes & 1.88 & $1.01-3.50$ \\
\hline \multicolumn{3}{|l|}{ Marital status } \\
\hline Single vs Married & 1.29 & $0.80-2.06$ \\
\hline \multicolumn{3}{|l|}{ Family size } \\
\hline Less than 4 member vs More than 4 members & 0.93 & $0.50-1.76$ \\
\hline \multicolumn{3}{|l|}{ House size(room number) } \\
\hline Less than 3rooms vs 3 rooms or more & 1.00 & $0.62-1.62$ \\
\hline \multicolumn{3}{|l|}{ Family income } \\
\hline Less than 1000 Sudanese pound(SP) vs $1000(\mathrm{SP})$ or more & 1.77 & $0.88-3.54$ \\
\hline \multicolumn{3}{|l|}{ Family support } \\
\hline Those without family support vs. Those with family support & 2.63 & $1.49-4.64$ \\
\hline \multicolumn{3}{|l|}{ Occupation } \\
\hline Blue collar work vs White work & 2.21 & $1.37-3.58$ \\
\hline \multicolumn{3}{|l|}{ Nationality } \\
\hline Non-Sudanese vs. Sudanese & 1.08 & $0.42-2.80$ \\
\hline \multicolumn{3}{|l|}{ Educational level } \\
\hline Illiterate vs Literate & 2.64 & $1.57-4.44$ \\
\hline \multicolumn{3}{|l|}{ Religion } \\
\hline Muslim vs Non muslim & 0.70 & $0.29-1.55$ \\
\hline
\end{tabular}


Table 3: Adjusted Odds Ratio (the model) factors associated with non- adherence ( OR and 95\% C,I):

\begin{tabular}{|l|l|l|}
\hline Socio-demographic factors & $\begin{array}{l}\text { Odds ratio } \\
(\mathrm{OR})\end{array}$ & $95 \%$ C .I \\
\hline Residence & & \\
\hline (rural versus urban) & 2.58 & $1.43-4.67$ \\
\hline Occupation & & $1.39-4.10$ \\
\hline (blue collar work vs white work) & 2.38 & \\
\hline Family support & & $1.12-4.11$ \\
\hline those without family support vs those with family support & 2.14 & \\
\hline Patient movement & & $2.90-10-35$ \\
\hline those moving or giving wrong address vs & & \\
\hline those not moved during treatment period & 5.47 & \\
\hline
\end{tabular}




\section{References}

1-Kanai I. introduction to Tuberculosis and Mycobacterium. South East- Asian Medical Information Centre Publication. International medical Foundation of Japan. 1990; 60:3-5.

2- World Health Organization. TB - A Global Emergence. Geneva :World Health Organization; 1994.

3. World Health Organization (WHO). Stop TB Partnership. Tuberculosis Facts. Geneva. 2008.

4. Getahun H, Gunneberg C, Granich R, and Nunn P. HIV infection-Associated Tuberculosis: the Epidemiology and the Response. Clin Infect Dis. 2010;50(3):201-7. 5. World Health Organization(WHO). Global tuberculosis control, surveillance, planning and financing. 2008.

6. World Health Organization (WHO). Global Tuberculosis Control . 2011.

7. Lönnroth K, Castro GK, Chakaya JM, ,Chauhan LS , Floy K, Glaziou P, Raviglione MC. Tuberculosis control and elimination 2010-50: cure, care, and social development. Lancet. 2010;375(9728):1755-7.

8. Federal Ministry of Health. General Directorate of Primary Health Care, Sudan. National Tuberculosis Control Programme. 2011.

9. Muture B, Keraka M, Kimuu P, Kabiru E, Ombeka V, Oguya F. Factor9s associated with default from treatment among tuberculosis patients in nairobi province, Kenya: A case control study. BMC Public Health. 2011;11:696:1-10.

10. Salla A, Simon A, Helen J S, Mark E, Atle F, Jimmy . Patient Adherence to Tuberculosis Treatment: A Systematic Review of Qualitative Research. PLoS Med. 2007;4(7):238.

11. Chuah SY. Factors associated with poor patient compliance with antituberculosis therapy in Northwest Perak, Malaysia. Tubercle. 1991 Dec;72(4):261-4. 
12. Menzies R, Rochert I, Vissandjee B. Factors associated with compliance in treatment of tuberculosis .Tuber\& and Lung Disease. 1993Jun; 74(3):32-1.

13. Wilkinson D. High-compliance tuberculosis treatment programme in a rural community. Lancet. 1994 Mar;343(8898):647-48.

14.William J B, Cohn D L, Rietmeijer CA, Judson F N, SbarbaroJA, Reves RR. Noncompliance With Directly Observed Therapy for Tuberculosis: Epidemiology and Effect on the Outcome of Treatment. Chest. 1997 May; 111(5):1168-73. 15. Jasmer RM, Seaman CB, Gonzalez LC, Kawamura LM, Osmond DH, Daley CL. Tuberculosis treatment outcomes: directly observed therapy compared with selfadministered therapy. American Journal of Respiratory and Critical Care Medicine. 2004;170(5):561-6.

16. Amoran O E, Osiyale O O and Lawal K M. Pattern of default among tuberculosis patients on directly observed therapy in rural primary health care centres in Ogun State, Nigeria. Journal of Infectious Diseases and Immunity. 2011 May; 3(5): 9095.

17. Suleiman M M A, Sodemann M. Evaluation of tuberculosis control programme in Khartoum State for the year 2006. Scandinavian Journal of Public Health. 2009;37:101-8.

18. World Health Organization (WHO). Operational Guide for National Tuberculosis Control Programmes. 2002.

19. Jochem K, Fryatt RJ, Harper I, White A, Luitel H, Dahal R. Tuberculosis control in remote districts of Nepal comparing patient-responsible short-course chemotherapy with long-course treatment. Int J Tuberc Lung Dis.1997;1(6):502-8. 20. Awofeso N. Anti-tuberculosis medication side-effects constitute major factor for poor adherence to tuberculosis treatment. Bull World Health Organ. 2008;86(3): B-D. 
21. Kate C C, Janet M B, Sarah E R , and Daniel P C. Movement of Tuberculosis Patients and the Failure to Complete Antituberculosis Treatment. . American Journal of Respiratory and Critical Care medicine .1998; 157: 1249-52.

22. Nyi N N, Catherine D, Abdul Rahman I, Rosemi S, Noraini B and Mohd R M. Factors Contributing to Poor Compliance with Anti-TB Treatment among Tuberculosis Patients. South East Asian J Trop Med Public health. 2001 June;32 (2):369-382.

23. Tatek W, Kifle W, Wondwossen K, Sofonias G. Delay in Initiating Tuberculosis Treatment and Factors Associated among Pulmonary Tuberculosis Patients in East Wollega, Western Ethiopia. Ethiop.J.Health Dev. 2007;21(2):148-156.

24. Jaggarajamma K, Sudha G, Chandrasekaran V, Nirupa C, Thomas A, Santha T, Muniyandi M and Narayanan P R. Reasons for Non-Compliance among Patients Treated Under Revised Natoional Tuberculosis Control Programme (RNTCP), Tiruvallur District, South India. Indian J Tuberc. 2007 Jul; 54(3):130-135.

25. Samuel AB, Tomoko K, Tomoko T, Nobuyuki H. Factors Contributing to Tuberculosis (TB) Defaulter Rate in New Juaben Municipality in the Eastern Region of Ghana. Journal of the National Institute of Public Health. 2010; 59(3): 291-7.

26. Castelnuovo B. A review of Compliance to Anti Tuberculosis Treatment and Risk Factors for Defaulting Treatment in Sub Saharan Africa. African Health Sciences. 2010 Dec; 10(4): 320 - 324.

27. Kelly E D, Ouafae L, Iraqi G, Janine K, Diss E, Imad C, Rajae E. Risk Factors for Tuberculosis Treatment Failure, Default, or Relapse and Outcomes of Retreatment in Morocco. BMC Public Health. 2011; 11:140. 28. Alyssa F, Joey L, Timothy H H, Karin W, Abe M and Martie V D W. Patientand provider-level risk factors associated with default from tuberculosis treatment, South Africa, 2002: a case-control study. BMC Public Health. 2012 Jan 20; 12:56. 
29. Fleiss L J. Statistical Methods for Rates and Proportions $-2^{\text {nd }}$ ed. $1981 ; 35-48$.

30. Kelsey J L, Whittemore A S, Thomson W D and Evans A S. Methods in Observational Epidemiology-2 ${ }^{\text {nd }}$ ed. 1986. New York: Oxford University Press.

31. Riegalman R K, and Hirsch R P. Studying a study and testing a test. How to read the medical literature $-2^{\text {nd }}$ ed. 1989. Boston: little , Brown and company,_Waltham, Massachusetts. 
Chapter 4 Disease- and treatment-related factors associated with tuberculosis treatment default in Khartoum State, Sudan: a case control study

\author{
Ahmed Osman A Ali \\ Martin H. Prins
}

Eastern Mediterranean Health Journal 2017.23(6):408-414 


\begin{abstract}
Defaulting on tuberculosis (TB) treatment remains a challenge to controlling TB. This case-control study aimed to identify determinants of treatment default among TB patients attending treatment clinics in Khartoum State from May to July 2011. Cases were TB patients who defaulted on treatment and controls were those who completed treatment. Of the 2727 TB patients attending the clinics, 328 (14\%) had defaulted. Of these, 185 had resumed treatment before data collection and 143 had not and were eligible as cases. Of the 143, 27 could not be traced and 11 declined to participate. Thus, 105 cases and 210 controls were included and interviewed. The variables significantly associated with treatment default were: rural residence (OR: 2.68; 95\% CI: 1.51-4.73), not being on a DOTS programme (OR: 2.53; 95\% CI: 1.49-4.30), having side-effects from treatment (OR: 1.94; 95\% CI: 1.14-3.29), and having a history of TB (relapse, multidrug-resistant TB or treatment failure) (OR: 5.11; 95\% CI: 2.69-9.69). Attention should be paid to these groups at risk of defaulting to encourage treatment adherence and continuation.
\end{abstract}

Key words: Tuberculosis, non-adherence, adherence, defaulter, compliance. 


\section{Introduction}

Tuberculosis (TB) has been known for a long time and is still a major public health problem (1). Worldwide TB kills more young and middle-aged adults than any other infectious disease, although it is a curable and preventable disease (2). The World Health Organization

(WHO) estimates that currently about 9.6 million new TB cases occur each year and that about 1.5 million deaths annually are related to TB $(3,4)$.

In 2010, it was estimated that the prevalence of TB cases in Sudan was 209 per 100000 population with an annual incidence of new cases of 119 per 100 000, resulting in about 37000 new cases each year in Sudan. Hence, Sudan has about $15 \%$ of the TB burden in the WHO Eastern Mediterranean Region and the second highest active TB prevalence of the countries in this region. In addition, the estimated death rate related to TB, including HIV-infected TB patients, was 24 per100 000 per year (5).

Successful treatment of TB involves taking anti-TB drugs for at least 6 months $(6,7)$. The therapeutic regimens given under direct observation short course therapy (DOTS) as recommended by WHO have been shown to be highly effective for both preventing and treating TB $(8,9)$. The health authority of Sudan follows the strategies for TB prevention and treatment recommended by WHO. Despite the efforts that had been made by health authorities, some patients still do not follow their TB treatment and do not complete the intensive stage of treatment. As defined by WHO, patients who fail to collect their TB treatment for 2 consecutive months are reported as defaulters (10). Defaulting on TB medication is a major barrier to its local and global control. In addition, defaulting increases the risk of drug resistance, relapse and death, and may prolong infectiousness (11-15). The TB patient treatment default rate is about $10 \%$ in Sudan (5) and $14 \%$ in Khartoum State (16). The high rate of 
default on TB treatment in Khartoum State makes the identification of the risk factors leading to patients to default essential. In a previous paper, we reported on the sociodemographic factors associated with non-adherence to TB treatment (17). In the present paper we identify the disease- and treatment-related determinants of treatment default among TB patients in Khartoum State. This information could help to suggest actions that could lead to a reduction of TB treatment defaulting.

\section{Methods}

\section{Study design}

This was an observational case $\square$ control study. Cases were the patients who defaulted from treatment and controls were those who completed treatment.

\section{Setting}

This study was conducted in Khartoum State. In 1993, the Ministry of Health in Khartoum State established a TB control programme. The decentralized health care system in Khartoum is divided into 7 districts and 19 health areas. Its health facilities include 43 hospitals, 147 health centres, 185 centres run by nongovernmental organizations, 235 dispensaries and 365 primary health care units. TB services are available in 53 of the primary health care centres in Khartoum State and is where TB patients receive their treatment (16). A registered nurse is designated responsible for TB treatment and follow up of continuation of treatment in the primary health care unit. This primary health care unit is the basic unit of management and reporting of the TB programme. Staff at the primary health care unit responsible for TB services include a medical assistant, a laboratory technician and a clerk. The programme provides care through the DOTS strategy as recommended by WHO. 


\section{Population}

Our cases and controls were drawn from all TB patients attending the 53 treatment clinics in Khartoum State. The inclusion criteria for both cases and controls were: patients over 15 years who were clinically and laboratory diagnosed with TB and registered at the treatment units in Khartoum State. Cases were those patients identified as having defaulted on TB treatment during the data collection period. Following identification of each case (defaulter), without exclusion criteria, the next 2 patients who had completed their treatment without defaulting were included as controls, without exclusion criteria. They were attending the clinics because they had been requested to come for follow up, in the same TB treatment unit or the nearest one in the same area, either to do the final sputum smear or to collect the smear results. Patients were excluded from the study if they were too ill for interview, had a psychiatric illness or had given an incorrect address and could not be traced.

The interview process was done from 1 May 2011 to 15 July 2011, but in order to reach the target defaulted group for the interviews, we used clinic records for the patients registered from May 2010 to May 2011.

\section{$T B$ and treatment definitions}

The following definitions were applied. A pulmonary TB patient was one with TB disease involving the lung parenchyma. An extra-pulmonary TB patient was one with TB of organs other than the lungs (e.g. pleura, lymph nodes, abdomen, genitourinary tract, skin, joints and bones and meninges). A patient in whom both pulmonary and extrapulmonary $\mathrm{TB}$ were diagnosed was classified as pulmonary $\mathrm{TB}$ (10).

Treatment default was defined as an interruption of TB treatment for 2 or more consecutive months during the intended treatment period. Relapse was defined as a 
patient previously treated for TB who has been declared cured or has completed treatment and is diagnosed with bacteriologically positive (smear or culture) TB. Treatment failure was defined as a patient who is sputum smear positive at 5 months or later during treatment. Multidrug resistant (MDR) TB was defined as TB resistance to at least isoniazid and rifampicin. Side-effects of treatment were defined according to a patient's complaint and as identified by doctors and taken from the records $(5,18-20)$.

Drug regimen was defined as a drug or several drugs given in certain doses for a stated duration, as described by the treating doctor according to the national TB control programme. All new TB patients should receive the category 1 (CAT1) regimen for 6 months, which includes rifampicin, isoniazid, pyrazinamide and ethambutol. The category 2 (CAT2) treatment regimen is used for retreatment of TB patients; it lasts for 8 months and includes streptomycin in the first 2 months $(5,10,19)$.

DOTS is directly observed treatment, or watching the patient take his/ her medication to ensure medications are taken in the right combination and for the correct duration $(10,19)$.

\section{Data collection}

Information on disease-related and treatment-related factors was retrieved from the medical records of the patients. In addition, face-to-face interviews were held, using a structured questionnaire, by trained interviewers to obtain information on the various factors possibly associated with treatment default. The questionnaire was pretested on 35 patients and, based on the results, was used without any major changes. All TB patients who had defaulted prior to the data collection period were identified and their address retrieved from patient records. Then, the interviewers used the following sequence of contact attempts: telephone calls, first to the patient 
and then to known family members or friends, and then home visits, first to patient and then to known family members or friends. If there was no telephone number on record, home visits were made.

Data on the following variables were collected: sociodemographic characteristics including age, sex, residence (urban/rural); and disease- and treatment- related factors including BCG vaccination status, sputum smear result, treatment regimen, on a DOTS programme or not, chest X-ray, response to treatment, side-effects from treatment, sputum smear after 2 months, previous history of TB (including relapse, treatment failure and MDR-TB), other treatments sought, and other chronic diseases, e.g. diabetes mellitus (1,4,11,16,20-22).

\section{Statistical analysis}

The sample size was calculated according to Fleiss (1981) (23-25) assuming a two-sided type one error of 0.05 , a power of $80 \%$ and the ability to detect an odds ratio (OR) of 2.0 with an exposure frequency of $30 \%$ in the control group and a ratio of cases to controls of 1:2. This gave a sample size of 105 cases and 210 controls.

Data were reviewed for consistency and completeness. Data analysis was performed in SPSS, version 16. The demographic characteristics of the cases and controls were compared using the chi-squared test for qualitative variables and Student t-test for continuous variables. Univariate and multivariate analyses were done. Descriptive statistics were calculated for the dependent variable (treatment default). Logistic regression analysis was done to calculate the ORs and its $95 \%$ confidence intervals $(\mathrm{CI})$. Variables that were related to treatment default with a Pvalue less than 0.20 were entered in a multivariate model, using a backward selection. 


\section{Ethical considerations}

Ethical approval was obtained from the ethics committee of the Ministry of Health, Khartoum State. Permission was granted by public committee leaders (senior health officers at the locality: director of health services, health team coordinator and PHC director) in the localities through official letters. Informed verbal consent was obtained from every eligible patient included in the study before the interview. Prior to the interview, all relevant aspects of the study were explained to the participants, including the purpose of the study, interview process and potential benefits. The interviews took place at the TB units in a suitable and separate room. The interviewers introduced themselves to the participants and outlined the scope of the interview and its approximate length at the beginning of each interview. The participants were informed that participation was entirely voluntary, and that privacy and confidentially would be maintained during data processing and reporting. Potential respondents also were informed that they had the right to decline to participate, or to end the interview at any time without jeopardizing their right for care and treatment.

Privacy and confidentially were maintained and the information was used only for this study and will not be used by any other person for any other purposes.

\section{Results}

\section{Cases and controls}

There were $2727 \mathrm{~TB}$ patients who attended the $53 \mathrm{~TB}$ treatment clinics in Khartoum State during the study period. Out of these, 2399 patients (86\%) had completed their treatment while 328 patients (14\%) had interrupted treatment. The 328 patients were divided into 2 categories: 1) 143 who had defaulted and never come back until the time of data collection, who were be eligible to be included as 
cases; and 2) 185 who had defaulted but were traced and came back to continue treatment before the start of data collection, who were excluded.

Of the 143 eligible cases, 15 had given a wrong address and 12 had moved away from Khartoum State and could not be interviewed. A further 11 patients declined the interview. None of the cases was too ill for interview or had a psychiatric illness. Hence, 105 cases were traced and interviewed. In addition, 210 patients who had completed their treatment were included as controls; none declined to participate.

\section{Demographic characteristics of the cases and controls}

The demographic characteristics of the cases and controls are given in Table1. Among the cases, $70.5 \%$ were males compared with $60.9 \%$ among the controls. The mean ages and standard deviations (SD) were 32.8 (SD14.4) years for the cases and 34.6 (SD 14.9) years for the controls; $53.3 \%$ of the cases and $47.6 \%$ of the controls were aged 15 to 30 years. Among the cases, $61.0 \%$ were urban residents while $80.5 \%$ of the controls were urban residents.

\section{Disease and treatment characteristics of the cases and controls}

The disease and treatment characteristics of the cases and controls are given in Table 1. Cases and controls had a similar BCG vaccination status $(61.9 \%$ and $53.3 \%$ had had the BCG vaccination respectively) and sputum smear results at the beginning of treatment ( $71.4 \%$ and $74.8 \%$ were positive respectively) as well as after 2 months (10.5\% and $6.1 \%$ were positive respectively). However, more cases had a previous history of TB (37.1\%), including relapse, failure and MDR-TB, compared with controls $(10.0 \%)$. Hence, more cases $(45.7 \%)$ received the CAT2 treatment

regimen than controls $(22.9 \%)$. Fewer cases were on DOTS $(36.2 \%)$ than the controls $(59.5 \%)$ and fewer had a good response to treatment $(76.2 \%)$ compared with controls $(88.6 \%)$. In addition, more cases (52.4\%) developed side-effects from 
treatment than the controls $(31.0 \%)$ and more also sought traditional remedies $(28.6 \%)$ than the controls (12.9\%) (Table1).

\section{Risk factors for defaulting}

In the univariate analysis the following disease- and treatment-related factors were statistically significant associated with defaulting $(P<0.01)$ : rural residence (OR: 2.64; 95\% CI: 1.57-4.44), CAT2 regimen (OR: 2.84; 95\% CI: 1.72-4.69), not being on a DOTS programme (OR: 2.59 ; 95\% CI: $1.59-4.201)$, poor response to treatment (OR: 2.42; 95\% CI: 1.305-4.49), having side-effects from treatment (OR: 2.45; 95\% CI: 1.52-3.97), previous history of TB (relapse, treatment failure and MDR-TB) (OR: 5.32; 95\% CI: 2.92-9.69) and seeking traditional remedies (OR: $2.71 ; 95 \% \mathrm{CI}: 1.51-4.87)$ (Table 1$)$.

The multiple logistic regression analysis and adjusted ORs (aOR) and 95\% CIs are shown in Table 2. The variables that remained in the model were: rural residence (aOR: 2.68; 95\% CI: 1.51-4.73), not being on a DOTS programme (aOR: 2.53; 95\% CI:1.49-4.30), having side-effects from treatment (aOR: 1.94; 95\% CI:1.14-3.29) and previous history of TB (aOR: 5.11; 95\% CI: 2.69-9.69) (Table 2).

\section{Discussion}

In our study, the overall prevalence of TB treatment default among the patients who attended TB treatment clinics during the study period was $14 \%$, which is similar to that reported in other studies conducted in Khartoum State $(5,16)$. A high default rate on TB treatment has also been reported in other developing countries in Africa and Asia, e.g. 22.88\% in Ethiopia and 10.33\% in India $(26,27)$.

Our study showed that DOTS reduced default rates as those not on a DOTS programme has 2.5-times higher odds of default. This agrees with the results of previous studies conducted in both developed and developing countries $(20,22.28$ $30)$. 
Rural residence was strongly associated with TB default which concurs with the findings of other studies in Ethiopia (31), and South Africa(32) TB treatment default was also strongly associated with having side-effects from the TB medication and having a history of TB (relapse, failure and MDR-TB), which concurs with other studies $(6,11,33-36)$. However our findings are in contrast to those reported from Malaysia where residence, medicine side-effects and history of TB were not associated with TB treatment default (20). Furthermore, in contrast to the findings of our study, a study in Estonia found that urban residence was positively associated with TB default (37).

The findings of our study might help doctors and policy-makers in Khartoum State and other developing countries in planning and policy development to strengthen TB control programmes in general. Although we highlight the relation between disease and treatment-related factors and defaulting TB treatment, further exploration of precipitating factors for defaulting are needed.

To combat the TB spread in communities, WHO launched the DOTS strategy in 1993. Since that time, DOTS implementation has achieved good results by increasing patient compliance to treatment and decreasing treatment interruption in communities of both low and high socioeconomic status $(28,29)$. The Ministry of Health in Khartoum State adopted a DOTS strategy when it was recommended by the WHO in 1993 (5). To make the access of TB services available, the Ministry of Health set up more than 50 TB units (microscopic and treatment centres) distributed all over the State, according to geography and population density (16). Despite these efforts, TB treatment default remains high.

In view of our findings, in order to reduce $\mathrm{TB}$ treatment default further, attention should be paid to more adequate follow-up of patients, treatment of their side-effects, increasing the number of health units that use DOTS and tracing 
defaulters, particularly among rural patients who may face barriers to continuing treatment and among those with a history of TB (those who have relapsed, experienced treatment failure and those with MDR-TB). An objective of the TB control programme in Khartoum State is to provide tracing teams for defaulters in all TB units, which are responsible for contacting defaulting patients, encouraging them to come back to continue their treatment and visiting them at their home if they do not reply so as to identify the barriers and advise them on how to overcome them when they first start to default. The fact that this does not appear to be happening, at least up our study period, may indicate that the programme and its allocated resources need to be reassessed. The introduction of a revised retrieval system in Saudi Arabia significantly improved the retrieval of non-attenders and reduced the dropout rate (38).

In terms of the generalizability of our findings, some methodological aspects of our study need to be considered. First, our study was conducted in Khartoum State, which is the most populated state in Sudan. Its population may be represent the whole country as most of the inhabitants come from various parts of Sudan. In addition, the TB patients included in this study were selected from all TB treatment units in the State. Thus, our findings can be generalized to the total TB population in the State and also Sudan as well as to communities with similar settings. Second, recall bias was minimized by using a standardized questionnaire during the interview and by cross-checking patients' responses for each study variable against their medical records. Third, the reliability of the information gathered from each patient could not be counter-checked but questions about sensitive issues were carefully handled to maximize the accuracy of the responses obtained. Fourth, possible confounders were taken into consideration in the design (by restricting the diagnosis criteria) and in the analysis by using logistic regression analysis. Lastly, the major 
problem we faced during the study was how to reach the defaulting patients (cases). This problem was tackled in 3 steps. First, the patient medical records were traced and identified and all contact information was reviewed. Then, study personnel first tried to telephone the patient and, failing that, to telephone known family members or friends. If telephone contact failed or if there was no telephone number on record, home visits were made, first to the patient and then to known family members or friends. Interestingly, we found that many of the defaulting patients did not have access to any phone (mobile or landline), a risk factor not previously described nor evaluated in our study. The interviewers made an average of 3 attempts to contact each defaulter before recording a defaulter was a non-respondent. Due to the number of eligible cases who could not be traced and interviewed (27 of 143), generalizing the findings to the whole population of patients with TB should be done with caution.

In conclusion, our study shows that living in a rural area, not being on a DOTS programme, developing side-effects to treatment, and having a history of TB (relapse, MDR-TB or treatment failure) increased the likelihood of defaulting on treatment. These findings may help guide improvement in the current TB treatment delivery in Sudan and similar developing countries.

\section{Acknowledgements}

We would like to thank our colleagues at Ministry of Health,

Khartoum State and TB control Programme. We are further grateful to all TB coordinators and health care workers at TB units for their cooperation.

\section{Funding: None}

Competing interests: None declared. 


\section{References}

1. Katia S, Tachfouti N, Obtel M, Nejjari C. Factors associated with treatment default by tuberculosis patients in Fez, Morocco. East Mediterr Health J. 2013;19(8):687-93.

2. TB advocacy, a practical guide. Geneva: World Health Organization; 1999.

3. Global tuberculosis report. 20th ed. Geneva: World Health Organization; 2015.

4. Lönnroth K, Castro GK, Chakaya JM, Chauhan LS, Floy K, Glaziou P, et al. Tuberculosis control and elimination 2010-50: cure, care, and social development. Lancet. 2010;375(9728):1755-7.

5. Federal Ministry of Health. General Directorate of Primary Health Care. Sudan: National Tuberculosis Control Programme; 2011.

6. Muture B, Keraka M, Kimuu P, Kabiru E, Ombeka V, Oguya F. Factors associated with default from treatment among tuberculosis patients in Nairobi province, Kenya: A case control study. BMC Public Health. 2011;11(696):1-10.

7. Munro SA, Lewin SA, Smith HJ, Engel ME, Fretheim A, Volmink J. Patient adherence to tuberculosis treatment: a systematic review of qualitative research. PLoS Med 2007, 4(7):e238.

8. Addington WW. Patient compliance: The most serious remaining problem in the control of tuberculosis in the United States. Chest. 1979;76:741-3.

9. Chhaya M, Gupta SC. Noncompliance to DOTS: How it can be decreased. Indian J Community Med. 2011;36(1):27-30.

10. Operational guide for national tuberculosis control programmes on the introduction and use of fixed-dose combination drugs. Geneva: World Health Organization; 2002.

11. Chuah SY. Factors associated with poor patient compliance with antituberculosis therapy in Northwest Perak, Malaysia. Tubercle. 1991;72:261-4. 
12. Menzies R, Rochert I, Vissandjee B. Factors associated with compliance in treatment of tuberculosis. Tuber Lung Dis. 1993;74:32-7.

13. Wilkinson D. High-compliance tuberculosis treatment programme in a rural community. Lancet 1994, 343:647.

14. William JB, Cohn DL, Rietmeijer CA, Judson FN, Sbarbaro JA, Reves RR. Noncompliance with directly observed therapy for tuberculosis: epidemiology and effect on the outcome of treatment. Chest. 1997;111:1168-73.

15. Jasmer RM, Seaman CB, Gonzalez LC, Kawamura LM, Osmond DH, Daley CL. Tuberculosis treatment outcomes: directly observed therapy compared with self-administered therapy. Am J Respir Crit Care Med. 2004;170(5):561-6.

16. Suleiman MMA, Sodemann M. Evaluation of tuberculosis control programme in Khartoum State for the year 2006. Scand J Public Health. 2009;37:101-8.

17. Ali AOA, Prins MH. Patient non adherence to tuberculosis treatment in Sudan: socio demographic factors influencing non adherence to tuberculosis therapy in Khartoum State. Pan Afr Med J. 2016;25:80 doi:10.11604/pamj.2016.25.80.9447.

18.Awofeso N. Anti-tuberculosis medication side-effects constitute major factor for poor adherence to tuberculosis treatment. Bull World Health Organ. 2008;86(3):B-D.

19. What is DOTS? A guide to understanding the WHO-recommended TB control strategy known as DOTS. Geneva: World Health Organization; 1999 ((http://apps.who.int/iris/ bitstream/10665/65979/1/WHO_CDS_CPC_TB_99.270.pdf, accessed 20 March 2017).

20. Nyi NN, Catherine D, Abdul Rahman I, Rosemi S, Noraini B, Mohd RM. Factors contributing to poor compliance with anti-TB treatment among tuberculosis patients. Southeast Asian J Trop Med Public Health. 2001;32(2):369-82.

21. Sabate E. WHO Adherence to long-term therapies: policy for action. Geneva: World Health Organization; 2001 (http://www.who.int/chp/knowledge/publications/adherencerep.pdf, accessed 20 March 2017). 
22.. Jaggarajamma K, Sudha G, Chandrasekaran V, Nirupa C, Thomas A, Santha $\mathrm{T}$, et al. Reasons for non-compliance among patients treated under Revised National Tuberculosis Control Programme (RNTCP), Tiruvallur District, South India. Indian J Tuberc. 2007;54:130-5.

23.. Fleiss LJ. Statistical methods for rates and proportions. 2nd ed. Hoboken, NJ: John Wiley \& Sons Ltd; 1981:35-48.

24.. Kelsey JL, Whittemore AS, Thomson WD, Evans AS. Methods in observational epidemiology. 2nd ed. New York: Oxford University Press; 1986.

25.. Riegalman RK, Hirsch RP. Studying a study and testing a test. How to read the medical literature. 2nd ed. Boston: Little, Brown and Company; 1989.

26.. Demeke D, Legesse M, Bati J. Trend of tuberculosis and treatment outcomes in Gambella region with special emphasize on Gambella Regional Hospital, Western Ethiopia. J Mycobac Dis. 2013;3(2).

27. Pardeshi GS. Time of default in tuberculosis patients on directly observed treatment. J Glob Infect Dis. 2010;2(3):226-30.

28. Marlucia DSG, Maria LP, Toma MP. Porcuna, Alexandra B S, et al. Factors associated with tuberculosis treatment default in an endemic area of the Brazilian Amazon: a case control-study. PLoS One. 2012;7(6):e39134.

29. Robert MJ, David CS, Jussi JS, Philip CH. etal. Short-Course Rifampin and Pyrazinamide Compared with isoniazid for Latent Tuberculosis Infection: A CostEffectiveness Analysis Based on a Multicenter Clinical Trial. Clin Infect Dis. 2004;38:363-9.

30. Ifebunandu NA, Ukwaja KN. Tuberculosis treatment default in a large tertiary care hospital in urban Nigeria: prevalence, trend, timing and predictors. J Infect Public Health. 2012;5(5):340-5. 
31. Wondimu T, W/Michael K, Kassahun W, Getachew S. Delay in initiating tuberculosis treatment and factors associated among pulmonary tuberculosis patients in East Wollega, WesternEthiopia. Ethiopian J Health Dev. 2007;21(2):148.

32. Ndwandwe Z S I, Mahomed S, Lutge E, Knight S E. Factors affecting non adherence to tuberculosis treatment in uMgungundlovu Health District in 2010. South Afr J Infect Dis 2014;29(2):56.

33. Pandi NT, Choudhary SK. A study of treatment compliance in directly observed therapy for tuberculosis. Indian J Community Med. 2006;31(4):241-3.

34. Sanchez PE, Marquer C, Kalon S, Qayyum S, Hayrapetyan A, Varaine F, et al. Reasons for defaulting from drug-resistant tuberculosis treatment in Armenia: a quantitative and qualitative study. Int J Tuberc Lung Dis. 2014;18(2):160-7.

35. Slama K, Tachfouti N, Obtel M, Nejjari C. Factors associated with treatment default by tuberculosis patients in Fez, Morocco. East Mediterr Health J. 2013;19(8):687-93.

36 Lalor MK, Greig J, Allamuratova S, Althomsons S, Tigay Z, Khaemraev A, et al. Risk factors associated with default from multi- and extensively drug-resistant tuberculosis treatment, Uzbekistan: a retrospective cohort analysis. PLoS One. 2013;8(11):e78364.

37. Kliiman K, Altraja A. Predictors and mortality associated with treatment default in pulmonary tuberculosis. Int J Tuberc Lung Dis. 2010 Apr;14(4):454-63. 38. Chaudhry LA, Al-Tawfiq J, Ba-Essa E, Robert AA. Low rate of noncompliance to antituberculous therapy under the banner of directly observed treatment short course (DOTS) strategy and well organized retrieval system: a call for implementation of this strategy at all DOTS centers in Saudi Arabia. Pan Afr Med J. 2015;21:267. 
Table1 Distribution of disease and treatment related factors in the tuberculosis (TB) patients

\begin{tabular}{|c|c|c|c|c|c|}
\hline $\begin{array}{l}\text { Disease and } \\
\text { treatment } \\
\text { related factors }\end{array}$ & $\begin{array}{c}\text { Cases }(n= \\
105)\end{array}$ & Controls $(n=210)$ & $P$-value & OR & 95\% CI \\
\hline & No. $(\%)$ & No. $(\%)$ & & & \\
\hline \multicolumn{6}{|l|}{ Age (years) } \\
\hline $15-30$ (ref) & $56(53.3)$ & $100(47.6)$ & & & \\
\hline$>30$ & 49 (46.7) & $110(52.4)$ & 0.34 & 0.80 & $0.50-1.27$ \\
\hline \multicolumn{6}{|l|}{ Sex } \\
\hline Male & $74(70.5)$ & $128(61.0)$ & 0.098 & 1.53 & $0.93-2.53$ \\
\hline Female (ref) & $31(29.5)$ & $82(39.0)$ & & & \\
\hline \multicolumn{6}{|l|}{ Residence } \\
\hline Urban (ref) & $64(61)$ & $169(80.5)$ & & & \\
\hline Rural & $41(39)$ & $41(19.5)$ & $<0.0001$ & 2.64 & $1.57-4.44$ \\
\hline \multicolumn{6}{|l|}{ Site of $T B$} \\
\hline Pulmonary & $92(87.6)$ & $180(85.7)$ & 0.643 & 1.18 & $0.60-2.37$ \\
\hline $\begin{array}{l}\text { Extra- } \\
\text { pulmonary (ref) }\end{array}$ & $13(12.4)$ & $30(14.3)$ & & & \\
\hline \multicolumn{6}{|l|}{$\begin{array}{l}\text { Sputum smear } \\
\text { at the } \\
\text { beginning }\end{array}$} \\
\hline Positive & 75 (71.4) & $157(74.8)$ & 0.52 & 084 & $0.50-1.43$ \\
\hline Negative (ref) & $30(28.6)$ & $53(25.2)$ & & & \\
\hline \multicolumn{6}{|l|}{ Chest X-ray } \\
\hline Normal & $80(76.2)$ & $173(82.4)$ & 0.19 & 0.68 & $0.39-1.21$ \\
\hline Positive (ref) & $25(23.8)$ & 37 (17.6) & & & \\
\hline
\end{tabular}




\begin{tabular}{|c|c|c|c|c|c|}
\hline $\begin{array}{l}\text { Treatment } \\
\text { regimen }\end{array}$ & & & & & \\
\hline CAT1 (ref) & $57(54.3)$ & $162(77.1)$ & & & \\
\hline CAT2 & 48 (45.7) & 48 (22.9) & $<0.0001$ & 2.84 & $1.72-4.69$ \\
\hline On DOTS & & & & & \\
\hline Yes (ref) & 38 (36.2) & $125(59.5)$ & & & \\
\hline No & $67(63.8)$ & $85(40.5)$ & $<0.0001$ & 2.59 & $1.59-4.21$ \\
\hline $\begin{array}{l}\text { Response to } \\
\text { treatment }\end{array}$ & & & & & \\
\hline Good (ref) & $80(76.2)$ & $186(88.6)$ & & & \\
\hline Poor & $25(23.8)$ & $24(11.4)$ & 0.004 & 2.42 & $1.30-4.49$ \\
\hline $\begin{array}{l}\text { Sputum smear } \\
\text { after } 2 \text { months }\end{array}$ & & & & & \\
\hline Positive & $11(10.5)$ & $13(6.1)$ & 0.166 & 1.82 & $0.78-4.27$ \\
\hline Not done & $23(21.9)$ & $44(21.0)$ & 0.686 & 1.13 & $0.63-2.01$ \\
\hline Negative (ref) & $71(67.6)$ & $153(72.9)$ & & & \\
\hline $\begin{array}{l}\text { Had side- } \\
\text { effects to TB } \\
\text { treatment }\end{array}$ & & & & & \\
\hline Yes & $55(52.4)$ & $65(31.0)$ & $<0.0001$ & 2.45 & $1.52-3.97$ \\
\hline No (ref) & $50(47.6)$ & $145(69.0)$ & & & \\
\hline $\begin{array}{l}\text { Previous } \\
\text { history of } T B\end{array}$ & & & & & \\
\hline $\begin{array}{l}\text { No: new case } \\
\text { (ref) }\end{array}$ & 66 (62.9) & $189(90.0)$ & & & \\
\hline Yes $^{\mathrm{a}}$ & $39(37.1)$ & $21(10.0)$ & $<0.0001$ & 5.32 & $2.92-9.69$ \\
\hline
\end{tabular}




\begin{tabular}{|l|c|c|c|c|c|c|}
\hline $\begin{array}{l}\text { Sought } \\
\text { traditional } \\
\text { remedies }\end{array}$ & & $30(28.6)$ & $27(12.9)$ & 0.001 & 2.71 & $1.51-4.87$ \\
\hline Yes & $75(71.4)$ & $183(87.1)$ & & & \\
\hline No (ref) & & & & & & \\
\hline $\begin{array}{l}\text { Had BCG } \\
\text { vaccine }\end{array}$ & & $40(38.1)$ & $98(46.7)$ & & & $0.88-2.29$ \\
\hline Yes & & $112(53.3)$ & & & \\
\hline No (ref) & & $95(90.5)$ & $175(83.3)$ & & 0.06 & $0.25-1.11$ \\
\hline $\begin{array}{l}\text { Have chronic } \\
\text { diseases }\end{array}$ & & $35(16,7)$ & & & \\
\hline Yes & & & & & & \\
\hline No (ref) & & & & & & \\
\hline
\end{tabular}

${ }^{\mathrm{a}}$ Including relapse, treatment failure and multidrug-resistant TB.

$\mathrm{OR}=$ odds ratio $; \mathrm{CI}=$ confidence intervals.

ref $=$ reference category. 
Table 2 multivariate analysis of the disease and treatment risk factors for defaulting on tuberculosis (TB) treatment

\begin{tabular}{|l|c|c|c|}
\hline $\begin{array}{l}\text { Disease and treatment } \\
\text { related factors }\end{array}$ & Adjusted OR & 95\% CI & P-value \\
\hline Rural residence & 2.68 & $1.51-4.73$ & 0.001 \\
\hline Not on DOTS & 2.53 & $1.49-4.30$ & 0.001 \\
\hline $\begin{array}{l}\text { Side-effects from TB } \\
\text { rreatment }\end{array}$ & 1.94 & $1.14-3.29$ & 0.015 \\
\hline Previous history of $\mathrm{TB}^{\mathrm{a}}$ & 5.11 & $2.69-9.69$ & $<0.0001$ \\
\hline
\end{tabular}

${ }^{\mathrm{a}}$ Including relapse, treatment failure and multidrug-resistant TB.

$\mathrm{OR}=$ odds ratio $\mathrm{CI}=$ confidence intervals . 
Chapter 5 Patient knowledge and behavioral factors leading to nonadherence to tuberculosis treatment in Khartoum State, Sudan

\author{
Ahmed Osman A Ali \\ Martin H. Prins \\ Journal of Public Health and Epidemiology.2016;8(11):316-325
}




\begin{abstract}
:
Although tuberculosis is a curable and preventable disease, defaulting from treatment can prolong infectiousness leading to increased transmission, an increased risk of drug resistance, relapse and death. Our objective was to identify patient related determinants (including knowledge and awareness, opinion about TB services and behavioral factors) of treatment defaulting among TB patients in Khartoum State, Sudan.
\end{abstract}

\title{
Methods:
}

Between May 2010 to May 2011, we conducted a case control study where the patients defaulting from treatment were considered as 'cases' and those completing treatment as 'controls'.

\section{Results:}

There were 2727 TB patients who attended TB treatment clinics during study period. Out of these 2399 patients $(86 \%)$ had continued their treatment while 328 patients (14\%) had interrupted it. 105 cases were traced and interviewed. In addition 210 patients who had continued their treatment were included as controls. In the multivariate analysis the variables that remained in the model were: rural residence $(\mathrm{OR}=2.16 ; 95 \% \mathrm{CI}=1.19-3.90)$, "had never heard about $\mathrm{TB}$ before had $\mathrm{it}(\mathrm{OR}=1.81$; 95\% CI=1.02-3.20), lack of knowledge on when to stop TB medication $(\mathrm{OR}=2.00$; $95 \% \mathrm{CI}=1.10-3.64)$, less support by families, friends and colleagues $(\mathrm{OR}=3.23$; $95 \% \mathrm{CI}=1.62-6-46)$, too many patients when visiting the $\mathrm{TB}$ center $(\mathrm{OR}=2.24$; $95 \% \mathrm{CI}=1.29$ - 3.88), and lack of counseling about $\mathrm{TB}$ and its treatment $(\mathrm{OR}=4.79$; $95 \% \mathrm{CI}=2.57-8.95)$.

\section{Conclusions}

The results of this study show that patient's knowledge about TB, its treatment and the experienced professional and peer support are associated with TB treatment 
continuation. Hence, adequate counseling of patients, including counseling of their peers for social support, and adequate training of the health care providers who have enough to time to attend to their patient's need are potential measures to reduce TB treatment default.

Key words: Tuberculosis, non-adherence, adherence, defaulter, compliance. 


\section{Introduction:}

Tuberculosis (TB), is a global health concern for both developing and developed countries (Nezenega et al., 2013). It has reached epidemic proportions in many developing countries, with a third of world population being infected with Mycobacterium tuberculosis (Khan et al., 2006). Although it is a curable and preventable disease. Worldwide TB is the second most common cause of death in adults attributable to a single infectious agent (World Health Organization, 2015).

In 2010, it was estimated that in Sudan there were 209 cases of active TB per 100.000 of the population with an annual incidence of new cases of 119/100.000, resulting in approximately 37.000 new cases each year. Hence, Sudan shoulders about $15 \%$ of TB burden in the Eastern Mediterranean Region and has the second highest active TB prevalence of the countries in this region. In addition, the estimated death rate related to $\mathrm{TB}$, including HIV infected TB patients, was 24/100.000 per year (Federal Ministry of Health, Sudan, 2011).

The health authority of Sudan subscribes to the strategies for TB prevention and treatment recommended by the WHO including The therapeutic regimens given under direct observation short course therapy (DOTS) programme. Despite the efforts that had been undertaken by health authorities still some patients fail to adhere to TB treatment and eventually default before completing the treatment. As defined by the WHO, patients who fail to collect their TB treatment for 2 consecutive months are reported as defaulters (World Health Organization, 2002).

The role of human behavior in health and illness has been increasingly recognized (Suleiman et al., 2014). In any cultural context, a precondition of healthseeking behavior is the recognition and interpretation of symptoms by individuals affected by a disease and by those around them (Ayisi et al.,2011). 
In the case of TB, personal experiences, perceived etiology of the disease, associated beliefs and attitudes could be important for appropriate health- seeking behavior, i.e. completing treatment. Hence, health education and counselling to TB patients may increase successful treatment completion (Ayisi et al.,2011, Rubel and Garo, 1992).

Many studies have addressed behavioral, biological, socio-demographic factors, and patient knowledge factors that were associated with TB treatment default or leading to delays in seeking TB treatment (Carolyn et al., 2009). Thus, understanding of patient knowledge, opinion, cultural believes and behavioral patterns, in addition to knowledge of health staff and their practice and their association with defaulters from TB treatment is crucial.

The present study was conducted to identify patient related determinants (including knowledge and awareness, opinion about TB services and behavioral factors) of treatment defaulting among TB patients.

\section{Materials and Methods}

This was an observational case control study where the patients defaulting from treatment were considered as 'cases' and those completing treatment as 'controls'.

\section{Setting}

This study was conducted in KhartoumState. In 1993, the Ministry of Health in Khartoum State established a tuberculosis control program. The decentralized healthcare system in Khartoum is divided into seven districts and 19 health areas. Its health facilities include 43 hospitals, 147 health centers, 185 NGOs centers, 235 dispensaries and 365 primary health care units. TB services are delivered in primary health care along with all other routine health services. A registered nurse is designated responsible for treatment and follow up for continuation of treatment in 
the primary health care unit. This primary health care unit is the basic unit of management of the program and also the unit of reporting. Personnel at the primary health care unit responsible for tuberculosis services include a medical assistant, a laboratory technician and a clerk. The program provides care through the DOTS strategy (Directly Observed Treatment with Short course chemotherapy) as recommended by WHO. TB patients receive their treatment through $53 \mathrm{~TB}$ treatment units distributed all over the State (Suleiman and Sodemann, 2009).

\section{Population}

The interview process was done in the period from $1^{\text {th }}$ of May 2011 to $15^{\text {th }}$ of July 2011, but in order to reach the target defaulted group for the interviews we used the clinics records for the patients registered in the period from May 2010 to May 2011. The inclusion criteria for both cases and controls were; patients age more than 15 years and clinically and laboratory diagnosed as tuberculosis, registered at the treatment units in Khartoum States. Cases were those patients identified as TB treatment defaulting during the data collection period. Following identification of each case (defaulter) without exclusion criteria, the next 2 subsequent patients without exclusion criteria, who had completed their treatment without defaulting, and requested to come for follow up, either to do the final sputum smear or to collect the smear results, in the same TB treatment unit or the near one in the same area, were taken as control into the study. The patients were excluded from the study if they were: too ill for interview, had a psychiatric illness, or gave incorrect address and could not be traced.

\section{Definition of variables}

The following definitions were applied according to the World Health Organization (WHO, 2002). 
Pulmonary TB: a patient with tuberculosis disease involving the lung parenchyma. Extra-pulmonary TB: a patient with tuberculosis of organs other than the lungs (e.g. pleura, lymph nodes, abdomen, genitourinary tract, skin, joints and bones, meninges). A patient in whom both pulmonary and extra-pulmonary TB has been diagnosed was classified as pulmonary TB(World Health Organization, 2002).

Categories of treatment outcomes' Treatment default: is defined as an interruption of TB treatment for two or more consecutive months during the intended treatment period (World Health Organization, 2002). Adherence to TB treatment may be defined as the extent to which the patient's history of therapeutic drug-taking coincides with the prescribed treatment (Urquhart, 1996). Complementary and alternative medicine (CAM): is a medical intervention which is not taught widely at medical schools or is not generally available in hospitals, seek folk remedies treatment: are those patients who seek alternative treatment other than TB recommended therapeutic chemotherapy (herbal, traditional and spiritual treatment) (Hirofumi et al., 2006).

\section{Data Collection}

Information on demographic factors, disease related factors and treatment related factors were retrieved from patients' medical records. In addition, a face to face interview was held, using a standardized questionnaire by trained interviewers to elicited information on the various factors possibly associated with treatment defaulting. All TB patients who had defaulted prior to data collection period were identified and their address had been retrieved from patient records. Then, the interviewers used the following sequence of contact attempts:calls - first to the patient and thereafter to known family members or friends - home visits - first to patient and thereafter to known family members or friends. 
Before the start of data collection the interviewers had been trained on how to interview the respondents, and had been given instructions on how to fill the questionnaire. After that, pretesting was conducted by interviewing few patients. Based on the pretesting results the questionnaire was used without any major changes.

The data collected included demographic and clinical variables (age,gender,site of TB infection, co-infection with HIV), patient's knowledge of TB and its treatment, the patient's rating of the TB treatment services provided and behavioral factors (Rubel and Garo,1992, (Finlay et al., 2012, Chuah, 1991, Marlucia et al., 2012, Comolet et al., 1998, Jaggarajamma et al., 2007, Nyi et al., 2001, Pardeshi ,2010, Muture et al., 2011). The abbreviated list of questions asked is detailed in Table1 and 2.

\section{Statistics}

The sample size was calculated according to Fleiss (1981) (Fleiss, 1981) using a two sided type one error of 0.05 and a power of $80 \%$ and the ability to detect an odds ratio of 2.0 with a exposure frequency of $30 \%$ in the control group and a ratio of cases to controls of 1:2. This yielded a sample size of 105 cases and 210 controls.

Data were reviewed for consistency and completeness. Data analysis was performed in SPSS(Statistical package of Social Sciences) version 16. The Demographic characteristics of cases and controls were compared using $\chi^{2}$ test for qualitative variables and student's t tests for continuous variables. Univariate and multivariate analysis were conducted. Descriptive statistics were calculated for all dependent variables. Logistic regression was used to calculate the odds ratio and its 95\% confidence interval. Variables that were related to treatment default with a pvalue less than 0.20 were entered in a multivariate model, using a backward approach (Fleiss, 1981). 


\section{Ethical Considerations}

Ethical approval was obtained from the Ministry of Health Khartoum State ' ethical Committee. Permission was granted by public committee leaders in the localities through official letters. Informed verbal consent was secured from every eligible patient included in this study before the interview. Privacy and confidentially was maintained. Prior to the arrival of the data collection team the respondents had been informed regarding all relevant aspects of the study, including the purpose of the study, interview process and potential benefits. The interviewers introduced themselves to respondents and outlined the scope of interview and its approximate length to the potential respondents at the beginning of each interview. The respondents had been informed that the participation was entirely voluntary, and that privacy and confidentially will be maintained during data processing and reporting. Potential respondents also were informed that they had the right to refuse to participate, or to end the interview at any time.

\section{Results}

\section{Patients}

There were 2727 TB patients who attended TB treatment clinics during study period. Out of these, 2399 patients $(86 \%)$ had completed their treatment while 328 patients (14\%) had interrupted it. Out of these, 185 patients had defaulted prior to the data collection period. Hence, 143 patients were potentially eligible as cases. Of these, 15 had given a wrong address and 12 had moved out of Khartoum State and could not be interviewed. A further 11patients refused the interview. Hence, 105 cases were traced and interviewed. In addition 210 patients who had completed their treatment were included (controls).

Among cases, $70.5 \%$ were males and $29.5 \%$ were females compared to $60.9 \%$ of males and $39.1 \%$ of females among the controls. The mean ages were 
respectively 32.8 years and 34.6 years for cases and controls. 53.3\% of the study cases were aged 15 to 30 years and $46.7 \%$ were more than 30 years old compared to respectively $47.6 \%$ and $52.4 \%$ for controls. Among cases, $61 \%$ were living in urban area and $39 \%$ in rural area compared to respectively $80.5 \%$ and $19.5 \%$ for controls. Also about $61 \%$ of cases were ready to stop taking treatment according to the health care workers advice and 39\% can stop taking treatment due to other factors such as feeling better compared to respectively $81.4 \%$ and $18.6 \%$ for controls. However, $29.5 \%$ of these cases were treated differently by their families, friends and colleagues of having TB compared to controls (11.0\%). Hence, cases felt that the medical center in which they were treated had more attendants than controls $(59 \%$ vs $42.9 \%$ ). Compared to controls, cases were less often received less health education (41.9\% vs $11.9 \%$ ) while more of them did not hear about TB disease before they had it $(44.9 \%$ vs $27.1 \%$. The demographic and TB characteristics are given in tables 1 and 2 .

\section{Patient's knowledge and opinion}

The distribution of factors related to knowledge of TB and it's treatment as well as the opinion and attitudes of cases and controls is given in tables 1 and 2 . Univariate odds ratios and their 95\% confidence intervals are given in Tables 3 and 4. In general, cases were more likely to lack adequate knowledge of TB such as; had never heard about TB before had it (OR: 1.93, 95\% CI: 1.18-3.17), when to stop TB medication (OR: 2.81, 95\% CI: 1.66-4.74), treatment duration (OR: 2.96, 95\%CI: 1.62-5.41) and can TB be cured (OR: 2.54, 95\%CI: 1.13-5.71). Hence, cases were more living in the rural areas (OR:2.64 and 95\%CI: 1.57-4.44) and having more social problems because they had TB. Especially, cases reported feeling more ashame(OR:1.88,95\%CI:1.04-3.39) and embarrassment because of having TB(OR:2.17,95\% CI:1.16-4.07), and were less likely to have support of 
their families, friends and colleagues(OR:3.41, 95\%CI: 1.86-6.22). The perception of health services was similar. However, cases had often received less counselling on TB and its treatment(OR:5.34, 95\% CI:3.02-9.44) and felt there were too many patients when visiting the TB center(OR:1.92,95\%CI:1.20-3.09),tables3and4.

\section{Risk factors for defaulting}

- In the multivariate analysis the variables that remained in the model were residential locality( P value: 0.011, OR:2.16; 95\% CI: 1.19-3.90), 'lack of knowledge on when to stop TB medication'(P value: 0.023, OR: 2.00; 95\%CI:1.103.64 ), "had never heard about TB before had it(P value:0.041, OR: 1.81; 95\%CI:1.02-3.20), 'less support by families, friends and colleagues'(P value: 0.001; OR: 3.23; 95\%CI: 1.62-6.46), 'too many patients when visiting the TB center'( $\mathrm{P}$ value: 0.004; OR: 2.24; 95\%CI: 1.29 -3.88), and 'lack of counseling about TB and its treatment' (P value: 0.000; OR: 4.79; 95\%CI: 2.57 -8.95), (Table5). 
Table1: Patients knowledge and awareness factors affecting non adherence to TB treatment:

\begin{tabular}{|c|c|c|c|}
\hline Patients knowledge and awareness factors: & $\begin{array}{l}\text { Cases } \\
(105) \\
\end{array}$ & $\begin{array}{l}\text { Control } \\
(210)\end{array}$ & P-value \\
\hline $\begin{array}{l}\text { Age }- \text { mean }(\mathrm{SD}) \\
15-30 \text { years } \\
\text { Over } 30 \text { years }\end{array}$ & $\begin{array}{l}32.8(14.4) \\
56(53.3 \%) \\
49(46.7 \%)\end{array}$ & $\begin{array}{l}34.6(14.9) \\
100(47.6 \%) \\
110(52.4)\end{array}$ & 0.339 \\
\hline $\begin{array}{l}\text { Sex } \\
\text { Male } \\
\text { Female }\end{array}$ & $\begin{array}{l}74(70.5 \%) \\
31(29.5 \%)\end{array}$ & $\begin{array}{l}128(60.9 \%) \\
82(39.1 \%)\end{array}$ & 0.98 \\
\hline $\begin{array}{l}\text { Site of tuberculosis } \\
\text { Pulmonary TB } \\
\text { Extra-pulmonary TB }\end{array}$ & $\begin{array}{l}92(87.6 \%) \\
13(12.4 \%)\end{array}$ & $\begin{array}{l}180(85.7 \%) \\
30(14.3 \%)\end{array}$ & 0.39 \\
\hline $\begin{array}{l}\text { Residential locality } \\
\text { City } \\
\text { Village }\end{array}$ & $\begin{array}{l}64(61 \%) \\
41(39 \%) \\
\end{array}$ & $\begin{array}{l}169(80.5 \%) \\
41(19.5 \%)\end{array}$ & 0.000 \\
\hline $\begin{array}{l}\text { Did you hear about } \\
\text { TB before you had it? } \\
\text { Yes } \\
\text { No }\end{array}$ & $\begin{array}{l}61(58.1 \%) \\
44(41.9 \%)\end{array}$ & $\begin{array}{l}153(72.9 \%) \\
57(27.1 \%)\end{array}$ & 0.006 \\
\hline $\begin{array}{l}\text { What do you expect if you stop TB treatment? } \\
\text { Know the consequences } \\
\text { Don' know the consequences }\end{array}$ & $\begin{array}{l}95(90.5 \%) \\
10(9.5 \%)\end{array}$ & $\begin{array}{l}183(87.1 \%) \\
27(12.9 \%)\end{array}$ & 0.251 \\
\hline $\begin{array}{l}\text { Know the consequence if stop TB treatment } \\
\text { Not cured } \\
\text { Relapse } \\
\text { Start treatment again } \\
\text { Died }\end{array}$ & $\begin{array}{l}16(16.8 \%) \\
42(44.2 \%) \\
12(12.7 \%) \\
25(26.3 \%)\end{array}$ & $\begin{array}{l}48(26.3 \%) \\
80(43.7 \%) \\
22(12.0 \%) \\
33(18.0 \%)\end{array}$ & 0.215 \\
\hline $\begin{array}{l}\text { Treatment duration } \\
\text { Known } \\
\text { Not known }\end{array}$ & $\begin{array}{l}76(72.4 \%) \\
29(27.6 \%) \\
\end{array}$ & $\begin{array}{l}186(88.6 \%) \\
24(11.4 \%)\end{array}$ & 0.000 \\
\hline $\begin{array}{l}\text { Mentioned the treatment duration } \\
6 \text { months duration } \\
8 \text { month duration }\end{array}$ & $\begin{array}{l}39(51.3 \%) \\
37(48.7 \%)\end{array}$ & $\begin{array}{l}131(70.3 \%) \\
55(29.7 \%)\end{array}$ & 0.065 \\
\hline $\begin{array}{l}\text { Can TB be cured? } \\
\text { Yes } \\
\text { No }\end{array}$ & $\begin{array}{l}91(86.7 \%) \\
14(13.3 \%)\end{array}$ & $\begin{array}{l}198(94.3 \%) \\
12(5.7 \%)\end{array}$ & 0.020 \\
\hline $\begin{array}{l}\text { When should you stop taking treatment? } \\
\text { When a health worker tells me } \\
\text { Others }\end{array}$ & $\begin{array}{l}64(61 \%) \\
41(39 \%)\end{array}$ & $\begin{array}{l}171(81.4 \%) \\
39(18.6 \%)\end{array}$ & 0.000 \\
\hline $\begin{array}{l}\text { Are you ashamed to have TB? } \\
\text { Yes } \\
\text { No }\end{array}$ & $\begin{array}{l}25(23.8 \%) \\
80(76.2 \%)\end{array}$ & $\begin{array}{l}30(14.3 \%) \\
180(85.7 \%)\end{array}$ & 0.038 \\
\hline $\begin{array}{l}\text { Do you try to hide that you have TB? } \\
\text { Yes } \\
\text { No }\end{array}$ & $\begin{array}{l}24(22.3 \%) \\
81(77.7 \%)\end{array}$ & $\begin{array}{l}42(20.0 \%) \\
168(80.0 \%)\end{array}$ & 0.560 \\
\hline $\begin{array}{l}\text { Do your family, friends and colleagues treat you different } \\
\text { because of TB? } \\
\text { Yes } \\
\text { No }\end{array}$ & $\begin{array}{l}31(29.5 \%) \\
74(70.5 \%)\end{array}$ & $\begin{array}{l}23(11.0 \%) \\
187(89.0 \%)\end{array}$ & 0.000 \\
\hline $\begin{array}{l}\text { How do you feel about being observed taking treatment? } \\
\text { Embarrassed } \\
\text { Not embarrassed }\end{array}$ & $\begin{array}{l}23(21.9 \%) \\
82(78.1 \%)\end{array}$ & $\begin{array}{l}24(11.4 \%) \\
186(88.6 \%)\end{array}$ & 0.012 \\
\hline
\end{tabular}


Table 2 :Patients opinion about TB services and behavior factors affecting non adherence to TB treatment:

\begin{tabular}{|c|c|c|c|}
\hline $\begin{array}{l}\text { Patient behavior and opinion } \\
\text { about TB services factors }\end{array}$ & $\begin{array}{l}\text { Cases(Non- } \\
\text { (adherence } \\
105(33,3 \%)\end{array}$ & $\begin{array}{l}\text { Control } \\
\text { ((adherence } \\
210(66.7 \%)\end{array}$ & P-value \\
\hline $\begin{array}{l}\text { Do you smoke? } \\
\text { Yes } \\
\text { No }\end{array}$ & $\begin{array}{l}15(14.3 \%) \\
90(85.7)\end{array}$ & $\begin{array}{l}44(21 \%) \\
166(79 \%)\end{array}$ & 0.099 \\
\hline $\begin{array}{l}\text { Do you use alcohol? } \\
\text { Yes } \\
\text { No }\end{array}$ & $\begin{array}{l}7(6.7 \%) \\
98(93.3)\end{array}$ & $\begin{array}{l}18(8.6 \%) \\
192(91.4 \%)\end{array}$ & 0.364 \\
\hline $\begin{array}{l}\text { Do you have AIDS? } \\
\text { Yes } \\
\text { No }\end{array}$ & $\begin{array}{l}2(1.9 \%) \\
103(98.1 \%)\end{array}$ & $\begin{array}{l}4(1.9 \%) \\
206(98.1 \%)\end{array}$ & 1.000 \\
\hline $\begin{array}{l}\text { Do you use intravenous drugs? } \\
\text { Yes } \\
\text { No }\end{array}$ & $\begin{array}{l}1(1.0 \%) \\
104(99.0 \%)\end{array}$ & $\begin{array}{l}2(1.0 \%) \\
208(99.0 \%)\end{array}$ & 1.000 \\
\hline $\begin{array}{l}\text { Do use other drugs? } \\
\text { Yes } \\
\text { No }\end{array}$ & $\begin{array}{l}4(2.9 \%) \\
101(97.1 \%)\end{array}$ & $\begin{array}{l}3(1.4 \%) \\
207(98.6 \%)\end{array}$ & 0.194 \\
\hline $\begin{array}{l}\text { What is your opinion on TB services? } \\
\text { Good } \\
\text { Not good }\end{array}$ & $\begin{array}{l}99(95 \%) \\
6(5 \%)\end{array}$ & $\begin{array}{l}205(97.6 \%) \\
5(2.4 \%)\end{array}$ & 0.118 \\
\hline $\begin{array}{l}\text { How do you rate the health workers attitude? } \\
\text { Receptive } \\
\text { Unreceptive }\end{array}$ & $\begin{array}{l}101(96.2 \%) \\
4(3.8 \%)\end{array}$ & $\begin{array}{l}206(98.1 \%) \\
4(1.9 \%)\end{array}$ & 0.256 \\
\hline $\begin{array}{l}\text { How do you rate the health center appearance? } \\
\text { Suitable } \\
\text { Not suitable }\end{array}$ & $\begin{array}{l}91(86.7 \%) \\
14(13.3 \%)\end{array}$ & $\begin{array}{l}173(82.4 \%) \\
37(17.6 \%)\end{array}$ & 0.21 \\
\hline $\begin{array}{l}\text { How do rate the number of patients at the TB } \\
\text { center? } \\
\text { Suitable } \\
\text { Not suitable }\end{array}$ & $\begin{array}{l}43(41 \%) \\
62(59 \%)\end{array}$ & $\begin{array}{l}120(57.1 \%) \\
90(42.9 \%)\end{array}$ & 0.005 \\
\hline $\begin{array}{l}\text { What was your average waiting time at the TB } \\
\text { center? } \\
<60 \text { minutes } \\
>60 \text { minutes }\end{array}$ & $\begin{array}{l}94(89.5 \%) \\
11(10.5 \%)\end{array}$ & $\begin{array}{l}195(92.9 \%) \\
15(7.1 \%)\end{array}$ & 0.211 \\
\hline $\begin{array}{l}\text { Are you satisfied with the given TB treatment? } \\
\text { Yes } \\
\text { Not }\end{array}$ & $\begin{array}{l}97(92.4 \%) \\
8(7.6 \%)\end{array}$ & $\begin{array}{l}198(94.3 \%) \\
12(5.7 \%)\end{array}$ & 0.515 \\
\hline $\begin{array}{l}\text { Did you receive health education about the } \\
\text { disease TB and its treatment? } \\
\text { Yes } \\
\text { No }\end{array}$ & $\begin{array}{l}61(58.1 \%) \\
44(41.9 \%)\end{array}$ & $\begin{array}{l}185(88.1 \%) \\
25(11.9 \%)\end{array}$ & 0.000 \\
\hline
\end{tabular}


Table 3: Distribution of Patients knowledge and awareness factors:

\begin{tabular}{|c|c|c|}
\hline Patient knowledge and awareness about TB & OR & $95 \% \mathrm{CI}$ \\
\hline $\begin{array}{l}\text { Age group } \\
15-30 \text { years vs. } \\
\text { Over } 30 \text { years }\end{array}$ & 0.80 & $0.50-1.27$ \\
\hline $\begin{array}{l}\text { Sex } \\
\text { Male vs. } \\
\text { Female }\end{array}$ & 1.53 & $0.93-2.53$ \\
\hline $\begin{array}{l}\text { Site of tuberculosis } \\
\text { Pulmonary vs. } \\
\text { Extra-pulmonary }\end{array}$ & 1.18 & $0.60-2.37$ \\
\hline $\begin{array}{l}\text { Residential locality } \\
\text { City vs } \\
\text { Village }\end{array}$ & 2.64 & $1.57-4.44$ \\
\hline $\begin{array}{l}\text { Did you hear about TB before you had it? } \\
\text { Yes vs } \\
\text { No }\end{array}$ & 1.93 & $1.18-3.17$ \\
\hline $\begin{array}{l}\text { What do you expect if you stop TB treatment } \\
\text { Know the consequences vs } \\
\text { Don' know the consequences }\end{array}$ & 1.40 & $0.65-3.02$ \\
\hline $\begin{array}{l}\text { Treatment duration } \\
\text { Known vs } \\
\text { Not known }\end{array}$ & 2.96 & $1.62-5.41$ \\
\hline $\begin{array}{l}\text { Can TB be cured? } \\
\text { Yes vs } \\
\text { No }\end{array}$ & 2.54 & $1.13-5.71$ \\
\hline $\begin{array}{l}\text { When should you stop taking treatment? } \\
\text { When a health worker tells me vs } \\
\text { Others }\end{array}$ & 2.81 & $1.66-4.74$ \\
\hline $\begin{array}{l}\text { Are you ashamed to have TB? } \\
\text { Yes vs } \\
\text { No }\end{array}$ & 1.88 & $1.04-3.39$ \\
\hline $\begin{array}{l}\text { Do you try to hide that you have TB? } \\
\text { Yes vs } \\
\text { No }\end{array}$ & 1.19 & $0.67-0.21$ \\
\hline $\begin{array}{l}\text { Do your family, friends and colleagues treat you } \\
\text { different because of TB? } \\
\text { Yes vs } \\
\text { No }\end{array}$ & 3.41 & $1.86-6.22$ \\
\hline $\begin{array}{l}\text { How do you feel about being observed taking } \\
\text { treatment? } \\
\text { Embarrassed vs } \\
\text { Not embarrassed }\end{array}$ & 2.17 & $1.16-4.07$ \\
\hline
\end{tabular}


Table 4 :Distribution of Patients opinion about TB services and behavior factors:

\begin{tabular}{|c|c|c|}
\hline $\begin{array}{l}\text { Patient opinion about TB services and } \\
\text { beahviour factors }\end{array}$ & OR & $95 \% \mathrm{CI}$ \\
\hline $\begin{array}{l}\text { Do you smoke? } \\
\text { Yes vs } \\
\text { No }\end{array}$ & 1.59 & $0.84-3.02$ \\
\hline $\begin{array}{l}\text { Do you use alcohol? } \\
\text { Yes vs } \\
\text { No }\end{array}$ & 0.76 & $0.31-1.89$ \\
\hline $\begin{array}{l}\text { Do you have AIDS? } \\
\text { Yes vs } \\
\text { No }\end{array}$ & 1.00 & $0.18-5.55$ \\
\hline $\begin{array}{l}\text { Do you use intravenous drugs? } \\
\text { Yes vs } \\
\text { No }\end{array}$ & 1.00 & $0.09-11.16$ \\
\hline $\begin{array}{l}\text { Do use other drugs? } \\
\text { Yes vs } \\
\text { No }\end{array}$ & 2.73 & $0.60-12.44$ \\
\hline $\begin{array}{l}\text { What is your opinion on TB services? } \\
\text { Good vs } \\
\text { Not good }\end{array}$ & 2.49 & $0.74-8.34$ \\
\hline $\begin{array}{l}\text { How do you rate the health workers attitude? } \\
\text { Receptive vs } \\
\text { Unreceptive }\end{array}$ & 0.49 & $0.12-2.00$ \\
\hline $\begin{array}{l}\text { How do you rate the health center appearance? } \\
\text { Suitable vs } \\
\text { Not suitable }\end{array}$ & 0.72 & $0.37-1.40$ \\
\hline $\begin{array}{l}\text { How do rate the number of patients at the TB center? } \\
\text { Suitable vs } \\
\text { Not suitable }\end{array}$ & 1.92 & $1.20-3.09$ \\
\hline $\begin{array}{l}\text { What was your average waiting time at the } \mathrm{TB} \\
\text { center? } \\
<60 \text { minutes vs } \\
>60 \text { minutes }\end{array}$ & 1.52 & $0.67-3.44$ \\
\hline $\begin{array}{l}\text { Are you satisfied with the given TB treatment? } \\
\text { Satisfied vs } \\
\text { Unsatisfied }\end{array}$ & 1.36 & $0.54-3.44$ \\
\hline $\begin{array}{l}\text { Did you receive health education about the disease } \\
\text { TB and its treatment? } \\
\text { Received health education vs } \\
\text { Not educated }\end{array}$ & 5.34 & $3.02-9.44$ \\
\hline
\end{tabular}


Table 5:Multivariate results: Patients knowledge and awareness, opinion about TB services and behavior factors leading to TB default

\begin{tabular}{|c|c|c|c|}
\hline Factor & $\mathrm{P}$ value & $\begin{array}{l}\text { Odds Ratio } \\
\text { (OR) }\end{array}$ & $95 \% \mathrm{CI}$ \\
\hline Living in rural areas & 0.011 & \multirow[t]{2}{*}{2.16} & $1.19-3.90$ \\
\hline $\begin{array}{l}\text { When should you stop taking } \\
\text { treatment? }\end{array}$ & 0.023 & & $1.10-3.64$ \\
\hline $\begin{array}{l}\text { Did you hear about TB before } \\
\text { you had it? }\end{array}$ & 0.041 & 1.81 & $1.02-3.20$ \\
\hline $\begin{array}{l}\text { Do your family, friends and } \\
\text { colleagues treat you different } \\
\text { because of TB? }\end{array}$ & 0.001 & 3.23 & $1.62-6.46$ \\
\hline $\begin{array}{l}\text { How do rate the number of } \\
\text { patients at the TB center? }\end{array}$ & 0.004 & 2.24 & $1.29-3.88$ \\
\hline $\begin{array}{l}\text { Did you receive health education } \\
\text { about the disease TB and its } \\
\text { treatment? }\end{array}$ & 0.0000 & 4.79 & $2.57-8.95$ \\
\hline
\end{tabular}




\section{Discussion:}

The present study showed that patients with less opportunity to receive health education and counseling about TB and its treatment and those living in the rural areas are at higher risk of defaulting TB treatment. Other potentially modifiable factors associated with TB treatment default identified in this study were lack of support by families, friends and colleagues, and overcrowding of the TB centers and its associated issues of long waiting times. Our study observed a default rate of $14 \%$ among TB treatment patients in Khartoum State. This high default rate was similar to rates reported in previous studies conducted in Khartoum State [(Federal Ministry of Health, Sudan, 2011, Suleiman and Sodemann, 2009). This observed rate is much higher than the World Health Organization's recommended target rate of 3\% (World Health Organization, 1994). Similar high default rates were reported in other developing countries e.g. in Ethiopia and India with default rates of $23 \%$ and $10 \%$, respectively[(Damte et al., 2013, Pardeshi ,2010). Such high default rates has a negative impact on the treatment outcome and may lead to spread of disease, treatment failure, drug resistance and death (Muture et al., 2011).

In the present study a substantial proportion of cases 44(42\%), and controls (12\%), did not receive health education and counseling when diagnosed with TB. While the intention of the TB-control program in Khartoum State is to provide adequate health education and counseling to patients diagnosed with TB, the fact that this did not happen in a substantial proportion of patients may be explained by shortage of health education personnel, increased health care burden, lack of training and supervision of health staff by the TB coordinators. This may indicate that the program and its allocated resources deserve a re-assessment.

Our observation that patients with less opportunity to receive health education and counseling about TB and its treatment increase the default rate confirms the 
results of previous studies conducted in both developed and developing countries (World Health Organization (WHO),2002, Muture et al., 2011, Marlucia et al., 2012). However, Nyi from Malaysia did not find an association between health education and counseling and TB treatment default ( Nyi et al., 2001).

In general, a large proportion of participants in this study had low knowledge about TB, duration of treatment, and whether TB is curable or not. The knowledge and behavioral factors contributing to TB default may vary in different communities and populations. Part of this can be attributed to patients' traditions and believes. In addition, health services, health staff receptiveness and patients' opinions towards those services are also contributing factors. Moreover, TB is a disease largely present in settings of the poor with limited resources.

The association of TB treatment default with lack of family, friends and colleague support, rural residence and overcrowding of the TB centers has been recognized before as it was in this study (World Health Organization (WHO), 2002, Rubel and Garo, 1992, Marlucia et al., 2012, and Ifebunandu et al., 2013). However, our findings were in contrast to those reported by Nyi and Chuah from Malaysia (Chuah, 1991, Nyi et al., 2001).

In our study population, HIV infection and intravenous drug users (IVDU) were rare, as might be expected among the population of Khartoum state (unpublished data). With regard to HIV infection status, it was interesting to note that about $15 \%$ of TB patients were not screened, while the intention of the TB control program is to perform the HIV testing in all TB patients. This is another indication for the need of reassessment of the TB control program in Khartoum state.

Surprisingly, behavioral factors including cigarette smoking, alcohol abuse, feeling shame and other stigmatizing factors were not associated with TB default 
in this study, in contrast to some earlier studies (Muture et al., 2011, Caylà et al., 2009).

The findings of this study might help health providers and policy makers in Sudan and other developing countries in planning and developing health policies to strengthen TB control programs in general. Of special importance seems that there is insufficient staff dedicated to counseling and education of the patients as well as their social support networks. Also more efforts should be taken to enhance the community participation and upgrading of the health personnel's communication and counseling skills.

Some methodological aspects of this study need attention: Firstly, this study was conducted in Khartoum State, capital of Sudan which is the most populated state in Sudan. The population in this state could be safely stated to represent the whole country as most of the inhabitants come from various parts of Sudan. In addition, the TB patients included in this study were selected from all tuberculosis treatment units (health centers and hospitals) in the state. Thus, the generalization of the study findings to the total tuberculosis population in the state and Sudan could be done and seems logical as well as in the communities with similar settings. Secondly, recall bias was minimized by reviewing the patient medical records and cross checking for each study variable and using a standardized questionnaire during the interview. Thirdly, the reliability of information gathered from each subject could not be counterchecked but questions about sensitive issues were carefully dealt with to maximize the reliability of the responses obtained. Fourthly, possible confounders were taken into consideration in the design (by restricting the diagnosis criteria) and by using logistic regression. Lastly, the major problem we faced during this study was how to reach the defaulting patients (cases) for this study. This problem was tackled stepwise. First, their medical records were traced and identified and all 
contact information was reviewed. Then, study personnel used the following sequence of contact attempts: calls - first to the patient and thereafter to known family members or friends - home visits - first to patient and thereafter to known family members or friends. Interestingly, it appeared during the study that many of the defaulting patients did not have access to mobile telephones, a risk factor not previously described nor evaluated in this study. The interviewers made an average of three attempts to contact each defaulter before deciding that a defaulter was a nonrespondent.

\section{Conclusions:}

This study confirms that health education and counseling to patients and their families on TB disease and it's treatment are of paramount importance and are strongly associated with treatment default, which is related to treatment failure and microbial resistance to antibiotics. Hence adequate counseling is highly recommended. In addition, fostering social support (family and community) and adequate training of the health care providers to adopt a warm and respectful approach towards patients and their families are also important. Also, reducing the number of patients attending health units e.g by increasing number of treatment centers may help reduce TB treatment default.

\section{Conflicts of interest:}

The authors have not declared any conflict of interests.

\section{Acknowledgments}

Authors would like to thank our colleagues at MOH Khartoum State and TB control programme. We are further grateful to all TB coordinators and health care workers at TB units for their cooperation. 


\section{References:}

- Ayisi JG, Hoog AH, Agaya JA, Mchembere W (2011). Care seeking and attitudes towards treatment compliance by newly enrolled tuberculosis patients in the district treatment programme in rural western Kenya: a qualitative study. BMC Publ. Health 11:515.

- Carolyn MF, Angela MB, Robert HG, Dami O (2009). Factors Associated with Delayed Tuberculosis Test-seeking Behavior in the Peruvian Amazon. Am. J. Trop. Med. Hyg. 81(6):1097-1102.

- Caylà JA, Rodrigo T, Manzano JR, Caminero JA (2009). Tuberculosis treatment adherence and fatality in Spain. Respir. Res. 10:121.

- Chuah SY (1991). Factors associated with poor patient compliance with antituberculosis therapy in Northwest Perak, Malaysia. Tubercle 72:261-264.

- Comolet TM, Rakotomalala R, Rajaonarioa H (1998). Factors determining compliance with tuberculosis treatment in an urban environment, Tamatave, Madagascar. Int. J. Tuberc. lung Dis. 2(11):891-897.

- Damte D, Mengistu L, Jango B (2013). Trend of Tuberculosis and Treatment Outcomes in Gambella Region with Special Emphasize on Gambella Regional Hospital, Western Ethiopia. J. Mycobact. Dis. 3(2).

- Federal Ministry of Health (2011). General Directorate of Primary Health Care, Sudan. National Tuberculosis Control Programme (2011).

- Finlay A, Lancaster J, Holtz TH, Weyer K, Miranda A, Walt M (2012). Patient- and provider-level risk factors associated with default from tuberculosis treatment, South Africa, 2002: a case-control study. BMC Publ. Health 12:56.

- Fleiss LJ (1981). Statistical Methods for Rates and Proportions. 2nd ed; pp. 35-48. 
- Hirofumi Mu, Toru W, Masashi A, Noriyuki K (2006). An Alternative Medicine, Agaricus blazei, May Have Induced Severe Hepatic Dysfunction in Cancer Patients. Japan J. Clin. Onccol. 36(12):808-810.

- Ifebunandu NA, Ukwaja KN, Osakwe PC, Alobu I (2013). Tuberculosis treatment outcome and its determinants in a tertiary care setting in south-eastern Nigeria. Niger. Postgrad. Med. J. 2(2):125-129.

- Jaggarajamma K, Sudha G, Chandrasekaran V, Nirupa C (2007). Reasons for NonCompliance among Patients Treated Under Revised National Tuberculosis Control Programme (RNTCP), Tiruvallur District, South India. Indian J. Tuberc. 54:130-135.

- Khan JA, Irfan MI, Zaki A, Beg M (2006). Knowledge, Attitude and Misconceptions regarding Tuberculosis in Pakistani Patients. J. Pak. Med. Assoc. 56:211-214.

- Muture BN, Keraka MN, Kimuu PK, Kabiru EW (2011). Factors associated with default from treatment among tuberculosis patients in nairobi province, Kenya: A case control study. BMC Publ. Health 11:696.

- Marlucia DSG, Maria LP, Toma M, Porcuna P (2012). Factors Associated with Tuberculosis Treatment Default in an Endemic Area of the Brazilian Amazon: A Case Control-Study. Plos One 7(6).

- Nezenega ZS, Gacho YM, Tafere TE (2013). Patient satisfaction on tuberculosis treatment service and adherence to treatment in public health facilities of Sidama zone, South Ethiopia. BMC Health Serv. Res. 13:110.

- Nyi NN, Catherine D, Abdul Rahman I, Rosemi S (2001). Factors Contributing to Poor Compliance with Anti-TB Treatment among Tuberculosis Patients. South East Asian J. Trop. Med. Publ. health 32(2):369-382.

- Pardeshi GS (2010). Time of default in tuberculosis patients on directly observed treatment. J. Global Infect. Dis. 2(3):226-230. 
- Rubel AL, Garo LC (1992). Social and cultural factors in the successful control of tuberculosis. Publ. Health Rep. 107:626-636.

- Suleiman MMA, Sahal N, Sodemann M, Elsony A (2014). Tuberculosis awareness in Gezira, Sudan: knowledge, attitude and practice case-control survey. EMHJ 20(2):120129.

- Suleiman MMA, Sodemann M (2009). Evaluation of tuberculosis control programme in Khartoum State for the year 2006. Scand. J. Publ. Health 37:101-108.

- Urquhart J (1996). Patient non-compliance with drug regimens: measurement, clinical correlates, economic impact. Eur. Heart J. 17(Suppl A):8-15.

- World Health Organization (1994). WHO Tuberculosis Programme. Framework for Effective Tuberculosis Control. Geneva, Switzerland, WHO /TB/94.1994:179.

- World Health Organization (WHO) (2002). Operational Guide for National Tuberculosis Control Programmes.

- World Health Organization (WHO) (2015). Global tuberculosis report 2015.20th edition. 
Chapter 6 Barriers Leading to Treatment Default among Tuberculosis Patients in Khartoum State, Sudan: a qualitative study

Ahmed Osman A Ali Martin H. Prins

Clinical and Medical Investigations. 2018;3(1): 1-8 


\begin{abstract}
:
Backgrounds: Tuberculosis (TB) is a major public health problem in Sudan and in many African countries. The objective of this study is to provide health authorities and patients with insight into the perceived factors affecting TB treatment default.

Methods: The data was collected by means of focus group discussions (FGD). Six FGD were conducted ( 3 for defaulted patients and 3 for health personnel). Overall, 27 TB defaulted patients and 24 health care providers were randomly selected.

Results: Participants reported that lack of knowledge about TB, high cost of transportation, difficulty for making a daily visit to health facilities for DOT programme due to distance of the facilities from their residences, rural residency, social circumstances, TB-related stigma, lack of family support, patient movement or giving wrong address, seeking traditional healers and treatment-related factors such as side-effects of drugs, the attitude of health care providers, the long delay in obtaining medications, and weakness and challenges facing defaulter tracing teams. There were consistent findings from interviews among patients and health care providers.
\end{abstract}

Conclusions: The study revealed several challenges and barriers leading to TB treatment default. Our findings may help in improving interaction between patients, families, health personnel and policy makers.

Key words: Tuberculosis, non-adherence, adherence, defaulter, compliance. 


\section{Introduction:}

Tuberculosis (TB) is a major public health problem in Sudan and in many African countries [1]. In 2010 It was estimated that in Sudan there were 209 cases of active TB per 100.000 of population with an annual incidence of new cases of 119/100.000, resulting in approximately 37.000 new cases each year in Sudan. Hence, Sudan shoulders about $15 \%$ of TB burden in the Eastern Mediterranean Region and has the second highest active TB prevalence of the countries in this region. In addition, the estimated death rate related to TB, including HIV infected TB patients, was 24/100.000 per year [2].

The TB Control Programme in Khartoum State, Sudan adopted treatment under direct observation short course therapy (DOTS) as recommended by WHO in 1993 [3]. Despite the efforts that had been undertaken by health authorities still some patients fail to adhere to TB treatment and eventually default before completing the intensive stage of treatment. As defined by the WHO, patients who fail to collect their TB treatment for 2 consecutive months are reported as defaulters [4].The TB Control Programme in Khartoum State estimates the default rate to be more than $14 \%$. This high default rate to TB therapy can prolong infectiousness leading to increased transmission, an increased risk of drug resistance, relapse and death $[5-9,10]$. Thus the identification of risk factors leading to this high TB treatment default rate in Khartoum State is essential.

In general few studies of TB defaulting treatment in Sudan were conducted. These studies dealt only with socio-economic and TB disease related factors leading to TB Treatment default. To our knowledge no study was conducted in Khartoum State, to explore in depth the opinions, experiences and believes of patients and health care providers on TB disease, services and other possible factors associated with TB treatment default.Thus we conducted qualitative study in 
Khartoum State, to explore the TB patient and health care provider's views about the factors prevent TB treatment continuation.

\section{Materials and Methods:}

\section{Setting}

This study was conducted in Khartoum State, the capital city of Sudan. In 1993, the Ministry of Health in Khartoum State established a tuberculosis control program. The decentralized healthcare system in Khartoum is divided into seven districts and 19 health areas. Its health facilities include 43 hospitals, 147 health centers, 185 NGOs centers, 235 dispensaries and 365 primary health care units. TB services are delivered in primary health care along with all other routine health services. A registered nurse is designated responsible for treatment and follow up for continuation of treatment in the primary health care unit. This primary health care unit is the basic unit of management of the program and also the unit of reporting. Personnel at the primary health care unit responsible for tuberculosis services include a medical assistant, a laboratory technician and a clerk.The program provides care through the DOTS strategy (Directly Observed Treatment with Short course chemotherapy) as recommended by WHO. TB patients receive their treatment through 53 TB treatment units distributed all over the state [11-12].

\section{Model of the Study Protocol:}

The humans of the study were selected from all tuberculosis patients (defaulters and controls) registered at tuberculosis centers and health professionals working in TB treating units in all provinces in Khartoum state from May 2010 to May 2011. A total of six focus group discussions were conducted in large three cities in Khartoum State: Khartoum, Omdurman and Khartoum North to capture believes, culture, geographical and financial differences in various communities. A twenty seven defaulted patient were interviewed in three different focus group discussions 
(FGD). Each group contained, on average of 8 to 10 participants. In order to further explore the possible leading factors for defaulting we subsequently conducted another 3 (FGD) with a total of 24 health professional representing 53 TB treatment units in Khartoum State. The inclusion criteria of participants: patients of more than 18 years old and who were receiving treatment for at least one month. Because they were perceived to be more experienced in having TB and good knowledge regarding tuberculosis treatment barriers.

\section{Data collection:}

A qualitative research using the technique of Focus Group Discussion (FGD) methodology was conducting in Khartoum State from May 2010 to May 2011. Data from the participated patients and health care professionals was collected during the period from $1^{\text {st }}$ of May 2011 to $15^{\text {th }}$ of July 2011. A total of six focus group discussions were held. All interviews were performed by the first Author who moderated the discussion in Arabic language. Few days before the FGD discussion the moderator visited the health units to ensure the privacy and logistic arrangement for the comfortable rooms for the these discussions. Also he informed the selected health care professionals telephonically about the study. Each session lasted approximately two and half hours with 20 minutes break in between using structured questionnaire with ended question to collect the necessary information. All interviews took place in privacy rooms and the discussions were recorded on notebook and audiotapes. We ensure that the all participants felt confident and tell reported their opinions freely. Before each FGD session, the moderator welcomed with the participants and explained to them the objectives of the study. The discussion was started with general information then focused on the TB disease, patients knowledge, treatment services, staff receptiveness, health education, the barriers leading to non-adherence and their suggestion to overcome these obstacles. 
The same questions were covered in each session. This discussion provides an opportunity for more in depth interaction of patients and beliefs about TB disease and reasons leading to treatment default . In addition, it was able the participants to give the insight and ideas on further improvement of the TB compliance. In the interview discussion for the health care professionals we explore their experiences with the barriers leading to TB default and the shortcoming of the medical services at TB units. The recordings were transcribed and translated into English language by the first author.

\section{Data Analysis:}

After the FGD sessions, all recordings of data from defaults patient's interviews and data from health care professional's interviews were transcribed verbatim and translated into English language. Then the data were summarized, coding and analysis was done based on the theme arising from the data. The analysis of data including the patient's perception about TB disease, the treatment services, patient knowledge, family and community supports, staff receptiveness, barriers leading to default and their suggestions to overcome these barriers. Also the data from health professionals interviews were coded and analyzed using the same contents theme. After coding, the grouping, condensing, categorizing and summarizing of these data were done. The findings of the in-depth interviews and FGD described the possible barriers leading to TB default were concluded and reported in the results section below.

\section{Ethical Considerations}

Ethical approval was obtained from Ministry of Health Khartoum State, Ethical Committee. Informed verbal consent was secured from every eligible patient and health care provider included in this study before the interview. Privacy and confidentially was maintained. The participants had been informed regarding all 
relevant aspects of the study, including the purpose of the study, the process of FGD and potential benefits. The participants in all 6 FGD felt confident and happy to be involved in this discussion and were speaking freely.

\section{Results:}

The characteristics of participants:

Six sessions of focus group discussion (FGD) were conducted to investigate the factors influencing non adherence to TB treatment. Three sessions were targeted at TB default patients while the other 3 sessions involved health care providers. The sessions aimed to address related experiences of stakeholders participated in TB treatment. The participating defaulted patients were made up of 21 males and 6 females. The mean age and standard deviation (SD) of patients were 36.2 and 8.1 respectively. All respondents were Muslims, with the majority came from urban area (74.1\%) and almost all were of low socioeconomic status. Six doctors, and 18 nurses participated in the interviews with mean age and SD of 37.7 and 7.6 respectively. The health care professionals interviewed were mainly from urban areas (75\%) and majority of them had worked in primary health care centers(79.2\%). About Fifty four percent of them had long working experiences with TB control programme in Khartoum state compared to only $(16.7 \%)$ with less than 10 years of working experiences. All of them worked in various health care facilities including health centers and hospitals, table 1 and table 2. 
Table 1.The characteristics of participants (patients):

\begin{tabular}{|l|l|}
\hline Variables & $\begin{array}{l}\text { FGD (defaulted patients(27) } \\
\text { Total }(\mathrm{n}=27) \mathrm{n}(\%)\end{array}$ \\
\hline $\begin{array}{l}\text { Age } \\
\text { Between 15 and 30 years }\end{array}$ & $5(18.5)$ \\
Over 30 years & $22(81.5)$ \\
\hline $\begin{array}{l}\text { Sex } \\
\text { Male }\end{array}$ & $21(77.8)$ \\
Female & $6(22.2)$ \\
\hline Education & $17(63)$ \\
Illiterate & $10(37)$ \\
Literate & \\
\hline Residence & $7(25.9)$ \\
Urban & $20(74.1)$ \\
Rural & \\
\hline Marital status & $11(40.7)$ \\
Married & $15(55.6)$ \\
Single & $1(3.7)$ \\
Others (divorced, widow) & $12(44.4)$ \\
\hline Occupation & $15(55.6)$ \\
Had no job & \\
Had a job & \\
\hline
\end{tabular}

Table 2.The characteristics of participants (health care providers):

\begin{tabular}{|l|l|}
\hline Variables & $\begin{array}{l}\text { FGD health care professionals (24) } \\
\text { Total }(\mathrm{n}=24) \mathrm{n}(\%)\end{array}$ \\
\hline $\begin{array}{l}\text { Age } \\
\text { Between 15 and 30 years }\end{array}$ & $4(16.7)$ \\
Over 30 years & $20(83.3)$ \\
\hline $\begin{array}{l}\text { Sex } \\
\text { Male }\end{array}$ & $19(79.2)$ \\
Female & $5(20.8)$ \\
\hline $\begin{array}{l}\text { Occupation } \\
\text { Doctor general practitioner }\end{array}$ & $6(25.0)$ \\
Nurse(6) and medical assistant(12) & $18(75.0)$ \\
\hline Experience in TB management and follow up & $13(54.1)$ \\
More than 20 years & $7(29.2)$ \\
10-20years & $4(16.7)$ \\
Less than 10 years(the minimum experience is 7 years) & \\
\hline Place of working & $5(3$ doctors and 2 nurses $)(20.8)$ \\
Specialized hospital(2 hospitals) & $19(3$ doctors, 4 nurses 12 medical \\
Health centers & officers)(79.2) \\
\hline Area of working & $18(75)$ \\
Urban & $6(25)$ \\
Rural &
\end{tabular}




\section{The results of interviews:}

The relatives variables identified from the results analysis can be categorized in five large groups: patients' knowledge about TB disease; behaviour related factors including traditions and norms; socio demographic factors; the health services including the health care providers' attitude and treatment related factors and believe in traditional healers and their methods.

\section{Patient's knowledge about TB disease}

The results analysis of interviews of FGD revealed that most of the patients had known TB disease, either from family members, relatives or lived with a contact (someone who has TB). Even though, most of TB defaulted patients were aware that TB is a serious disease, more than $60 \%$ of them had limited information about the causes of disease, clinical presentation and mode of transmission. These results were confirmed by health care providers (about $66.7 \%$ of TB default patients had lack of knowledge). The possible causes of TB mentioned by respondents included: TB is an inherited, drinking cold water, witchcraft, and heavy works such as making bricks. However,, 2 of them mentioned that TB is caused by germs.

The participants listed various symptoms and signs of TB including: dry cough, fever, tiredness, and back pain. Almost all the interviewed TB patients reported that they presented to the health centers with productive cough, fever, weakness, anorexia, and or shortness of breath. However, around $40 \%$ of them explained that they didn't know about TB before having it table1,3 and 4.

I heard about TB from my eldest brother, when he had infected with TB 6 years ago (39 years old illiterate man ).

I did not know about TB before I had it (35 years old women).

The TB disease can be transmitted by shaking hand with an infected person(male opinion).

My father told me that I got TB since I was a child, my grandmother had similar symptoms, it is in our lineage inherited (female opinion). 
TB got me because I worked hard, Iam a farmer (male opinion)

We got TB from cold drink, we used to drink cold water in the market especially during summer seasons, and it was very serious (4 male participants).

Similar results were mentioned by health care providers, (during my practical experience for more than 20 years working in TB programme in various health units and the last 6 years in this hospital, I had met a good number of TB patients who came seeking medical advice who lacked knowledge of the TB disease including causes, mode of transmission, clinical presentation, and treatment. Among patients I met, some preferred seeking treatment from traditional healers. (One medical practitioner doctor).

\section{The behavioural and socio demographic factors:}

The analysis of FGDs revealed that the most social factors leading to default TB treatment were financial (low family income (81.5\%), had no job (55.6), the transportation cost (77.8\%) and cost of drugs), distant health unit (70.4\%) and lack of family support (70.4\%). All FGD endorsed the financial burden as the strongest factor affecting access and patients' adherence to treatment. The participants mentioned that although, the treatment services were offered free of charge by the state TB program, still some patients may face obstacles of accessing this free services; such as far distances, cost of transportation in addition to other social reasons such as the fact that women in some rural communities need to be escorted to the health unit. The interviewee said these obstacles may force some of them to buy their medication for one or two months only from any near private health facilities. Thus the social and financial factors significantly affected treatment seeking behavior: they find it much easier to seek care from traditional healers than going to a distant public health care facility especially in rural areas and among illiterate patients (63\%). Cost of drugs, consultation, and hospital admission were identified as key barriers by some respondents. In addition to of accommodation and 
living expenses, as well as the risk of losing job table1, 3and 4. Similar reasons were revealed from the analysis of health care providers' discussions.

I faced a very embarrassing situation, that I had no money. Frankly speaking, how will we survive if we have no money in our hands, no treatment, no transportation, no food and without job (one male opinion)

To collect my free medication from the health unit, I had to travel for 2 hours daily, specially during the first 2 months and I needed a companion to go with me, also I have to stay for more than an hour to collect the medication. The cost of transportation is more than 20 Sudanese pounds; my husband told me that he cannot afford this. Then he brought a herbal medication from his friends (41 years old, one woman).

\section{Distance and travelling cost:}

A group of participants stated that the challenge for TB patients is geographical distance and they had to come on daily basis to take their medication under direct supervision at health center, These challenges faced mainly those lived in rural communities or those who lived far from the health center.The health care professional mentioned the relation of distance (83.3\%), and transportation cost $(66.7 \%)$ to treatment default.

\section{Patient movement or changing address:}

About $63 \%$ of participant mentioned that they moved or changed address during TB treatment duration which was confirmed by the health care providers. In addition, $(83.3 \%)$ of health care providers stated that wrong address or incomplete information and patient movement were associated factors for non adherence to treatment..

(From my experience, I would like to tell this story, one day I went to trace a defaulted patient, I took his address from patient records, I found that he was shifted to another house not far from here. The patient mentioned that the main reason to discontinue his treatment because he felt better after one month of starting treatment, and he must look for a job to provide his family 
with daily living expenses as there was no body to help him. Now he used herbal remedies brought from a traditional healer(30 years one medical assistant in a health center).

\section{Lack of family support and stigma:}

The participants discussed that patients with TB disease need family and community support (financial, psychological and moral support) to adhere to treatment especially during the first two months. Some patients mentioned that sometimes they felt guilty as this will affect their family income especially if a family member left his work to accompany him to the health unit.

(the family support is important factor to continue the treatment, I faced stress from my brothers. This discourage me from taking drugs)(one female opinion).

Many patients believed that they were predisposed to stigma (63\%) because of TB. These believes prevented them to attend social events and occasions. (My relatives and friends believed that I was infectious, as I had TB disease, and they tried to avoid me. (one male opinion).

Other respondents stated that no significant changes in the behavior of peoples towards them, no precautions were taken against them, and social support of family and friends was continued as normal which helped them taking treatment. The health care professional emphasized that TB patients feel stigmatized by closed relatives or friends due lack of knowledge about TB in the community. This encouraged some patients to hide that they had TB even form their spouses. (TB may affect patient interaction with others, specially females could not get married as she had TB disease( 2 males, health care providers). These circumstances may lead patients to delay seeking treatment.(I got TB few months ago, I did not tell anybody, even my family member, TB was infectious disease, nobody will respect me and all will try to avoid me(one male opinion). Other few participants stated that they told their families and close friends about TB infection, they provided them support and encouragement during the treatment duration. (I accept that I got TB infection, without complain, I told my family and old friends, about my TB infection. They told me to be strong, TB is a curable disease, we pray for you and ask god to bless you.(one male opinion). 
Some health care providers mentioned that till now there are separate clinics in some health centers for treating TB patients, this make them feel stigmatized.

\section{Health services, treatment related factors and attitude of health care providers:}

There were divergent views among patients regarding the barriers leading to TB default, especially the health services and treatment related factors (side effect of drugs, barriers related to health center for DOTS programme, and health professional attitude).

\section{The treatment factors:}

About $63 \%$ of defaulted patients were not on DOTS programme. They mentioned that DOTS with daily supervision of treatment for the first two months (initial phase) was a challenge to them especially during this phase. During the initial phase many patients were ill, weak and suffered from the severity of the disease. This meant that they needed to visit the TB clinic with a family member. Thus not merely the patients bearing the burden of TB, but involved their families and relatives.

"I had to come every day for injections and to swallow the medication in front of the nurse. I came daily with my brother because Iam ill, I tell you the truth, we had to hurry to reach here early in the morning, sometimes without even having breakfast. We cannot afford to come every day. It was very difficult to me and my family. In addition, we sold all properties, now we need financial support but no body to help us, so how can we continue the treatment for 2 months?" (41 year-old female":

The DOTS programme was compounded by several challenges: geographical distance, transportation cost and daily attendance, especially for women and those coming from rural areas. Those who had no cars used public transportation, bicycles, riding camels and donkey or even on foot. 
I had to wake up early at 5:30 A.M every day to catch a car to travel for more than $25 \mathrm{KM}$ to the health unit and then returning back home. I was asked to continue treatment for 2 months. If there was a rain I had to stay with my relative in Khartoum North. The transportation cost me a lot. All this cost provided from my relatives as I had no job during this period. Also the far distance made me uncomfortable, and sweat a lot, in addition, the dust and smoke exhausted by the car made us feel dirty. I tried this for a month before deciding to discontinue the treatment, especially after I felt better. (39 male patient from a rural area).

The health care providers expressed their well awareness of TB treatment and emphasized the availability of health services at DOTS health centers. At the same time they admitted the shortage of health staff, and lack of training. All health care providers stated that DOTS programme is an important factor for treatment adherence and cure. However, some reported that coming daily to the TB clinic especially in the intensive phase of treatment was physically and financially demanding for sick patients.. (from my experience, seeking medical treatment is related to the patients knowledge, as treatment of TB may continue for more than 6months, this needs commitment. DOTS programme helps patients to continue their treatment, offers opportunity for interaction between patients and health personnel, to increased their information. But still coming on daily bases was difficult for sick, poor patients, and those coming from far. Thus some patients may discontinue treatment after short period, especially when he feels better or finds alternative treatment.(one male health care provider)

(Some patients seek medical advice too late, one day We got a very sick patient, he was diagnosed with TB. He told me that he thought that it was a normal cough, although he complained of it for more than 6 weeks. (one male medical doctor)

\section{Side effects to treatment:}

More than $77 \%$ of defaulted patients experienced side effects to $\mathrm{TB}$ medication and mentioned the burden of TB drugs and their side effects being the major challenges on concomitant treatment. The main side effects noted by the 
patients and health care providers included headache, rash, nightmares, burning abdomen, feeling of hunger, vomiting and generalized body weakness.

Since I have started to swallow tablets and to be injected on daily basis, my body was harmed. Few days later I developed itching, hungry and burning abdomen. I mentioned this to the nurse. He said to me these symptoms will subside and gave me another medication but the side effects never subsided. When I told the nurse that I still suffer from the same side effects, he always retort and did not believe what I said, and considered me as annoying patient. Then I decided to discontinue treatment(44 years male). These results were reinforced by 6 health care providers. Other health care providers reported that some patients seek medical treatment when they feel ill, and stop treatment when feeling better. Additionally, they mentioned that medications side effect were a leading cause of default( $(75 \%)$.

\section{The attitude of health care providers:}

The majority of defaulted patients in the study were not happy about attitude and approach of health professionals $(81.5 \%)$. The participants mentioned that the health care provider should be receptive, friendly, follow a warm approach when educating patients. The health care provider mentioned that their main roles are diagnosis and treatment of the disease, but also they used to provide their patients with some information on TB disease. All of them followed friendly approach with patients and increased interaction with them to enhance continuation of treatment. They all emphasized the importance of having a health educators at each health unit.

I visited the health unit many time: at the first visit they told me that I have a chest infection. After 15 days I came back with the same symptoms and then referred me to the TB unit. They told me that I had TB disease. The nurse asked me to come tomorrow for treatment. When I came next day I stayed for more than 1 hour, after that the nurse called me, please come in, today you will start TB treatment. He didn't give me enough information about the disease and its treatment, he seemed to be in hurry to finish this visit as if he afraid to catch this disease and avoid sitting 
beside me. This approach embarrassed me and I felt this disease as stigma in the community. (48 years women).

The health care providers mentioned that they try to support their patients and families but still some patients cannot accept their infection with TB and may hide it even from their close relatives, and eventually discontinue the treatment.

\section{The TB treatment default tracing team:}

A key barriers raised during the interviews discussion by a proportion of patients and the health care providers was the weakness of defaulters tracing team-. Interestingly, this factor had not been included in the questions asked by the moderator. Some patients mentioned they discontinued the treatment for months and had not been called or visited by the health professional, while few patients mentioned that had received calls from the health units. One patient said he had been visited once by his treating nurse, he explained that his house lie near to the health unit, also he had a friendship with this nurse.

The health care providers mentioned that the TB control programme had problems in tracing TB defaulters. This was attributed to shortage of staff, lack of transportation and communication means, incomplete patients address information and staff related difficulty such as female health professionals inability to trace defaulted patient due to cultural factors.(we feel and know the importance of communication with our patients, the tracing of defaulted patients, but how can we achieve this? There was no default tracing team at the health unit, no car or any mean of transportation, sometimes had no means of communication with these patients, either due to wrong or incomplete address for the patients or the telephone at health center was out of service(44 years male nurse).

"how can I visit the patient's home, Iam a female and my husband cannot accept that (32years female nurse). 


\section{Traditional healers:}

About $63 \%$ of defaulted TB patients admitted that according to their culture and norms, going to the traditional healers or taking herbal drugs was preferable to visiting health centers. As per patients and health care providers, other reasons for seeking traditional healing were: lack of knowledge, cost of travelling, daily collection of medication, misbelieves about, lack of social support, waiting time at health facility, health care providers attitude, stigma, high expectation of immediate healing and improvement, medications' Side effects, injectable treatment, and duration of treatment.

(I preferred to go take herbal treatment as the traditional healer was more friendly and well known to me, and I trust him as well.(one female patient).

(I got a cough for 4 weeks, I had to wake up early to visit a far health center, It costed me more than 30 pounds daily for transportation and breakfast. After one week my elder brother asked me to go with him to a famous traditional healer, who claimed to be having long experience in treating many diseases. He was a simple man, friending had a good sense of humor, accept any amount of money and even other gifts. He prepared for me herbal medicine.(one man opinion).

(Illiterate, Poor patients cannot afford treatment completion regardless the source of the treatment (one male, health care provider).

(The norms and traditional in our community had negative impact on TB treatment, some patients started treatment at the health unit, few days may go to seek other advice either from private sectors or go to traditional healers. Therefore, health education, and involvement of community organizations is mandatory to increase awareness of patients, and their families about TB disease and the treatment compliance. One male medical doctors)

The traditional healer in our village was friendly, gave drug with little money, no waiting time, no cost of travelling, (one male patient) 
Table 3. The barriers leading to TB treatment default according to health care professionals FGD:

\begin{tabular}{|c|c|}
\hline The factors & $\begin{array}{l}\text { Opinions of health care } \\
\text { professionals } \\
\text { Total }(\mathrm{n}=24) \mathrm{n}(\%)\end{array}$ \\
\hline $\begin{array}{l}\text { Site of tuberculosis } \\
\text { Pulmonary } \\
\text { Extra-pulmonary }\end{array}$ & $24(100)$ \\
\hline $\begin{array}{l}\text { Type of residential area } \\
\text { City } \\
\text { Village }\end{array}$ & $\begin{array}{l}6(25) \\
18(75)\end{array}$ \\
\hline $\begin{array}{l}\text { Distance to clinic } \\
\text { Between } 1 \text { and } 5 \text { kilometers } \\
\text { More than } 5 \text { kilometers }\end{array}$ & $\begin{array}{l}4(16.7) \\
20(83.3)\end{array}$ \\
\hline $\begin{array}{l}\text { Patient moving or giving wrong address } \\
\text { Yes } \\
\text { No }\end{array}$ & $\begin{array}{l}4(16.7) \\
20(83.3)\end{array}$ \\
\hline $\begin{array}{l}\text { Transportation cost } \\
\text { Less than } 3 \text { Sudanese pound(SD) } \\
3 \text { Sudanese pound(SD) or more }\end{array}$ & $\begin{array}{l}8(33.3) \\
16(66.7)\end{array}$ \\
\hline $\begin{array}{l}\text { Time to clinic } \\
\text { Up to } 60 \text { minutes } \\
\text { More than } 60 \text { minutes }\end{array}$ & $\begin{array}{l}11(45.8) \\
13(54.2)\end{array}$ \\
\hline $\begin{array}{l}\text { Family income }=(\text { mean }, S D) \\
\text { Less than } 1000 \text { Sudanese pound(SP) } \\
\text { More than } 1000(\text { SP })\end{array}$ & $24(100)$ \\
\hline $\begin{array}{l}\text { Family support } \\
\text { those with family support } \\
\text { those without family support }\end{array}$ & $24(100)$ \\
\hline $\begin{array}{l}\text { Patient's knowledge } \\
\text { Good knowledge } \\
\text { Little knowledge }\end{array}$ & $\begin{array}{l}8(33.3) \\
16(66.7)\end{array}$ \\
\hline $\begin{array}{l}\text { Response to treatment } \\
\text { Good } \\
\text { Not good }\end{array}$ & $24(100)$ \\
\hline $\begin{array}{l}\text { Side effects to TB treatment } \\
\text { Had side effects } \\
\text { No side effects }\end{array}$ & $\begin{array}{l}6(25) \\
18(75)\end{array}$ \\
\hline $\begin{array}{l}\text { Try to hide that had TB disease(stigma) } \\
\text { Yes } \\
\text { No }\end{array}$ & $\begin{array}{l}13(54.2) \\
11(45.8)\end{array}$ \\
\hline $\begin{array}{l}\text { DOTS } \\
\text { Those on Dots vs } \\
\text { Not DOTS }\end{array}$ & $24(100)$ \\
\hline $\begin{array}{l}\text { Seek folk remedies } \\
\text { Yes } \\
\text { No }\end{array}$ & $24(100)$ \\
\hline Health care provider approach & $24(100)$ \\
\hline
\end{tabular}


Table 4. The barriers leading to TB treatment default according to patients

\begin{tabular}{|c|c|c|}
\hline The factors & $\begin{array}{l}\text { defaulted patients } \\
\text { Total }(\mathrm{n}=27) \mathrm{n}(\%)\end{array}$ & $\begin{array}{l}\text { adherence patients Total }(\mathrm{n} \\
=9) \mathrm{n}(\%)\end{array}$ \\
\hline $\begin{array}{l}\text { Site of tuberculosis } \\
\text { Pulmonary } \\
\text { Extra-pulmonary }\end{array}$ & $\begin{array}{l}25(92.6) \\
2(7.4)\end{array}$ & $\begin{array}{l}7(77.8) \\
2(22.2)\end{array}$ \\
\hline $\begin{array}{l}\text { Type of residential area } \\
\text { City } \\
\text { Village }\end{array}$ & $\begin{array}{l}20(74.1) \\
7(25.9)\end{array}$ & $\begin{array}{l}8(88.9) \\
1(11.1)\end{array}$ \\
\hline $\begin{array}{l}\text { Distance to clinic } \\
\text { Between } 1 \text { and } 5 \text { kilometers } \\
\text { More than } 5 \text { kilometers }\end{array}$ & $\begin{array}{l}8(29.6) \\
19(70.4)\end{array}$ & $\begin{array}{l}6(66.7) \\
3(33.3)\end{array}$ \\
\hline $\begin{array}{l}\text { Patient moving or giving wrong address } \\
\text { Yes } \\
\text { No }\end{array}$ & $\begin{array}{l}10(37.0) \\
17(63.0)\end{array}$ & $\begin{array}{l}7(77.8) \\
2(22.2)\end{array}$ \\
\hline $\begin{array}{l}\text { Transportation cost } \\
\text { Less than } 3 \text { Sudanese pound(SD) } \\
3 \text { Sudanese pound(SD) or more }\end{array}$ & $\begin{array}{l}6(22.2) \\
21(77.8)\end{array}$ & $\begin{array}{l}5(55.5) \\
4(44.5)\end{array}$ \\
\hline $\begin{array}{l}\text { Time to clinic } \\
\text { Up to } 60 \text { minutes } \\
\text { More than 60minutes }\end{array}$ & $\begin{array}{l}12(44.4) \\
15(55.6)\end{array}$ & $\begin{array}{l}7(77.8) \\
2(22.2)\end{array}$ \\
\hline $\begin{array}{l}\text { Family income }=(\text { mean, SD }) \\
\text { Less than } 1000 \text { Sudanese pound }(\mathrm{SP}) \\
\text { More than } 1000(\mathrm{SP})\end{array}$ & $\begin{array}{l}22(81.5) \\
5(18.5)\end{array}$ & $\begin{array}{l}5(55.5) \\
4(44.5)\end{array}$ \\
\hline $\begin{array}{l}\text { Family support } \\
\text { those with family support } \\
\text { those without family support }\end{array}$ & $\begin{array}{l}8(29.6) \\
19(70.4)\end{array}$ & $\begin{array}{l}8(88.9) \\
1(11.1)\end{array}$ \\
\hline $\begin{array}{l}\text { Patient's knowledge } \\
\text { Good knowledge } \\
\text { Little knowledge }\end{array}$ & $\begin{array}{l}10(37.0) \\
17(63.0)\end{array}$ & $\begin{array}{l}5(55.5) \\
4(44.5)\end{array}$ \\
\hline $\begin{array}{l}\text { Presenting symptoms to the clinics(productive cough, } \\
\text { fever, weakness, anorexia, and or shortness of breath) } \\
\text { Yes } \\
\text { No }\end{array}$ & $\begin{array}{l}27(100.00) \\
0(0.00)\end{array}$ & $\begin{array}{l}9(100.00) \\
0 .(0.00)\end{array}$ \\
\hline $\begin{array}{l}\text { Response to treatment } \\
\text { Good } \\
\text { Not good }\end{array}$ & $\begin{array}{l}16(59.3) \\
11(40.7)\end{array}$ & $9(100)$ \\
\hline $\begin{array}{l}\text { Side effects to TB treatment } \\
\text { Had side effects } \\
\text { No side effects }\end{array}$ & $\begin{array}{l}21(77.8) \\
6(22.2)\end{array}$ & $\begin{array}{l}1(11.1) \\
8(88.9)\end{array}$ \\
\hline $\begin{array}{l}\text { DOTS } \\
\text { Those on Dots vs } \\
\text { Not DOTS }\end{array}$ & $\begin{array}{l}10(37.0) \\
17(63.0)\end{array}$ & $\begin{array}{l}8(88.9) \\
1(11.1)\end{array}$ \\
\hline $\begin{array}{l}\text { Try to hide that had TB disease(stigma) } \\
\text { Yes } \\
\text { No }\end{array}$ & $\begin{array}{l}10(37.0) \\
17(63.0)\end{array}$ & $\begin{array}{l}0(0.00) \\
9(100)\end{array}$ \\
\hline $\begin{array}{l}\text { Seek folk remedies } \\
\text { Yes } \\
\text { No }\end{array}$ & $\begin{array}{l}10(37.0) \\
17(63.0)\end{array}$ & $\begin{array}{l}8(88.9) \\
1(11.1)\end{array}$ \\
\hline $\begin{array}{l}\text { Health care providers approach } \\
\text { Receptive } \\
\text { Non receptive }\end{array}$ & $\begin{array}{l}5(18.5) \\
22(81.5)\end{array}$ & $\begin{array}{l}7(77.8) \\
2(22.2)\end{array}$ \\
\hline
\end{tabular}




\section{Discussion :}

The present qualitative study revealed five major factors that most TB treatment defaulting patients mentioned when assessing the TB services offered by the TB Control Programme in Khartoum State. These factors were: 1) patients' knowledge about the disease TB; 2) behavior related factors that included traditions and norms; 3) sociodemographic factors, especially income versus cost and distances to the TB center; 4) the health services provided itself, including the health care providers attitude and treatment related factors and; 5) believe in traditional healers and their methods. These factors represent opinions of three samples of TB treatment defaulting patients and three samples of health care providers who worked for a long period in TB units in Khartoum State.

The barriers reported by TB treatment defaulting patients and health care providers who participated in this study were not well known and not familiar to both the Khartoum community and the policy makers of the TB control program in Khartoum state, although they were reported previously in many international studies [3,13-15]. In addition, this the first larger qualitative wide study that explored the opinions and experiences of the patients and treating staff themselves about the barriers related to interruption of TB treatment. Moreover the results highlight the attitude of health care workers towards the patients, patients knowledge about TB disease and its treatment, the economic effects, including cost of travelling, food and loss of work and the believe in traditional healers. Interestingly, there was another barrier raised by the participants in the six focus group discussions, i.e. the poor availability of communication and transportation for the treatment default tracing team.

TB is a disease prevalent among poor communities and when diagnosed needs continuous treatment for at least 6 months [16]. This means that patients on a DOTS 
program will need to come on daily basis to take their treatment in presence of the nursing staff at the TB clinic. This create challenges, identified in this study, including the cost of travelling, especially for those who lived in rural areas. Another barrier, reported by the participants concerned especially females who, as necessitated by the traditions and norms of the Khartoum society, need companion to visit the TB units. Our findings consolidate the previous results in the developing and developed countries ([5,17-20]. The patients tried to overcome these challenges by seeking help from their relatives and non-governmental charity organizations. Although the TB services are offered on free base to all patients, these still barriers to the accessibility and acceptability to these services. One way to improve accessibility could be the integration of $\mathrm{TB}$ services in the primary health care centers scattered all over the state. The absence of specialized knowledge on diagnosis and treatment of TB could be amended be e.g. weekly visits of a TB center specialist. In addition, it would be important to further study and measure patient satisfaction with the TB services that includes their and their relative's opinion regarding the DOTS program. For example those who live far from the TB units may take their treatment under supervision of one their family members, with e.g. a confirmatory texting message.

TB is a familiar disease worldwide, nevertheless, a large number of patients lack knowledge about the disease. This due to illiteracy, and the insufficient education and counseling given to the patients. Also we observed that patients seeking treatment from traditional healers are more likely to default their TB treatment. These findings are similar to results of other studies in developing countries with low resources in Africa and Asia which carry the highest burden of TB $[13,18,21-23]$. 
We found that the patient's perception regarding the health care provider attitude is an important determinant factor for adherence to TB treatment. However, the health provider attributed the influence of this factor to shortage of staff and high work load, lack of health education given to the patients, and self-stigmatization among patients. Therefore we recommend that health personnel to follow a warm approach with their patients and assure them that TB is curable. This approach will create good rapport between health providers and their patients. Hence, encourage patients adherence to treatment. These findings are in line with results reported by other studies [3,13,15,21-22,24]. Although our findings in contrast with that mentioned by Nyi form Malaysia [25] and Ayé from Tajikistan[4].

This study confirmed that waiting time, side effect of treatment and patient movement are associated with TB defaults. These findings match previous studies in developed and developing countries $[3,10,12,13]$. Although our findings are in contrast with that reported by Nyi [25].

Although the intention of the National TB Control Programme was to have an effective tracing team, the interesting barrier related to treatment default which raised by most of the participants in this study was the weakness of TB default tracing team. This needs special attention and deserve an assessment of TB control programme. This weakness was attributed to shortage of staff, lack of transportation and communication means and cultural barriers. These findings in line with the result reported by other international studies(south Africa) [26].

The findings of this study might help the policy makers in Khartoum state, Sudan and other developing countries in planning and policy development to strengthen TB control programs in general. Moreover the barriers need special attention including: health education, travel cost, family support, waiting time, patients movement, traditional healers, staff receptiveness. It needs the cooperation 
of the community members, patients, families, treating staff, and governmental and non-governmental organizations. These efforts may help patients socially and financially. These will help strengthening interaction between the patients, their families and treatment staff. In addition, more attention should be paid to staff training, regarding the health education, supervision and receptiveness.

Overall the findings of present study raise important issues on TB treatment default in Sudan since we could not identify previous detailed studies on this subject in this area. These results can help in decreasing the TB treatment default. Thus, decreasing treatment failure, multi drugs resistant, TB relapse and inhibit spreading of tuberculosis in the community.

Some methodological aspects of this study need attention: First, the major problem we faced during the study was how to reach the defaulting patients. This problem was tackled in 3 steps. First, the patient medical records were traced and identified and all contact information was reviewed. Then, study personnel first tried to telephone the patient and, failing that, to telephone known family members or friends. If telephone contact failed or if there was no telephone number on record, home visits were made, first to the patient and then to known family members or friends. Secondly, this study was qualitative study which help in identifying the perception, opinions and problems of different patients and health care providers. Thirdly, the qualitative study may help in improving the treatment and strengthening the TB control programme. Fourthly, the results of focus group discussion included the patients opinions and the long experience of health care providers. Lastly, to reduce the recall bias, we interviewed three groups of patients who were recently defaulted and came back in addition to interviewing health staff who had long working experiences. 


\section{Conclusion:}

The study highlighted several challenges and barriers leading to TB treatment default. Our findings may help the interaction between patients, families, health personnel and policy makers. We believe that the findings are applicable to current situation of TB management and control in Sudan and other developing countries.

\section{Disclosure statement}

The authors declare that there is no conflict of interest or funding received regarding the publication of this paper. 


\section{References:}

1.WHO (2015) Global tuberculosis report. 20th Ed. Geneva.

2. Federal Ministry of Health (2011) General Directorate of Primary Health Care. Sudan: National Tuberculosis Control Programme.

3. Muture B, Keraka M, Kimuu P, Kabiru E, Ombeka V, et al. (2011) Factors associated with default from treatment among tuberculosis patients in Nairobi province, Kenya: A case control study. BMC Public Health 11:1-10.

4. WHO (2002) Operational guide for national tuberculosis control programmes on the introduction and use of fixed-dose combination drugs. Geneva.

5. Chuah SY (1991) Factors associated with poor patient compliance with antituberculosis therapy in Northwest Perak, Malaysia. Tubercle 72: 261-4.

6. Menzies R, Rocher I, Vissandjee B (1993) Factors associated with compliance in treatment of tuberculosis. Tuber Lung Dis 74: 32-37.

7. Wilkinson D (1994) High-compliance tuberculosis treatment programme in a rural community. Lancet 343: 647.

8. William JB, Cohn DL, Rietmeijer CA, Judson FN, Sbarbaro JA, et al. (1997)

Noncompliance with directly observed therapy for tuberculosis: epidemiology and effect on the outcome of treatment. Chest 111:1168-1173

9. Jasmer RM, Seaman CB, Gonzalez LC, Kawamura LM, Osmond DH, et al. (2004) Tuberculosis treatment outcomes: directly observed therapy compared with self administered therapy. Am J Respir Crit Care Med 170: 561-566.

10. Ahmed OA Ali, Martin HP (2017) Disease and treatment-related factors associated with tuberculosis treatment default in Khartoum State, Sudan: a casecontrol study. East Mediterr Health J 23: 346-352. 
11. Ahmed Suleiman MM, Aro AR, Sodemann M (2009) Evaluation of tuberculosis control programme in Khartoum State for the year 2006. Scand J Public Health 37: 101-108.

12. Ali AOA, Prins HM (2016) Patient non adherence to tuberculosis treatment in Sudan: socio-demographic factors influencing non adherence to tuberculosis therapy in Khartoum State. Pan Afr Med J. 25: 80

13. Elbireer S, Guwatudde D, Mudiope P, Sekandi,JN, Manabe YC (2011) Tuberculosis treatment default among HIV-TB co-infected patients in urban Uganda. Trop Med Int Health 16: 981-987.

14. Ayé R, Kaspar Wyss K, Abdualimova H, Saidaliev S (2010) Illness costs to households are a key barrier to access diagnostic and treatment services for tuberculosis in Tajikistan. BMC Res Notes 3: 340.

15. Sanou A, Dembele M, Theobald S, Macq J (2004) Access and adhering to tuberculosis treatment: Barriers faced by patients and communities in Burkina Faso. Int J Tuberc Lung Dis 8: 1479-1483.

16. Sharma SK, Mohanan S, Sharma A (2012) Relevance of latent TB infection in areas of high TB prevalence. Chest 142: 761-773.

17. Ibrahim LM, Hadejia IS, Nguku P, Lakda GM, Ogiri S, et al. (2015) Factors Associated with Outcomes of Treatment among Pulmonary Tuberculosis Patients in Plateau State, Nigeria. J US China Med Sci. 12: 172-179.

18. Ayisi JG, Hoog AH, Agaya JA, Mchembere W, Odylia M et al. (2011) Care seeking and attitudes towards treatment compliance by newly enrolled tuberculosis patients in the district treatment programme in rural western Kenya: a qualitative study. BMC Public Health 11: 515. 
19. Sagbakken M, Frich JC, Bjune GA, Porter JDH (2013) Ethical aspects of directly observed treatment for tuberculosis: a cross-cultural comparison. BMC Med Ethics $14: 25$.

20. Ahorlu CK, Bonsu F (2013) Factors affecting TB case detection and treatment in the Sissala East District, Ghana. Journal of Tuberculosis Research. 1: 29-36.

21. Carolyn MF, Angela MB, Robert HG, Dami O (2009) Factors Associated with Delayed Tuberculosis Test-seeking Behavior in the Peruvian Amazon. Am J Trop Med Hyg 81:1097-1102.

22. Ali AOA, Prins HM (2016) Patient knowledge and behavioral factors leading to nonadherence to tuberculosis treatment in Khartoum State, Sudan. Journal of Public Health and Epidemiology 8: 316-325.

23. Waisbord S (2010) Participatory communication for tuberculosis control in prisons in Bolivia, Ecuador, and Paraguay. Rev Panam Salud Publica 27: 168-174. 24. Ibrahim LM, Hadejia IS, Nguku1 P, Lakda GM, et al. (2014) Health care workers' knowledge and attitude towards TB patients under Direct Observation of Treatment in Plateau state Nigeria. PAMJ 18: 1-8.

25. Nyi NN, Catherine D, Abdul Rahman I, Rosemi S (2001) Factors Contributing to Poor Compliance with Anti-TB Treatment among Tuberculosis Patients. South East Asian J.Trop. Med. Publ. health 32: 369-382.

26. Bristow CC, Podewils LJ, BronnerLE, Bantubani N (2013) TB tracer teams in South Africa: knowledge, practices and challenges of tracing TB patients to improve adherence. BMC Public Health 13:801. 
Chapter 7 Mobile health to improve adherence to tuberculosis treatment in Khartoum State, Sudan

\author{
Ahmed Osman A Ali \\ Martin H. Prins
}

Journal of Public Health in Africa. 2019; 10(1101):84-89 


\section{Acknowledgements}

We would like to thank our Colleagues at MOH Khartoum State and TB control Programme.

\section{Authors' contributions}

Ahmed Osman Ahmed Ali and Martin H Prins both contributed to initiate study concept and developed the study design. Ahmed Osman performed data collection, analysis and wrote the first draft of manuscript. Martin Hendrik Prins contributed and supervised study design, results, and discussion. Both authors approved the final manuscript.

\section{Competing interests}

The authors declare no potential conflict of interests.

\section{Funding}

None. 


\begin{abstract}
Setting:Although tuberculosis is a treatable disease, the high frequency of treatment default remains a challenge. The use of mobile phones structurally in a TB program has the potential to lower the frequency of default.However, it's impact on treatment outcome in Sudan has not yet been evaluated.
\end{abstract}

Objective:To evaluate the potential use of cell phones for lowering treatment default.

Design:We conducted a controlled intervention pilot study during the period from 1th of May 2017 to 31th of March 2018,in eight TB treatment units in Khartoum state,Sudan.Newly diagnosed patient with positive sputum smear on DOTS therapy were enrolled in intervention and control groups.SMS reminder were sent to the intervention group.Assessments were done at the beginning and at the end of the treatment.

Results:One hundred and forty-eight patients were enrolled, seventy-four patients in each group.The participants in the two groups were similar in demographic characteristics and behavioral and knowledge related factors about TB disease at baseline.The patients in the intervention group had a lower default rate(6.8\%), higher documented cure rate(78.4\%), better knowledge compared to control group.SMS reminder was useful and facilitated good interaction between patients and health personnel.

Conclusions:Mobile texting seemed useful and was highly accepted by participants. Further evaluation of it's potential benefit was warranted.

Key words: Tuberculosis, default, non-adherence, adherence, mobile health 


\section{Introduction:}

Tuberculosis (TB) is the ninth leading cause of death worldwide and the leading cause from a single infectious agent, ranking above HIV/AIDS ${ }^{1}$. Moreover, it continues to be a major global cause of death and morbidity, disproportionately affect the poorest communities ${ }^{2,3}$. Thus WHO recommend directly observed treatment short course (DOTS) strategy ${ }^{4,5}$. This strategy aims to detect individuals with sputum smear-positive tuberculosis, initiation of anti-tuberculosis chemotherapy and adherence to treatment and decrease defaulting rate. Treatment of active pulmonary TB patients remains the most effective strategy to stop the spread of the disease ${ }^{6,7}$. Defaulting from treatment may remain the major challenge to control TB. In addition, it increases the risk of drug resistance, relapse, and death and may prolong infectiousness ${ }^{8,9}$.

Sudan shoulders about $15 \%$ of TB burden in the Eastern Mediterranean Region and has the second highest active TB prevalence of the countries in this region ${ }^{10}$. In line with WHO, Sudan adopted DOTS strategy since 1993. Despite the efforts that had been undertaken by health authorities still some patients fail to adhere to TB treatment and eventually default before completing the treatment. There are many factors leading to high default rate in Khartoum state. These include: socio-demographic factors; behavioural factors, disease and treatment relating factors; lack of knowledge and stigma and default tracing team problems.The default tracing is major challenge to TB control programme in Khartoum State, this due to wide area of the State, shortage of staff, shortage of transport facilities for default tracing teams ${ }^{8,11}$. As defined by the WHO, patients who fail to collect their TB treatment for 2 consecutive months are reported as defaulters (World Health Organization, $2002{ }^{12}$. 
The use of mobile phones has substantially increased throughout the world over the last decade and also in Sudan. The global expansion in cell phone use presents new opportunities to incorporate mobile phones into health care delivery services ${ }^{13-15}$.The World Health Organization (WHO) has defined mHealth as 'medical and public health practice supported by mobile devices, such as mobile phones, personal digital assistants and other wireless devices ${ }^{16}$.

Thus we conducted an intervention comparative study in Khartoum province, Khartoum state aiming to determine the approach of use of mobile phone in improving adherence and decreasing the default rate among patients receiving $\mathrm{TB}$ medication under DOTS program.

\section{Material and methods}

\section{Study design}

To evaluate the potential use of cell phones for improving adherence to treatment, we conducted a controlled intervention pilot study in TB patients on a DOTS program. Those TB patients who owned a cell phone or had shared access to such a devise formed the intervention group. These patients received the current standard of care with the addition of informative text messages. TB patients on the same DOTS program who did not have access to a cell phone received the current standard of care and were the control group. The trial was conducted in Khartoum state. We conducted this study to determine the effect of cell phone usage in decreasing TB treatment default.

\section{Setting}

This study was conducted in Khartoum province, Khartoum State. The patients were recruited form $8 \mathrm{~TB}$ treatment units. A registered nurse is responsible for promoting and checking treatment adherence as well as for tracing the patient in case of missing a planned follow up visit. Other personnel in a TB treatment unit include 
a medical doctor or a specially trained medical assistant, a laboratory technician and a clerk. The tuberculosis control program has been described in detail elsewhere ${ }^{11}$.

\section{Patient eligibility}

All TB patients who participated in a DOTS program and were registered at the participating centers were eligible. Inclusion criteria were: newly diagnosed, smear positive pulmonary $\mathrm{TB}$, age over 15 years and the provision of informed consent. Exclusion criteria were: psychiatric illness, limited vision, extrapulmonary or relapsing TB.

\section{Patient accrual}

Patients who had access to a cell phone were considered the intervention group. After each such patient who consented to participate the next patient(s) without access to a cell phone were asked to participate in the control group.

\section{Standard of care}

All patients were in a DOTS program according to the TB control program strategy in Khartoum State. This strategy coincides with WHO recommendations. The DOTS program consists of 6 months of TB treatment. In the first 2 months (intensive phase) patients receive 4 drugs: isoniazid, rifampicin, pyrazinamide and ethambutol. Here after, patients receive 4 months of isoniazid and rifampicin (continuation phase). All patients came on a daily basis to the TB center to take their medication in the presence of health care personnel ${ }^{17}$. All patients who interrupted their treatment were traced by the routine methods carried out by the TB control program in Khartoum State.

\section{Intervention}

The patients in the intervention group received standard of care, with the addition of text messages every 48 hours during the first 2 months and hereafter weekly till 
the end of treatment. The content of the text messages is displayed in Table 1. Also, these patients received a telephone call at least once during the first week of their treatment. In case of treatment interruption, the patients received cell phone messages to encourage them to come back and continue their treatment. Moreover, on top of the usual tracing activities performed by the TB control program, they received telephone call, additional text messages and, if need a home visit.

\section{Data collection methods}

The data collection was done by 2 trained persons who recorded demographic, disease related factors and treatment related variables from the medical records. In addition, a face to face interview was done, using a semi- structured questionnaire, to elicit information on the various factors possibly associated with treatment default. (figure 1).

\section{Definition of outcomes}

Treatment default was defined as a patient who failed to collect his TB treatment for 2 consecutive months. A documented cure was defined as a patient who was smear- or culture-negative in the last month of treatment and on at least one previous occasion $^{18}$.

Knowledge of TB disease and its treatment was defined as "the facts, feelings, and experiences reported by the patient ${ }^{19}$. This was implemented using the following 5 questions: do you hear about TB disease before you had it?, do you know duration of treatment?, what you expect if you stop treatment?, can TB be cured?, when to stop TB treatment? and do you know the cause of TB?.

Finally, in the intervention group the perceived usefulness of the text messages was assessed. 


\section{Biometrics}

Sample size was calculated by using the WHO calculator for a controlled study. The default rate among TB patients reported by the National TB control program in Sudan was 11\%. We expected an improvement in default rate to 5\% (or less). Hence, with A type I error - two-sided of 0.05 and a $80 \%$ of power, the sample size was calculated to be 138 patients. We reviewed 148 patients (74 in each group) ${ }^{20}$.

All calculations were done based on the intention to treat principle. Data analysis was performed in SPSS (Statistical package of Social Sciences) version 21. Chi-square tests were performed for qualitative variables and Student's t tests for continuous (outcome) variables. In addition, the defined outcomes were related to group of assignment, adjusted for potentially confounding variables using logistic regression analysis.

\section{Ethical Considerations:}

Ethical approval was obtained from Ministry of Health of Khartoum State ethical Committee. Informed verbal consent was secured from every eligible patient included in this study before the interview. All participants were informed that the interview was entirely voluntary. Privacy and confidentially were maintained during data processing and reporting. Also, patients who participated were informed that they had the right to end the initial interview at any time, or refuse participation during the follow up at any time. 
Figure 1: explain the study design:

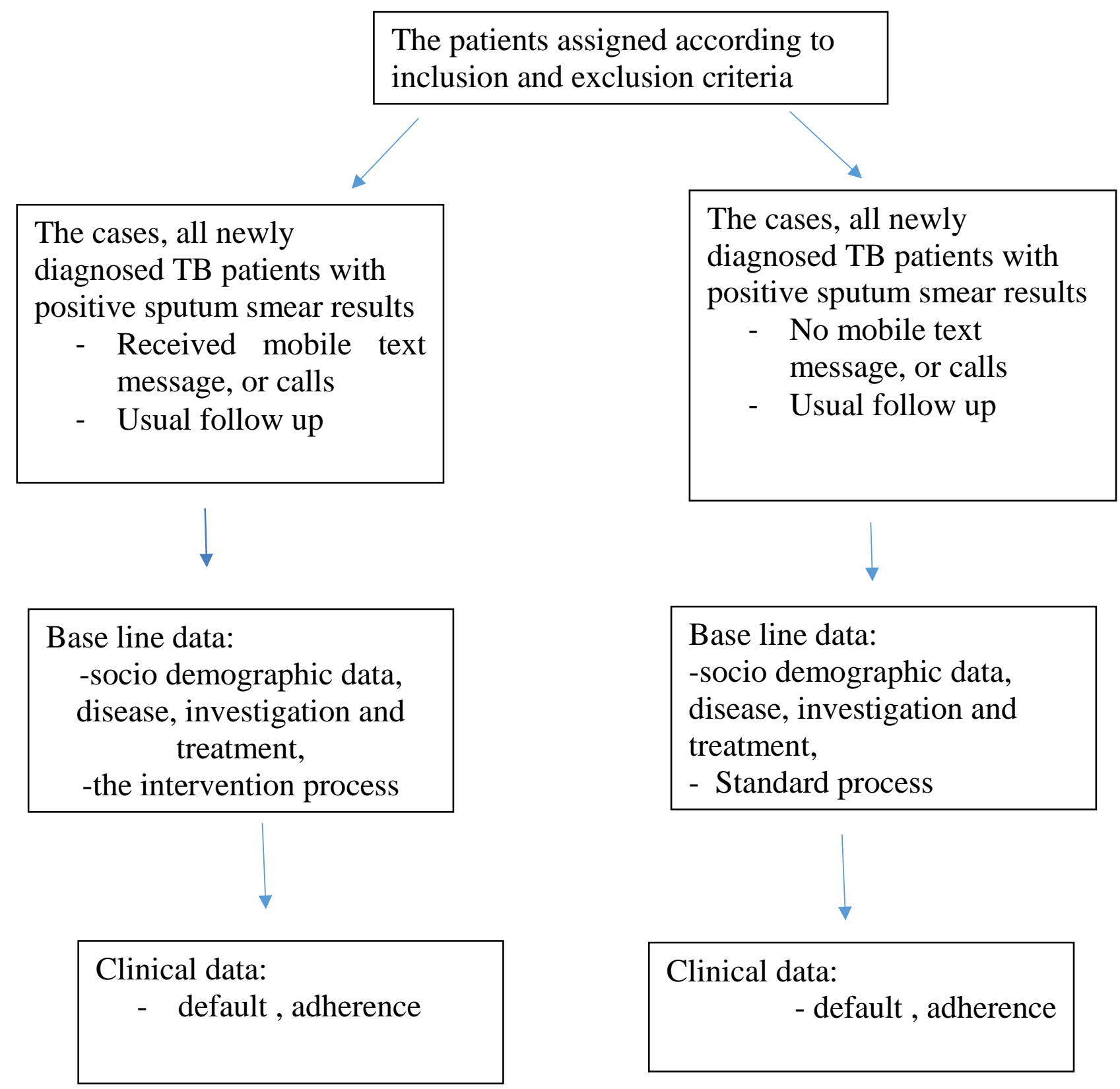




\section{RESULTS}

\section{Participants}

Between the period $1^{\text {th }}$ of May 2017 to $31^{\text {th }}$ of March 2018, a total of 169 consecutive patients who initiated TB treatment based on the inclusion and exclusion criteria were assessed for eligibility to participate in this study. Of these, 148 were enrolled in the study and 21 patients met an exclusion criterion. The demographic characteristics of the intervention and control groups are given in Table 2. Patients in the intervention and control group were well matched, and none of the differences were statistically or clinically significant. The participants in two groups were also similar in behavioral related factors and knowledge about TB disease at baseline (Table 3 and 4).

\section{Adherence to intervention and control group assignment}

All 74 patients in the intervention group received text messages and telephone calls during the study period. Out of them 70 patients responded to our SMS's and texted or called back. A total of $61(82.4 \%)$ patients of the intervention group were able to read and send SMS's, while 13(17.6\%) patients shared the mobile phone with their families as they were not able to use it or read the messages themselves. There were $72(97.3 \%)$ patients in the intervention group who rated the SMS's as very useful, useful or may be useful while only $2(2.7 \%)$ patients rated the SMS's as not useful.

There were $70(82.4 \%)$ patients asked for counselling assistant, while $36(48.6 \%)$ patients provided a request regarding information about side effect of drugs and 24(32.4\%) patients asked for Medication and social support.

None of the 74 patients in the control group received the SMS messages. However, the responsible treatment center tried to call or trace the 8 patients who did not appear on their planned visits. All patients completed the study protocol. 


\section{Adherence to the TB treatment protocol}

The patients in the intervention group had a lower default rate $(6.8 \% ; 5$ out of 74 patients) compared to those in the control group (10.8\%; 8 out of 74 patients). This difference was not statistically significant (P-value 0.563; OR: 1.673, 95\% C.I. $0.521-5.374)$.

The patients in the intervention group had higher cure rate $58 / 74$ (78.4.0\%) compared to 44 (59.5) of the 74 patients in the control group (P-value 0.020; OR: 2,472, 95\% CI:1.133 - 5.434).

\section{Knowledge of TB disease and its treatment between the groups}

At the beginning of treatment, knowledge of TB disease and its treatment, were similar between the groups, with odds ratios varying between 0.78 to 1.32 (Table 5).

At the end of treatment, the knowledge in the intervention group was better than in the control group for all 5 variables, and was statistically significant in 3 of them (Table 5).

\section{Knowledge of TB disease and its treatment in relation to treatment default and documented cure.}

There was no statistically significance found between the patient's knowledge and treatment default among the intervention group for all 5 knowledge variables. In the control group a single variable ('know when to stop') was statistically significant, (OR: 7.421; 95\% CI: 1.374- 40.085; P < 0.015 ).

In the intervention group the relationship between patient's knowledge and documented cure was statistically significant, namely 'duration of treatment' (OR: 6.136; 95\% CI: $1.417-26.581 ; \mathrm{P}<0.019$ )and when to stop treatment (OR: 4.371; 95\% CI: 1.211-15.784; $\mathrm{P}<0.028$ ). In a multivariate analysis the variable "when to stop treatment' remained statistically significant in the model (OR: 2.261; 95\% CI: 
$1.050-4.870 ; \mathrm{P}<0.037)$. In the control group, no statistically significant relationship was found between all 5 knowledge variables and documented cure.

\section{DISCUSSION}

The present study explored the use of mobile phone services to decrease default rates in newly diagnosed patients with smear positive results for Mycobacterium Tuberculosis (TB) who received treatment under a DOTS program. We found that patients in the intervention group had a lower default rate (albeit not statistically significant), a statistically significant higher documented cure rate and better knowledge than those in the control group at end of the treatment period, regarding the duration of treatment, what to expect if treatment is stopped and when to stop TB treatment. Also, it was observed that there was à statistically significant relationship between patient knowledge (know when to stop TB treatment) and TB treatment default among patients in the control group. In addition, there was a statistically significant association between the patients' knowledge and documented cure rate (duration of treatment and when to stop treatment) among the intervention group. Moreover, the use of mobile phone services created good opportunities for interaction between health personnel and patients in the intervention group who often responded by texting or calling back, asking about drug side effects and requesting for help and social support. Finally, most patients in the intervention group were positive about the mobile services.

The TB treatment default rate observed in the control group in this study was (10.8\%) which is high compared to WHO target maximal default rate of (3\%) ${ }^{21}$. However, it is lower than those reported (14\%) in recent studies conducted in the same geographical area ${ }^{8,11}$. A potential cause could be the relative high education of residents from Khartoum state and the patients who participated in the study, compared to other regions of Sudan ${ }^{22,23}$. Our observations regarding the association 
between SMS text messages reminders and default rate and documented cure rate confirms the results of previous studies conducted in both developed and developing countries ${ }^{24,25,26,27}$. However, our findings were in contrast to that reported by Sabine M H form Uganda and Cameron that SMS reminder did not show any difference between intervention and control group ${ }^{28,29}$. Our observation that the SMS recipients, texted or called asking help and social support were similar to those reported in India and Uganda, in which study the recipient also were favorable about the use of mobile services ${ }^{30,31}$.

$\mathrm{TB}$ is a chronic disease and its treatment lasts for more than 6 months. In addition, the treatment needs multiple drugs that are to be taken once daily for this period. After starting treatment patients usually feel better since symptoms and signs improve or disappear. Hence some patients may discontinue, forget or stop their treatment. Such a default in finishing appropriate treatment is a danger for the spread of the disease, as well as induces multi-resistant TB bacteria strains. Texting can be sent every morning to remind patients to take treatment. The patient can reply with SMS confirming taking medication. Moreover, short message service (SMS) are cheap and quick means of communication between health personnel and TB patients. In fact, the availability and wide spread use of mobile phones is an encouraging fact that would help implemented texting successfully in a TB control program. However, there are challenges facing the use of this communication means that need consideration. For example, mobile phones needs electric charging and patients may live in the absence of such facilities. In addition, the telecommunication network may be weak in some areas.

Although, we conducted a pilot study and did not do formal calculation of the actual cost of the mobile services, the observations in the present study show promising results with regard to lesser treatment default, higher documented cure 
rate and increased knowledge of the patients. We believe that a properly powered and funded study is warranted to explore this possibility. Moreover, mobile phone services may be in general of help for health personnel and patients to have an improved interaction.

Some methodological aspects of this study require attention. First, our study was conducted in Khartoum State, which is the most populated state in Sudan. Most of the inhabitants come from various parts of Sudan so it is likely that subjects included in the study may represent the whole country. Second, recall bias was minimized by using a semi standardized questionnaire during the interview and by cross-checking patients' responses for each study variable against their medical records. Third, the reliability of the information gathered from each patient could not be counter-checked but questions about sensitive issues were carefully handled to maximize the accuracy of the responses obtained. Fourth, the sample size was calculated using previous reports of default rates in Sudan. However, the observed frequency of default was substantially lower in the control group. Hence, the power to find a similar relative effect was reduced. Fifth, for this pilot study we used a controlled but not randomized design. However, the demographic characteristics of both groups were similar, most importantly for education and by using logistic regression analysis. Finally, a major challenge during the study was how to reach the defaulting patients in the two groups. This was tackled in 3 steps. First, the patient medical records were traced and identified and all contact information was reviewed. All patients who interrupted their treatment were traced by the routine methods carried out by the TB control program in Khartoum State. Then, for the control group patients study personnel first tried to telephone the patient and, failing that, to telephone known family members or friends. If telephone contact failed or if there was no telephone number on record, home visits were made, first to the patient 
and then to a known family members or friends. If the patient was not traced in the intervention group, the patient text-messages. Moreover, they received a telephone call, additional text messages and, if need a home visit. Interestingly, all defaulting patients responded. They came back and continued their treatment (only 3 of them needed home visits two among the control group and one among the intervention group).

\section{Conclusions:}

We believe that our data shows promising results to lower treatment default in patients with TB using mobile services that included both texting and if required calls. Hence, we recommend the conduction of a properly powered randomized clinical trial in a region with similar social conditions to establish its clinical effectiveness and document the associated extra costs. 


\section{References}

1. Global tuberculosis report. Geneva: World Health Organization; 2017.

2. Global tuberculosis report. 20th ed. Geneva: World Health Organization; 2015.

3. Muture B, Keraka M, Kimuu P, Kabiru E, Ombeka V, Oguya F. Factors associated with default from treatment among tuberculosis patients in Nairobi province, Kenya: A case control study. BMC Public Health. 2011;11(696):1-10.

4. Chhaya M, Gupta SC. Noncompliance to DOTS: How it can be decreased. Indian J Community Med. 2011;36(1):27-30.

5. World Health Organization(WHO). What is DOTS? A Guide to Understanding the WHOrecommended TB Control Strategy Known as DOTS.1999.

6. Operational guide for national tuberculosis control programmes on the introduction and use of fixed-dose combination drugs. Geneva: World Health Organization; 2002.

7. Sia IG, and Wieland M L. Current Concepts in the Management of Tuberculosis. Symposium on Antimicrobial therapy. Mayo Clin Proc. 2011;86(4):348361.www.mayoclinicproceedings.com.

8 Ali A O A, Prins M H. Patient non adherence to tuberculosis treatment in Sudan: socio demographic factors influencing non adherence to tuberculosis therapy in Khartoum State. Pan African Medical Journal. 2016; 25(80).

9. Ali A O A, Prins M H. Patient knowledge and behavioral factors leading to nonadherence to tuberculosis treatment in Khartoum State, Sudan. Journal of Public Health and Epidemiology. 2016; 8(11):316-325.

10. Federal Ministry of Health. General Directorate of Primary Health Care. Sudan: National Tuberculosis Control Programme;2011. 
11. Suleiman M M A, Sodemann M. Evaluation of tuberculosis control programme in Khartoum State for the year 2006. Scandinavian Journal of Public Health. 2009;37(1):1018.

12. WHO. An Expanded DOTS Framework for Effective Tuberculosis control. Stop TB Communicable Diseases.2002.

13. Denkinger CM, Grenier J, Stratis AK, Akkihal A, et al. Mobile health to improve tuberculosis care and control: a call worth making. Int J Tuberc Lung Dis. .2013; 17(6):719-727.

14. Brinkman I, Bruijn M \& Bilal H. The mobile phone, 'modernity' and change in Khartoum, Sudan.2009. $\quad$ https://core.ac.uk/download/pdf/82998951.pdf

15.World Health Organization(WHO). Handbook for the use of digital technologies to support tuberculosis medication adherence.2017.

16. Choun K, Achanta S, Naik B, Tripathy J P, et al. Using mobile phones to ensure that referred tuberculosis patients reach their treatment facilities: a call that makes a difference. BMC Health Services Research (2017) 17:575.

17. World Health Organization(WHO).Treatment of Tuberculosis: Guidelines for National Programmes.3rd edition.2003.

18.World Health Organization. Definitions and reporting framework for tuberculosis 2013 revision (updated December 2014).2013.

19. Akeju OO, Wright SCD, Maja TM. Lived experience of patients on tuberculosis treatment in Tshwane, Gauteng province. Health sa Gesondheid. 2017;22;259-267. 20. Lwanga S K and Lemeshow S. Sample size determination in health studies. A Practical Manual. World Health Organization, Geneva.1991.

21. World Health Organization(1994). WHO Tuberculosis Programme. Framework for Effective Tuberculosis Control. Geneva, Switzerland, WHO /TB/94.1994:179. 
22. United Nations, Educational, Scientific and Cultural Organization. World Data on Education. 7th edition, 2010/11. http://www.ibe.unesco.org/ .

23.Ministry of Higher Education and Scientific Research: http://www.mohe.gov.sd/ [In Arabic. Last checked: May 2012.

24. Iribarren SI, Beck SL, Pearce PF, Chirico C. MHealth Intervention Development to Support Patients With Active Tuberculosis. Journal of Mobile Technology in Medicine. 2014; 3(2):1627.

25. Farooqi R J , Ashraf S, Zaman M. The Role of Mobile SMS-Reminders in Improving Drugs Compliance in Patients Receiving Anti-TB Treatment from DOTS Program. J Postgrad Med Inst. 2017; 31(2): 156-62.

26.Falzon D, Raviglione M, Bel E H, Gratziou C, Douglas Bettcher D. The role of eHealth and mHealth in tuberculosis and tobacco control :a WHO/ERS consultation. Eur Respir J 2015; 46: 307-311.

27. Barclay E. Text messages could hasten tuberculosis drug compliance. Lancet. 2009;373:15-16.

28. Hermans S A, Elbireer S, Tibakabikoba H, Hoefman BJ, et al. Text messaging to decrease tuberculosis treatment attrition in TB-HIV coinfection in Uganda. Patient Preference and Adherence.2017;11: 1479-1487.

29. Bediang G. Beat Stoll B. Elia N, Abena JL, Geissbuhler A. SMS reminders to improve adherence and cure of tuberculosis patients in Cameroon (TB-SMS Cameroon): a randomized controlled trial. BMC Public Health (2018) 18:583.

30. Elangovan R, Arulchelvan S. A study on the role of mobile phone communication in tuberculosis DOTS treatment. Indian Journal of Community Medicine.2013;38(4):229-233. 
31. Ggita JM, Ojok C,Meyer AJ, Farr K, et al. Patterns of usage and preferences of users for tuberculosis-related text messages and voice calls in Uganda. Int J Tuberc Lung Dis. 2018; 22(5): 530-536. 
Table 1: messages sent to the patient through SMS text: Please beep or sent SMS to 00249990284733.

Please don't worry: TB is a curable disease

TB patients present with cough for more than 2 weeks, night sweeting, and fatigability

Taking TB treatment regularly will enhance cure, shortening duration of symptoms and prevent complications of the disease

Please follow the advice and instructions given by the treating health personnel

Please try to take your meals regularly, this improve the immunity against the disease

Please do not forget to take your TB medicine regularly to reduce the risk for further spread of TB

Please do not forget to take your TB medicine to prevent infecting your family and friends

Do not forget your appointment: please come back to the clinic tomorrow. Come with your remaining TB medicine and TB card.

If you have any questions or need any help please do not hesitate to contact us or to send SMS.

Please try to Use your own cup and plate

Please try to Cover your mouth and nose when sneezing or coughing

For good ventilation: Keeping the windows open

If you feel with any side effect of medication please inform your treating health personnel or send SMS

Please try to inform your doctor if you would like to travel anywhere and don't for get to take your medication with you. 
Table2: Sociodemographic characteristics.

\begin{tabular}{|c|c|c|c|}
\hline Sociodemographic Factors & Cases $(n=74)$ & Control $(n=74)$ & P-value \\
\hline $\begin{array}{l}\text { Age }- \text { mean }(\mathrm{SD}) \\
15-30 \text { years } \\
\text { Over } 30 \text { years }\end{array}$ & $\begin{array}{l}37.79(17.91) \\
36(48.6 \%) \\
38(51.4 \%)\end{array}$ & $\begin{array}{l}34.28(13.75) \\
39(52.7 \%) \\
35(47.3 \%)\end{array}$ & $\begin{array}{l}0.183 \\
0.637\end{array}$ \\
\hline $\begin{array}{l}\text { Sex } \\
\text { Male } \\
\text { Female }\end{array}$ & $\begin{array}{l}45(60.8 \%) \\
29(39.2 \%)\end{array}$ & $\begin{array}{l}43(58.1 \%) \\
31(41.9 \%)\end{array}$ & 0.434 \\
\hline $\begin{array}{l}\text { Marital status } \\
\text { Single vs } \\
\text { Married }\end{array}$ & $\begin{array}{l}32(43.2 \%) \\
42(56.8 \%)\end{array}$ & $\begin{array}{l}25(33.8 \%) \\
49(66.2 \%)\end{array}$ & 0.311 \\
\hline $\begin{array}{l}\text { Education level } \\
\text { Literate } \\
\text { Illiterate } \\
\end{array}$ & $\begin{array}{l}61(82.4 \%) \\
13(17.6 \%) \\
\end{array}$ & $\begin{array}{l}66(89.2 \%) \\
8(10.8 \%)\end{array}$ & 0.346 \\
\hline $\begin{array}{l}\text { Residence } \\
\text { City } \\
\text { Village } \\
\end{array}$ & $\begin{array}{l}64(86.5 \%) \\
10(13.5 \%)\end{array}$ & $\begin{array}{l}56(75.7 \%) \\
18(24.3 \%)\end{array}$ & 0.141 \\
\hline $\begin{array}{l}\text { Nationality } \\
\text { Sudanese } \\
\text { Others }\end{array}$ & $\begin{array}{l}72(97.3 \%) \\
2(2.7 \%)\end{array}$ & $\begin{array}{l}67(90.5 \%) \\
7(9.5 \%)\end{array}$ & 0.166 \\
\hline $\begin{array}{l}\text { Occupation } \\
\text { White work } \\
\text { Blue work } \\
\end{array}$ & $\begin{array}{l}32(43.2 \%) \\
24(32.4 \%) \\
\end{array}$ & $\begin{array}{l}42(56.8 \%) \\
50(67.6 \%) \\
\end{array}$ & 0.235 \\
\hline $\begin{array}{l}\text { Family income } \\
1000-2000 \mathrm{SB} \\
\text { More than 2000SB }\end{array}$ & $\begin{array}{l}36(48.6 \%) \\
38(51.4 \%)\end{array}$ & $\begin{array}{l}42(56.8 \%) \\
32(43.2 \%)\end{array}$ & 0.410 \\
\hline $\begin{array}{l}\text { Religion } \\
\text { Muslim } \\
\text { Others }\end{array}$ & $\begin{array}{l}72(97.3 \%) \\
2(2.7 \%)\end{array}$ & $\begin{array}{l}68(91.9 \%) \\
6(8.1 \%)\end{array}$ & 0.275 \\
\hline $\begin{array}{l}\text { Transportation means } \\
\text { On foot } \\
\text { Bicycle } \\
\text { Public transportation } \\
\text { Own car }\end{array}$ & $\begin{array}{l}2(2.7 \%) \\
2(2.7 \%) \\
61(82.4 \%) \\
9(12.2 \%) \\
\end{array}$ & $\begin{array}{l}1(1.4 \%) \\
1(1.4 \%) \\
62(83.8) \\
10(13.4 \%)\end{array}$ & 0.867 \\
\hline $\begin{array}{l}\text { Transportation cost } \\
\text { Costly } \\
\text { Suitable, cheap or no cost }\end{array}$ & $\begin{array}{l}12(16.2 \%) \\
62(83.8 \%)\end{array}$ & $\begin{array}{l}7(9.5 \%) \\
67(90.5 \%) \\
\end{array}$ & 0.326 \\
\hline $\begin{array}{l}\text { Distance to Health unit } \\
\text { Less than one KM -to 10KM } \\
\text { More than } 10 \mathrm{KM}\end{array}$ & $\begin{array}{l}54(73.0 \%) \\
20(27.0 \%) \\
\end{array}$ & $\begin{array}{l}56(75.7 \%) \\
18(24.3 \%) \\
\end{array}$ & 0.851 \\
\hline $\begin{array}{l}\text { Time to health center } \\
\text { Less than } 1 \text { hour } \\
\text { One hour and more }\end{array}$ & $\begin{array}{l}59(79.7 \%) \\
15(20.3 \%)\end{array}$ & $\begin{array}{l}62(83.8 \%) \\
12(16.2 \%)\end{array}$ & 0.671 \\
\hline
\end{tabular}


Table3: Behavioural Characteristics:

\begin{tabular}{|c|c|c|c|}
\hline Behavioural related Factors: & Cases $(n=74)$ & Control $(n=74)$ & P-value \\
\hline \multicolumn{4}{|l|}{ Smoking } \\
\hline Yes & $26(35.1 \%)$ & $35(47.3 \%)$ & \multirow{2}{*}{0.181} \\
\hline No & $48(64.9 \%)$ & $39(52.7 \%)$ & \\
\hline \multicolumn{4}{|l|}{ Alcohol status } \\
\hline Yes & $4(5.4 \%)$ & $10(13.7 \%)$ & \multirow[b]{2}{*}{0.013} \\
\hline No & 70(94.6) & $64(86.5 \%)$ & \\
\hline \multicolumn{4}{|l|}{ HIV status } \\
\hline Yes & $0(0.0 \%)$ & $1(1.4 \%)$ & \multirow{2}{*}{1.000} \\
\hline No & $74(100.0 \%)$ & $73(98.6 \%)$ & \\
\hline \multicolumn{4}{|l|}{ IVDU status } \\
\hline Yes & $0(0.0 \%)$ & $1(1.4 \%)$ & \multirow{2}{*}{1.000} \\
\hline No & $74(100.0 \%)$ & $73(98.6 \%)$ & \\
\hline
\end{tabular}


Table 4: Knowledge Characteristics::

\begin{tabular}{|c|c|c|c|c|c|c|}
\hline Disease and & At the begir & of the study & & At the end & the study & \\
\hline $\begin{array}{l}\text { knowledge related } \\
\text { Factors: }\end{array}$ & $\begin{array}{l}\text { Cases } \\
74\end{array}$ & $\begin{array}{l}\text { Control } \\
74\end{array}$ & P-Value & $\begin{array}{l}\text { Cases } \\
74\end{array}$ & $\begin{array}{l}\text { Control } \\
74\end{array}$ & P-Value \\
\hline $\begin{array}{l}\text { Hear about TB } \\
\text { Yes } \\
\text { No }\end{array}$ & $\begin{array}{l}49(66.2) \\
25(33.8)\end{array}$ & $\begin{array}{l}53(71.6) \\
21(28.4)\end{array}$ & 0.594 & & & \\
\hline $\begin{array}{l}\text { Duration of } \\
\text { treatment } \\
\text { Yes } \\
\text { No }\end{array}$ & $\begin{array}{l}46(62.2 \%) \\
28(37.8 \%)\end{array}$ & $\begin{array}{l}43(58.1 \%) \\
31(41.9 \%)\end{array}$ & 0.737 & $\begin{array}{l}65(87.8 \%) \\
9(12.2 \%)\end{array}$ & $\begin{array}{l}52(70.3 \%) \\
22(29.7 \%)\end{array}$ & 0.014 \\
\hline $\begin{array}{l}\text { Can TB be cured } \\
\text { Yes } \\
\text { No }\end{array}$ & $\begin{array}{l}54(73.0 \%) \\
20(27 \%)\end{array}$ & $\begin{array}{l}51(68.9 \%) \\
23(31.1 \%)\end{array}$ & 0.718 & $\begin{array}{l}65(87.8 \%) \\
9(12.2 \%)\end{array}$ & $\begin{array}{l}64(86.5 \%) \\
10(13.7 \%)\end{array}$ & 1.000 \\
\hline $\begin{array}{l}\text { What do you expect } \\
\text { if stop treatment } \\
\text { Know } \\
\text { Do not know }\end{array}$ & $\begin{array}{l}44(59.5 \%) \\
30(40.5 \%)\end{array}$ & $\begin{array}{l}46(62.2 \%) \\
28(37.8 \%)\end{array}$ & 0.866 & $\begin{array}{l}64(86.5 \%) \\
10(13.5 \%)\end{array}$ & $\begin{array}{l}53(71.6 \%) \\
21(28.4)\end{array}$ & 0.042 \\
\hline $\begin{array}{l}\text { When to stop TB } \\
\text { treatment } \\
\text { When advised } \\
\text { Others (side effect, } \\
\text { response, no } \\
\text { response) }\end{array}$ & $\begin{array}{l}46(62.2 \%) \\
28(37.8 \%)\end{array}$ & $\begin{array}{l}41(55.4 \%) \\
33(44.6 \%)\end{array}$ & 0.504 & $\begin{array}{l}61(82.4) \\
13(17.6 \%)\end{array}$ & $\begin{array}{l}49(66.2 \%) \\
25(33.8 \%)\end{array}$ & 0.038 \\
\hline $\begin{array}{l}\text { Causes of TB } \\
\text { Germs } \\
\text { Others }\end{array}$ & $\begin{array}{l}52(70.3 \%) \\
22(29.7 \%)\end{array}$ & $\begin{array}{l}50(67.6 \%) \\
24(32.4 \%)\end{array}$ & 0.859 & $\begin{array}{l}66(89.2 \%) \\
8(10.8 \%)\end{array}$ & $\begin{array}{l}57(77.0 \%) \\
17(23.0 \%)\end{array}$ & 0.078 \\
\hline
\end{tabular}


Table 5: Bivariate analysis of knowledge related factors between intervention and control groups:

\begin{tabular}{|c|c|c|c|c|}
\hline \multirow{2}{*}{$\begin{array}{l}\text { Disease and } \\
\text { Treatment related } \\
\text { Factors: }\end{array}$} & \multicolumn{2}{|c|}{ At the beginning of the study } & \multicolumn{2}{|c|}{ At the end of the study } \\
\hline & $\begin{array}{r}\text { Odds ratio } \\
(\mathrm{OR})\end{array}$ & $95 \%$ C .I & Odds ratio $(\mathrm{OR})$ & $95 \%$ C .I \\
\hline $\begin{array}{l}\text { Hear about TB } \\
\text { Yes } \\
\text { No }\end{array}$ & 0.777 & $0.386-1.561$ & & \\
\hline $\begin{array}{l}\text { Duration of treatment } \\
\text { Yes } \\
\text { No }\end{array}$ & 1.184 & $0.613-2.289$ & 3.056 & $1.297-7.199$ \\
\hline $\begin{array}{l}\text { What do you expect if } \\
\text { stop treatment }\end{array}$ & 0.893 & $0.461-1.728$ & 2.536 & $1.099-5.853$ \\
\hline $\begin{array}{l}\text { Can TB be cured } \\
\text { Yes } \\
\text { No }\end{array}$ & 1.218 & $0.598-2.479$ & 1.128 & $0.430-2.960$ \\
\hline $\begin{array}{l}\text { When to stop TB } \\
\text { treatment }\end{array}$ & 1.322 & $0.686-2.549$ & 2.394 & $1.110-5.163$ \\
\hline $\begin{array}{l}\text { Causes of TB } \\
\text { Germs } \\
\text { Others }\end{array}$ & 1.135 & $0.565-2.277$ & 2.461 & $0.988-6.125$ \\
\hline
\end{tabular}


Chapter 8 General Discussion 
In the research presented in this dissertation, we explored the risk factors associated with TB treatment default using three different study designs: a casecontrol study, focus group discussions, and an intervention study. Our objective was to identify determinants of treatment default among TB patients in Khartoum State, Sudan. Based on our process evaluation and the findings of our studies, several recommendations were made. It is hoped that these recommendations will help policy makers and health care providers make changes that will improve treatment adherence, leading to a reduction in TB default.

This chapter presents a discussion of our research findings, which focus on the predictors of TB treatment default. A number of TB treatment barriers were identified which were related to treatment default among TB patients in Khartoum state.

\section{Reasons for treatment default in Khartoum State:}

The WHO guidelines for monitoring and evaluating TB treatment outcomes have been used to assess TB control programme outcomes across Sudan. Tuberculosis continues to be a major public health problem in Sudan, particularly in Khartoum State, despite the fact that there has been a reduction in tuberculosis-related mortality, and a decline in incidence and prevalence (2). In fact, Sudan ranks 3rd of the 10 highest-burden countries in the Eastern Mediterranean region (3). The results of a TB survey conducted in Sudan in 2014 indicated a prevalence of 159/100,000. The survey results pointed to a higher prevalence of TB in the young, in males, and among those living in urban settings (1.4). Over the last decade, the number of notified TB cases has remained relatively constant. In 2018, the total number of reported cases in Sudan was 20117 with a total incidence rate of 71/100.000 population; a MDR incidence of 2.6/100.000 population; a TB incidence rate among people living with HIV of 2.3/100.000, and a mortality rate of $17 / 100.000$ population 
(4-6). In 2009, the National Tuberculosis Control Programme (NTBCP) reported the following treatment outcomes: a treatment success rate of $82 \%$, a treatment default rate of $9.9 \%$, a death rate of $2.2 \%$, a treatment failure rate of $0.6 \%$ and a transferredout rate of $4.9 \%$ ) (7). Similar results were achieved by the tuberculosis control programme (TBCP) in Khartoum state in 2018. These results included an incidence rate of $85 / 100.000$ population. In terms of treatment outcomes, figures showed a success rate of $84.8 \%$, a default rate of $12 \%$, a death rate of 2.1 , a treatment failure of $0.8 \%$ and a transferred-out rate of $1.3 \%(8)$.

Defaulting from treatment remains the major challenge for TB control programmes in Khartoum State. Over the last decade, the default rate has remained high at around $14 \%$, as reported by various studies conducted in Khartoum State (911). In 2015, the World Health Organization (WHO) launched the End TB Strategy with the aim of ending the global TB pandemic by 2035. However, meeting the targets set by the WHO in order to achieve this goal will be challenging, bearing in mind the current levels of treatment default in Sudan. This is because treatment default contributes to the spread of TB $(12,13)$. In addition, it increases the risk of treatment failure, relapse, acquisition of drug resistance, prolonged infectiousness, and death $[2,3,7,12,13]$. Furthermore, if left untreated, a contagious person is expected to infect up to 15 people every year (14). The identification of risk factors leading to treatment default in Khartoum State is therefore crucial.

The research presented in this dissertation constitutes the first in-depth study conducted in Sudan to identify the determinant factors associated with TB treatment default. Using three different study designs, we studied multiple variables that could potentially be associated with non-adherence to TB treatment. These variables included sociodemographic factors, disease- and treatment-related factors, behavioural factors, beliefs and knowledge about TB, receptiveness of the health 
care providers, and patient opinions. This approach reflects the fact that health is no longer considered simply as a biomedical problem; rather, it is influenced by social, cultural, physiological, economic and political factors that can determine the decision of the individuals concerned $(15,16)$. Hence, our study differs from previous studies - which targeted only the TB disease and treatment outcomes - by also taking into account patient opinions and the doctor patient interaction. We hope that these findings will help the NTBCP, policy makers and health care providers in Sudan (and other countries with similar settings) to improve their performance. Ultimately, we hope that these findings will lead to better TB treatment adherence.

\section{Main findings:}

\section{Case-control study:}

The default rate in Khartoum state stands at $14 \%$. We found the following factors to be significantly associated with TB treatment default: residential locality (rural area); patient relocation or change of address; absence of support from family, friends and colleagues; occupation (blue collar work), not being part of a DOTS programme; suffering from adverse treatment effects; having a history of TB (relapse, multidrug-resistant TB or treatment failure); not having heard about TB before contracting it; lack of knowledge about when to stop TB medication; stigma; visiting an overcrowded TB centre; and lack of counselling about TB and its treatment (Chapters 3-5).

\section{Focus Group Discussions:}

The results from the interviews of six focus group discussions (FGDs) (three for defaulted patients and three for health personnel) were consistent in terms of identifying the determinant factors leading to TB treatment default. These results were also in line with the outcomes of the case-control study (Chapter 6). 


\section{The intervention study:}

The patients in the intervention group had a lower default rate (6.8\%), a higher documented cure rate $(78.4 \%)$, and better knowledge about TB treatment compared to the control group. Our results showed than an SMS reminder was useful in terms of encouraging treatment adherence and facilitated good interactions between patients and health personnel (Chapter 7).

\section{Comparison of our findings with previous literature:}

The results of our case control study showed that $14 \%$ of TB patients in Khartoum State were treatment defaulters (11). This high default rate is similar to figures that have been reported in other developing countries in Africa and Asia, as outlined in our systematic review (16-18). These findings were confirmed in our intervention study which showed that the patients in the intervention group had a lower default rate (6.8\%) compared to those in the control group (10.8\%). Furthermore, patients in the intervention group had a higher cure rate (78.4\%) compared to patients in the control group (59.5\%) (Chapter 7).

We identified several factors associated with TB treatment default. These predictors included sociodemographic factors, TB disease- and treatment-related factors, patient knowledge, and behavioural factors. Similar factors predictors were identified in the focus group discussions, where we explored the opinions of both TB patients and health care providers. The results from the intervention study were also consistent with these findings (Chapters 3-7).

For the most part, our findings regarding factors which are associated with TB default are similar to those reported in studies carried out in developing countries with low resources in Africa and Asia which carry the highest burden of TB (16-18), as well as those conducted in developed countries [16-24]. However, in contrast to 
some previous studies, we did not find an association between certain sociodemographic or disease-related factors and TB default [21].

Surprisingly, some factors previously thought to be related to TB treatment default (e.g. age, sex, religion, family income, family size, house size and nationality) were not found to be statistically significantly associated with default in our studies or in the systematic review $(24,25)$. Furthermore, other behavioural factors - including cigarette smoking, alcohol abuse, and feeling shame - were not associated with TB default in our study, in contrast to the findings of some earlier studies $(16,27)$. However, there are relatively few papers that have specifically investigated the association between these factors and TB treatment default (17-19).

In our research, patient awareness about $\mathrm{TB}$ and its treatment was significantly associated with $\mathrm{TB}$ default, especially among those with a low education level. Highly educated individuals, whether employers or employees, had a very good awareness of the disease, and so did those living in urban areas. Results showed that patients with a low education level are more likely to change their address or stop their treatment prematurely when feeling better, without informing their care providers. Moreover, they may be more likely to seek traditional or herbal medicine. Our study highlights the importance of health care workers providing health education to their patients, by showing that a lack of this information had a negative impact on patients' adherence to their TB treatment. We recommend that health workers provide health education and counselling for both TB patients and their families. These efforts should encourage patients and their families to adhere to TB treatment and ensure family support during the treatment period. The fact that more than $66 \%$ of TB patients are illiterate or receive less than 6 years of schooling (6) further highlights the importance of care workers providing health education. 
TB patients living in rural areas are more liable to default TB treatment. Poverty, poor nutrition, illiteracy and lack of knowledge represent major risk factors for TB disease and are associated with noncompliance to treatment among displaced individuals and refugees who live in camps, where TB medical services are provided in clinics managed by non-governmental organizations. These clinics are not fully equipped in terms of laboratory services, trained health personnel and the availability of medication for drug resistant TB (DR TB) (18,33-36). Our findings were similar to results of previous studies suggesting that TB is associated with low socioeconomic status $(18,28-31)$. In Sudan, for example, it has been shown that more than $80 \%$ of TB cases had a family income of less than 100 dollars per month (6). We therefore suggest that both governmental and non-governmental organizations should ensure that social and financial support is provided to TB patients who are out of work or of low socioeconomic status.

The stigma surrounding TB has long been recognized as an important factor leading to TB treatment default, especially among those with a lower level of education, or those who live in rural areas. The psychological effects of stigma on TB patients include increased levels of stress and anxiety, decreased levels of selfconfidence, and other issues related to self-identity. Stigma can also have a negative impact on TB patients and their families socially and economically. Social stigma of TB may force some patients to give up their work, and its effects for some may be lifelong. Moreover, stigma can make TB patients more likely to feel shame, hide their disease, and decrease their motivation to seek medical care. In addition, stigmatized patients may be more likely to turn to herbal and traditional medicines. In summary, social stigma can lead to a worsening of patient's condition, disease complications, treatment default, treatment failure, drug resistance, and the spread of TB infection (32-34). 
Overcoming TB stigma needs active interventions using non-traditional health education methods. To ensure the success of a health education initiative, it is important to have an ambitious plan which communicates and reinforces specific messages, such as the fact that TB is a curable and preventable disease. Moreover, it is important that these health education messages are designed and targeted with specific groups - such as TB patient, their families, students, and the wider community - in mind. The education plan needs to be implemented by well-trained health staff. Furthermore, it is crucial that various outreach methods are employed, including social media, movies, drama, public talks, and brochures. In this way, health care staff as well as various non-governmental organizations can encourage community participation and contribute to the health education of TB patients, their families, and the wider community.

It has been shown that receiving treatment under the DOTS programme significantly enhances adherence to TB treatment. Adopting the DOTS programme is usually associated with free services (TB diagnosis and medication), and enhanced accessibility to services through primary health care centres (PHCC) (37). However, there are still some challenges facing the implementation of DOTS programme, such as inequity of health services utilization, especially in rural areas. Our findings on this confirmed the results of previous studies $(28,35)$.

In order to encourage adherence to treatment, the Ministry of Health $(\mathrm{MOH})$ in Khartoum State adopted a DOTS strategy when it was recommended by the WHO in 1993 (35). Adopting DOTS ensured that TB patients would be receiving their treatment under the supervision of health care workers. Moreover, DOTS increased the accessibility of TB services; the Ministry of Health established more than 50 TB units (microscopic and treatment centres) distributed all over the state, according to geography and population density (8). Despite these efforts, TB treatment default 
remains high. One objective of the TB control programme in Khartoum State is to provide tracing teams in all TB units, which are responsible for contacting defaulting patients, encouraging them to come back to continue their treatment, and visiting them at their home if they do not reply, so as to identify any barriers and give advice on how to overcome them when they first start to default. The fact that this does not appear to be happening, at least during our study period, may indicate that the programme (and its allocated resources) need to be reassessed (36). The introduction of a revised retrieval system in Saudi Arabia has been shown to significantly improve the retrieval of non-attenders and reduce the dropout rate (37). There are several possible reasons why default tracing is a major challenge to TB control in Khartoum State, including the wide area of the state, a shortage of available staff, the inadequacy of the patient referral system from one TB health unit to another, a shortage of transport means for default tracing teams, and a reliance on landline telephones and irregular home visits (36). To overcome the obstacles facing the DOTS programme in Khartoum State, we recommend that future research investigates both social and economic aspects of patient care. We further recommend that the family situation and the opinions of both patients and their families are further explored and taken into account when it comes to policy decisions regarding treatment. In this way, TB health services will be respectful of, and responsive to, individual patient preferences, needs and values. This will ensure that the patient's values will guide all clinical decisions. Our recommendations are in line with the WHO post-2015 global tuberculosis strategy framework. This framework, built on the foundations of the DOTS treatment strategy, consists of three strategic pillars and components, the first of which focuses on integrated, patient-centred care and prevention. The goal of this strategy is to end the global tuberculosis epidemic by 
the year 2030, and the overall vision is of a world that will be free of TB disease, with zero deaths and zero suffering due to tuberculosis $(11,12)$.

The TBCP in Khartoum State does not use new technology for the follow-up of TB patients during the treatment period despite the fact that the use of mobile phones has substantially increased throughout the world over the last decade, also in Sudan. The global expansion in mobile phone use presents new opportunities to incorporate mobile phones into health care delivery services (38-40). Our intervention study findings provide the basis for solid recommendations which we hope will provide new opportunities to increase health education and improve doctor-patient interaction. In turn, we hope that this will help to improve treatment outcomes such that there will be a higher cure rate and a lower default rate. We suggest that the adoption of mobile phone use (or other new technology) by the TBCP will help the policy makers in planning, enhance communication with TB patients and facilitate follow-up. Our findings are similar to those reported in previous studies (41-44).

The receptiveness of the health care providers in Khartoum State and the approach they adopted was significantly associated with TB treatment default. These finding confirmed the results of previous studies conducted in developing countries $(19,45)$. Several factors, including lack of training, work overload and overcrowding at health units, patients' behaviour, and a shortage of health services and facilities (including health education materials) may affect the attitude of health staff. The interaction between health care staff and their patients is important, as it offers an opportunity to increase patient awareness about TB. Moreover, this interaction allows the doctor to assess/determine the social circumstances and economic status of patients and their families. Having access to this information may mean that some of the aforementioned obstacles can be overcome. Finally, this interaction allows the 
doctor to discuss a suitable treatment plan tailored to each patient, which will increase the likelihood of the patient adhering to the treatment (46-48).

Our studies explored in depth several factors associated with TB default related to patients, their families and community. We identified more variables associated with TB treatment default than those identified in our systematic review (which included the results of 53 articles). Our research included three types of study design (observational, focus group discussion and intervention), in contrast to the single study designs of the research included in the systematic review. Moreover, our findings across the three studies were similar and consistent, while the results of the research included in the systematic review may be controversial.

In summary, we believe that our studies have identified the important factors associated with TB default. With this knowledge, more focus can be placed on helping patients most at risk of treatment default adhere to their treatment plan. Our findings are applicable not only to the current situation regarding TB management and control in Sudan, but also to those in a similar situation in other developing countries.

\section{Methodological considerations:}

\section{Selection of our study populations:}

Our case control study was conducted in Khartoum State, which is the most populated state in Sudan. Its population can be assumed to represent the whole country, as most of the inhabitants come from various parts of Sudan. The TB patients included in this study were selected from all of the TB treatment units (health centres and hospitals) in the state. The population of the three patient focus group discussions were selected from all tuberculosis patients (defaulters and controls) registered at tuberculosis centres in Khartoum State, in order to capture beliefs, culture, geographical and financial differences across various communities. 
The inclusion criteria for participants specified that patients had to be at least 18 years old and receiving treatment for at least one month; it was thought that these patients would provide better insight into TB treatment barriers. In order to further explore the driving factors for defaulting, we subsequently conducted another three focus group discussions with a total of 24 health professionals representing 53 TB treatment units in Khartoum State. The health professionals who participated were all experienced in treating TB patients.

The participants in our intervention study were randomly selected from the health units in Khartoum State (using the same selection criteria). Patients who had access to a cell phone were allocated to the intervention group, if they agreed to participate. For every patient placed in the intervention group, the following patient without access to a cell phone was allocated to the control group, if they agreed to participate.

In summary, we suggest that our findings from the three study designs can be generalized to the total TB population in the state, to Sudan as a whole, and to other communities with similar settings.

\section{Potential bias:}

Recall bias was minimized by the use of a semi standardized questionnaire during the interviews and by cross-checking patients' responses for each study variable against their medical records. While the reliability of the information gathered from each patient could not be counter-checked, questions about sensitive issues were carefully handled in order to maximize the accuracy of the responses obtained. Moreover, potential confounding variables were taken into consideration in the design (by restricting the diagnosis criteria) and in the analysis (by using logistic regression analysis). 


\section{Tracing of default patients:}

The major problem we faced during the study was how to reach the defaulting patients (cases). This problem was tackled in three steps. First, the patient medical records were traced and identified and all contact information was reviewed. Then, study personnel first tried to telephone the patient and, failing that, to telephone known family members or friends. If telephone contact failed, home visits were made, first to the patient and then to known family members or friends. Interestingly, we found that many of the defaulting patients did not have access to any phone (mobile or landline), a risk factor not previously described or evaluated in our study. The interviewers made an average of three attempts to contact each defaulter before recording the defaulter as a non-respondent.

\section{Study design:}

Our three study designs allowed us a more in-depth investigation of the determinant factors associated with TB treatment default. Firstly, we conducted a case control study. In this study, the participants (cases and controls) were interviewed using a questionnaire. Secondly, we conducted the focus group discussions, in order to ascertain the opinions of TB patients and health care providers. The barriers reported by TB treatment defaulting patients and health care providers who participated in this study were not well known and not familiar to either the Khartoum community or the policy makers of the TB control program in Khartoum State, despite being previously reported in many international studies $(3,13-15)$. It is important to note that this is the first large scale qualitative study exploring the opinions and experiences of both patients and the staff treating them about the barriers related to the interruption of TB treatment. Our results shed light on the attitudes of health care workers towards the patients, patient 
knowledge about TB disease and its treatment, the economic impact of TB (including the cost of travelling to treatment centres, food, and potential loss of work) and the belief in traditional healers. Interestingly, there was another barrier raised by the participants in the six focus group discussions, i.e. the poor availability of communication tools and transportation for the treatment default tracing teams. Finally, in order to further investigate risk factors associated with TB default, we conducted an intervention study about the structural use of mobile phones in a TB program as a potential way of lowering the frequency of default. However, the impact of this intervention on treatment outcomes in Sudan has not yet been evaluated. We therefore conducted a controlled intervention pilot study to evaluate the potential role of cell phone use in lowering treatment default.

\section{Future implications:}

The results of our studies have the potential to positively impact TB patient care in the following ways:

\section{Implications for patient health care}

- The intervention study investigated the use of modern communication technology (SMS via cell phone) by the NTCP for the follow-up of TB patients. We found that the use of cell phones achieved positive outcomes such as: a higher cure rate, a decrease in the default rate and an increase in patient knowledge about TB. Our results show that there is considerable promise in using cell phone technology to improve the efficiency and quality of TB treatment. While recognising that there are many advantages to using cell phones in place of landline telephones, other alternative means of communication should also be considered. These might include the use of voice messages for those who cannot read SMS messages, the use of video- 
observed therapy to follow-up patients taking TB medication, or the use of reminders to help patients take the correct dose at the right time.

- Our studies are the first to investigate the default tracing team in Khartoum State, and Sudan as a whole. Based on our results, we recommended that improvements are made to the default tracing teams, building capacity by providing additional training for health personnel, and increasing the availability of transportation and communication tools.

- Our findings show that some patients may default during the referral process from one TB clinic to another. There is therefore a need to update the guidelines regarding the referral system of TB patients, and improve the communication methods in order to ensure information is effectively shared between the TB health units.

- There was a substantial group of TB patients in Khartoum State who had not been screened for HIV status, despite the fact that it is the core policy of the NTB programme to screen all TB patients for HIV. It is therefore of vital importance to expand the provision of HIV testing services in all TB clinics.

- Our study indicates that DRTB patients require additional and special attention from the health care providers over the long treatment duration period, due to the fact that DRTB is associated with a high default rate.

- The default rate is higher among the patients who live in rural locations. These patients also tend to have a low education level. It is important, then, that the health care provider can focus on these patients and tailor a treatment strategy to their specific needs, with the idea that this will increase the likelihood of treatment adherence.

- Our study indicates that special attention is needed for the displaced people with a high default rate living in rural and remote areas around the big cities 
in Khartoum State. The NTP program needs to develop an intervention plan that includes training for health personnel, capacity building for the health units, and provision of drugs and investigation services.

- Building on the DOTs programme and adopting a patient-centred approach to care will help to achieve the END TB strategy. Such an approach takes into account each patient's personal situation and social status. A decision can then be made about whether a home-based or a hospital-based treatment plan would be best.

- Our findings show that lack of knowledge and stigma were strong determinant factors for TB treatment default. It is therefore of vital importance that health care workers provide health education to all TB patients, their families, and the wider community. In order to communicate this effectively, we recommend that health care workers adopt a receptive and welcoming approach to their patients. Furthermore, it is necessary for the NTB to update the guidelines for health education to include the use of non-traditional health education methods which offer good opportunities for interaction between patients and their health care providers.

- We strongly recommend that the NTB programme actively encourages more community participation. This can be achieved by co-ordinating with governmental and non-governmental organisations and charity associations to get them involved in the provision of health services for TB patients.

- Finally, we advocate periodic updates of TB guidelines in light of recommendations provided by the World Health Organization and the local practice. 


\section{Research Implications}

Based on the findings presented in this thesis, we have several suggestions for further research:

- We conducted a pilot of an intervention study to investigate the use of mobile phone use in decreasing the rate of TB treatment default. This was the first study conducted in Khartoum State to evaluate the use of such devices. Based on our findings, we highly recommend that the NTBP conducts a randomized controlled trial study to evaluate the role of mobile phone use on TB treatment adherence.

- Ours was the first study conducted in Khartoum State (or Sudan as a whole) to investigate the determinants factors for TB treatment default. We used three different study designs, and explored several different variables, some of which had not been studied in the area before, e.g. the evaluation of the DOTS programme and the TB default tracing team. Further prospective research could provide in-depth insight regarding the determinant factors for TB treatment default.

- In the light of our study findings, we recommend the reassessment and evaluation of NTCP strategies.

- We suggest that future research opportunities include an investigation of the feasibility, affordability and benefits of adopting a patient-centred approach, a comparison of home-based versus hospital-based DOTS, and further exploration of the obstacles which prevent daily attendance at TB health units.

\section{Conclusions:}

Our research identified determinant factors influencing TB treatment default. We believe that the findings are applicable to the current situation of TB management and control in Sudan and in other developing countries. 
This thesis addresses some important issues in TB control in Khartoum State as well as the rest of Sudan (and other locations in similar settings with limited resources). In summary, our recommendations are as follows:

- Implement capacity building of TB programme staff and provide ongoing training in relation to certain elements of $\mathrm{TB}$ control programmes such as case classification, treatment monitoring, record keeping, outcome recording, patient follow-up and quality control.

- Use advanced communication tools to increase awareness of TB in patients and their families and increase the provision of counselling. It is important to determine which groups in particular should be targeted and to encourage community participation.

- Improve the coordination between the different departments in the Ministry of Health and other related sectors e.g. the Ministry of Education.

- Continually evaluate the TB control programme. 


\section{References:}

1. World health organization. Compendium of indicators for monitoring and evaluating national Tuberculosis programs.2004. WHO/HTM/TB/2004.344.

2. World Health Organization, Regional Office Eastern Mediterranean. TB in Sudan http://www.emro.who.int/sdn/programmes/stop-tb-sudan.html

3. World Health Organization, Regional Office Eastern Mediterranean. Stop Tuberculosis.2011.

http://www.emro.who.int/tuberculosis/epidemiologicalsituation/epidemiological-situation.html

4. Federal Ministry of Health. Sudan National TB Management Guideline. 2018. 2019/07/Sudan-National-TB-management-Guideline-March.2019-1.pdf

5. World Health Organization (WHO). Definitions and Reporting Framework for Tuberculosis - 2013 revision (updated December 2014).2014.Hans I. R, Chiang C.Y, Robert P. G, Donald A. E. Crofton's Clinical Tuberculosis.2013.3rd edition.

6. Federal Ministry of Health. General Directorate of Primary Health Care, Sudan. National Tuberculosis Control Programme. 2011.

7. Preventive Medicine Department Ministry of Health Khartoum State, Sudan. Yearly integrated analysis report for year 2018.

8. Suleiman M M A, Sodemann M. Evaluation of Tuberculosis Control Programme in Khartoum State for the Year 2006. Scandinavian Journal of Public Health. 2009;37:101-8.

9. Preventive Medicine Department Ministry of Health Khartoum State, Sudan. Yearly Integrated Analysis Report for Year 2011. 
10. Ali AOA, Prins MH. Patient Non Adherence to Tuberculosis Treatment in Sudan: Socio demographic Factors Influencing Non adherence to Tuberculosis Therapy in Khartoum State. Pan Afr Med J. 2016;25:80 doi:10.11604/pamj.2016.25.80.9447.

11. World Health Organization(WHO). Global strategy and targets for tuberculosis prevention, care and control after 2015. 2013; EB134/12.

http://apps.who.int/gb/ebwha/pdf_files/EB134/B134_12-en.pdf?ua=1

12. World Health Organization.The End TB Strategy.2018.

$\mathrm{WHO} / \mathrm{CDS} / \mathrm{TB} / 2018.29$

13. World Health Organization(WHO). Global tuberculosis report 2019.

14. World Health Organization. What are the main factors that influence the implementation of disease prevention and health promotion programmes in children and adolescents?. 2005.

http://www.euro.who.int/_data/assets/pdf_file/0010/74674/E86766.pdf

15. Quilala D. Knowledge, attitudes and practices (KAP) of public school teachers in Ilocos Sur regarding tuberculosis. Philippines Journal of Internal Medicine 2005;43:159-67.

16. Kate C C, Janet M B, Sarah E R, and Daniel P C. Movement of Tuberculosis Patients and the Failure to Complete Antituberculosis Treatment. . American Journal of Respiratory and Critical Care medicine .1998; 157: 1249-52.

17. Castelnuovo B. A review of Compliance to Anti Tuberculosis Treatment and Risk Factors for Defaulting Treatment in Sub Saharan Africa. African Health Sciences. 2010 Dec; 10(4): 320 - 324.

18. Kelly E D, Ouafae L, Iraqi G, Janine K, Diss E, Imad C, Rajae E. Risk Factors for Tuberculosis Treatment Failure, Default, or Relapse and Outcomes of Retreatment in Morocco. BMC Public Health. 2011; 11:140. 
19. Muture B, Keraka M, Kimuu P, Kabiru E, Ombeka V, Oguya F. Factors associated with default from treatment among tuberculosis patients in nairobi province, Kenya: A case control study. BMC Public Health. 2011;11:696:1-10.

20. Salla A, Simon A, Helen J S, Mark E, Atle F, Jimmy . Patient Adherence to Tuberculosis Treatment: A Systematic Review of Qualitative Research. PLoS Med. 2007;4(7):238.

21. Nyi N N, Catherine D, Abdul Rahman I, Rosemi S, Noraini B and Mohd R M. Factors Contributing to Poor Compliance with Anti-TB Treatment among Tuberculosis Patients. South East Asian J Trop Med Public health. 2001 June;32 (2):369-382.

22. Tatek W, Kifle W, Wondwossen K, Sofonias G. Delay in Initiating Tuberculosis Treatment and Factors Associated among Pulmonary Tuberculosis Patients in East Wollega, Western Ethiopia. Ethiop.J.Health Dev. 2007;21 (2):148156.

23. Jaggarajamma K, Sudha G, Chandrasekaran V, Nirupa C, Thomas A, Santha T, Muniyandi M and Narayanan P R. Reasons for Non-Compliance among Patients Treated Under Revised Natoional Tuberculosis Control Programme (RNTCP), Tiruvallur District, South India. Indian J Tuberc. 2007; 54(3):130-135. 24. Samuel AB, Tomoko K, Tomoko T, Nobuyuki H. Factors Contributing to Tuberculosis (TB) Defaulter Rate in New Juaben Municipality in the Eastern Region of Ghana. Journal of the National Institute of Public Health. 2010; 59(3): 291-7.

25. Chuah SY. Factors associated with poor patient compliance with antituberculosis therapy in Northwest Perak, Malaysia. Tubercle. 1991 Dec;72(4):261-4. 
26. Nyi N N, Catherine D, Abdul Rahman I, Rosemi S, Noraini B and Mohd R M. Factors Contributing to Poor Compliance with Anti-TB Treatment among Tuberculosis Patients. South East Asian J Trop Med Public health. 2001 June;32 (2):369-382.

27. Caylà A J, Teresa R, Juan R M José A C, Rafael V. Tuberculosis treatment adherence and fatality in Spain. Respir Res. 2009; 10(1): 121.

28. Preventive medicine department Ministry of Health Khartoum state, Sudan. Yearly integrated analysis report for year 2009. 2010.

29. Eyasu E, Getenet B, Getu B, Zegeye B, Gemeda A. Factors associated with unsuccessful treatment outcome in tuberculosis patients among refugees and their surrounding communities in Gambella Regional State, Ethiopia.Plos One. 2018;13(10).

30. Shahid U, Abdullah HM, Saeed A, Omer F, Shad MA, Siddiqui AM, Akram J. Urban-rural inequities in knowledge, attitudes and practices regarding tuberculosis in two districts of Pakistan's Punjab province. International Journal Equity Health. 2011;10(1):8.

31. Weiss MG, Auer C, et al.. Gender and Tuberculosis: Cross-site analysis and implications of a multi-country study in Bangladesh, India, Malawi, and Colombia. International Journal of Tuberculosis and Lung Diseases 2008;12(7):856-66.

32. Good BJ. Medicine, rationality and experience. An anthropological perspective. New York: Cambridge University Press 1994.

33. Bereket D, Asres, Getinet A, and Zegeye Y.Perceived Stigma and Associated Factors amongPatient with Tuberculosis, Wolaita Sodo, Ethiopia:Cross-Sectional Study. Tuberculosis Research and Treatmen.2019.

34. Sebsibe T. Stigma against Tuberculosis Patients in Addis Ababa, Ethiopia. Plos One.2016:11(4). 
35. El Sony AI, Baraka O, Enarson DA,Bjune G. Tuberculosis control in Sudan against seemingly insurmountable odds. International Journal of Tuberculosis and Lung Disease 2000;4:657-64.

36. Ahmed AOA, Martin HP. Disease and treatment-related factors associated with tuberculosis treatment default in Khartoum State, Sudan: a case-control study. Eastern Mediterranean Health Journal.2017;23(6):408-418.

37. Chaudhry LA, Al-Tawfiq J, Ba-Essa E, Robert AA. Low rate of noncompliance to antituberculous therapy under the banner of directly observed treatment short course (DOTS) strategy and well organized retrieval system: a call for implementation of this strategy at all DOTS centers in Saudi Arabia. Pan Afr Med J. 2015;21:267.

38. Denkinger CM, Grenier J, Stratis AK, Akkihal A, et al. Mobile health to improve tuberculosis care and control: a call worth making. Int J Tuberc Lung Dis. .2013; 17(6):719-727.

39. Brinkman I, Bruijn M \& Bilal H. The mobile phone, 'modernity' and change in Khartoum, Sudan.2009. https://core.ac.uk/download/pdf/82998951.pdf 40. World Health Organization(WHO). Handbook for the Use of Digital Technologies to Support Tuberculosis Medication Adherence.2017.

41. Iribarren SI, Beck SL, Pearce PF, Chirico C. MHealth Intervention Development to Support Patients With Active Tuberculosis. Journal of Mobile Technology in Medicine. 2014; 3(2):1627.

42. Farooqi R J, Ashraf S, Zaman M. The Role of Mobile SMS-Reminders in Improving Drugs Compliance in Patients Receiving Anti-TB Treatment from DOTS Program. J Postgrad Med Inst. 2017; 31(2): 156-62. 
43. Falzon D, Raviglione M, Bel E H, Gratziou C, Douglas Bettcher D.The Role of eHealth and mHealth in Tuberculosis and Tobacco Control :a WHO/ERS consultation. Eur Respir J 2015; 46: 307-311.

44. Barclay E. Text Messages Could Hasten Tuberculosis Drug Compliance. Lancet. 2009;373:15-16.

45. Marlucia D S G, Maria L P, Toma M. P Porcuna, et al. Factors Associated with Tuberculosis Treatment Default in an Endemic Area of the Brazilian Amazon: A Case Control-Study. Plos One; 2012: 7(6).

46. Ifebunandu N. A, Ukwaja K.N , Osakwe P.C and Alobu I. Tuberculosis Treatment Outcome and its Determinants in a Tertiary Care Setting in SouthEastern Nigeria. The Nigerian postgraduate medical journal.2013; 2(2):125-129. 47. Rubel AL, Garo LC. Social and Cultural Factors in the Successful Control of Tuberculosis. Public Health Rep.1992; 107:626-636.

48. Suleiman M M A, Sahal N, Sodemann M, Elsony A, et al . Tuberculosis Awareness in Gezira, Sudan: Knowledge, Attitude and Practice Case-Control Survey. EMHJ.2014; 20 (2):120-129. 


\section{The impact of the research}

Tuberculosis (TB) is the major causes of illness and death worldwide for more than three decades. It is classified among the top ten causes of global cause of death, particularly in developing countries. Our objective was to identify factors associated with discontinue treatment among TB patients in Khartoum State, Sudan. Based on our findings, relevant suggestions and recommendations can be made with the aim to help the patient, families, communities, policy makers and health care providers make changes that will improve treatment compliance and treatment outcomes, and leading to a reduction in TB dropout among tuberculosis patients in Khartoum State and Sudan.

The results of our studies have the potential to positively impact TB patient care as the findings of our research identified several factors leading to discontinue TB treatment

\section{Impact for patient health care, health care providers, TB control program and the future research:}

The results of these studies show that the patients lack of knowledge, those with with low level of education, and stigma such as feeling shame were strong factors for discontinue TB treatment. It is therefore of vital importance that health care workers provide health education to all TB patients, their families, and the wider community. In order to communicate this effectively, we recommend that health care workers adopt a receptive and welcoming approach to their patients. Furthermore, it is necessary for the national TB program (NTBC) to update the guidelines (plans, procedures and strategies) for health education to include the use of non-traditional health education methods which offer good opportunities for interaction between patients and their health care providers. 
Moreover, Our study indicates that special attention is needed for the poor patients, displaced individuals and refugees with a high dropout rate living in camps, rural and remote areas around the big cities in Khartoum State where TB medical services are provided in clinics managed by nongovernmental organizations. The national TB control program needs to develop an intervention plan that includes training for health personnel, provision of equipment and tools, and availability of drugs and laboratory services.

Due to lack of resources for the national TB control program in Khartoum State, we strongly recommend that the NTB programme actively encourages more community participation. This can be achieved by coordinating with governmental and non-governmental organisations and charity associations to get them involved in the provision of health services for TB patients. In addition, these nongovernmental organization can participate in overcoming the stigma by active intervention using nontraditional health education methods. To ensure the success of a health education initiative, it is important to have a motivated plan which communicates and emphasizes specific messages, such as the fact that TB is a treatable and preventable disease. Furthermore, it is essential that various outreach methods are employed, including social media, movies, drama, public talks, and brochures.

Also, Our study evaluated the use of new communication technology (short message services (SMS via mobile phone) by the NTCP for the followup of TB patients. We found that the use of mobile phones achieved positive results such as: a higher cure rate, a decrease in the dropout rate and an increase in patient knowledge about TB. Our results show that there is 
considerable promise in using mobile phone technology to improve the efficiency and quality of TB treatment. While recognising that there are many benefits to using mobile phones in place of landline telephones, other alternative means of communication should also be considered. These might include the use of voice messages for those who cannot read SMS messages, the use of video-observed therapy to follow-up patients taking TB drugs, or the use of reminders to help patients take the correct dose at the right time.

Our studies are the first to evaluate the team tracing the patients who discontinue treatment in Khartoum State, and Sudan as a whole. Based on our results, we recommended that improvements are made to the retrieval tracing teams, by providing additional training for health personnel, and increasing the availability of transportation and communication tools. This team will try to encourage the non- attender TB patients to come back to continue their treatment and reduce dropout rate. The team follow sequence of contact attempts including phone call and home visit. Moreover, we found that some patients may discontinue their treatment during the referral process from one TB clinic to another. There is therefore a need to play special attention regarding the referral system of TB patients, and improve the communication methods in order to ensure information is effectively shared between the TB health units.

As TB is a chronic disease that need treatment with multiple drugs for more than six month duration. This had social, financial and psychological effects for TB patients, their families and the community. Discontinue treatment or taking treatment irregular may enhance the spreading of the disease, In addition, it increases the risk of treatment failure, disease may become active again,, acquisition of drug resistance, prolonged duration of 
illness, and death. Furthermore, if left untreated, an infected person is expected to spread infection up to 15 people every year. Hence identification of risk factors leading to discontinue treatment in Khartoum State is therefore essential. Thus our study indicates that TB patients specially those had drug resistant require additional and special attention from the health care providers over the long treatment duration period, due to the fact that patients with drug resistant are associated with a high dropout rate.

Our study reported that there was a substantial group of TB patients in Khartoum State who had not been screened and tested for HIV status, despite the fact that it is the core policy of the NTB programme to screen all TB patients for HIV. It is therefore of vital importance to expand the provision of HIV testing services in all TB clinics.

Our research identified several factors influencing discontinue TB treatment. We believe that the findings are applicable to the current situation of TB management and control in Sudan and in other developing countries. Based on the findings presented in this thesis, we have several suggestions for further research to assess in depth the factors associated with discontinue TB treatment not evaluated in our studies. Also, in the light of our study findings, we recommend the reassessment and evaluation of NTCP strategies. Furthermore, we recommend to evaluate use of mobile phone use in decreasing the dropout rate of TB treatment. 


\section{Summary}

Tuberculosis (TB) is the major causes of illness and death worldwide for more than three decades. In 1993, the World Health Organization (WHO) declared TB infection to be a global public health problem . TB continues to cause high morbidity and mortality rates, and is classified among the top ten causes of global mortality, particularly in developing countries.

Since then, many efforts have been undertaken by experts in international organisations to control TB disease. The WHO launched the "Directly Observed Treatment; Short-course (DOTS)" strategy in 1994 as the essential, most costeffective means of tuberculosis control. The success of this strategy later underpinned the development and implementation of the "Stop TB Strategy" (20062015). This was incorporated in the subsequent "End TB Strategy" by the year 2035 which launched by the WHO as a post-2015 global TB strategy.

TB continues to be a major public health problem in Sudan, particularly in Khartoum State. Sudan ranks the $3^{\text {rd }}$ of the 10 highest burden countries in the Eastern Mediterranean region. It alone carries about $15 \%$ of TB burden in the region In Khartoum State, the total number of TB cases detected in 2010 was 6670; an incidence rate of 119/100.000 population (population of the state was 5.558.647 in the year 2010). The annual risk for TB was $1.8 \%$, hence the programme was able to detect 2196 new smear positive cases ( $83.5 \%$ of the target) and achieve a cure rate of $48.4 \%$ from the detected cases. The treatment success rate increased from 66\% in 2011 to reach $81.0 \%$ and $84.0 \%$ in 2017 and 2018, respectively (of all registered new smear positive cases). These figures come close to the target set $(85 \%)$.

TB shows high morbidity and mortality, and has proven difficult to eliminate, despite the fact that it is both curable and preventable. Many professionals reiterate 
that poor compliance associated with TB treatment remains a challenge for the national TB control programmes in developing countries and in Sudan, including Khartoum State . Treatment compliance is as crucial as the early detection of disease for achieving a high cure rate . Despite all of the efforts taken by the TB control programme, there is still a high TB treatment default rate (14\%) in Khartoum State, as compared to the WHO benchmark (of less than 3\%). Irregular, interrupted or incomplete TB treatment increases the risk of disease spread, treatment failure, relapse of disease, acquisition of drug-resistant TB, prolonged infectiousness, and death .

In this thesis we presented studies conducted to investigate the factors leading to defaulting TB treatment. Thus the relevant suggestions and recommendations can be made with the aim of reducing treatment default, and improving TB treatment adherence and treatment outcomes among tuberculosis patients in Khartoum State and Sudan.

\section{The factors leading to treatment default among TB patients}

In chapter 2 we reported the Patient characteristics associated with nonadherence to Tuberculosis treatment. This results were obtained by conducting a systematic review study which included the reveiw of 53 eligible studies. The elegible studies included different sudy designs and were conducted in both developed and developing countries The results of this systematic review show that family income, moving of patient or giving wrong address, tuberculosis relapse or MDR TB, intensive phase of treatment, history of default, long course treatment regimen, response to treatment, homeless, stigma, seeking traditional healers, staff receptiveness, DOTS, poor knowledge or lack of health education were consistently and statistically significantly related to tuberculosis treatment non-adherence. 
In chapter 3, 4 and 5 we reported the determinants of treatment defaulting among adults TB patients (15 years and above) in Khartoum State, Sudan. The findings obtained by conducting a case control study where the patients defaulting from treatment were considered as 'cases' and those completing treatment as 'controls' between May 2010 to May 2011. The data collection for the case control study was carried out from $1^{\text {th }}$ of May 2011 to $15^{\text {th }}$ of July 2011. The aim of this study was to identify determinants of treatment defaulting among TB patients in Khartoum State, Sudan.

There were 2727 TB patients who attended TB treatment clinics during study period. Out of these 2399 patients $(86 \%)$ had continued their treatment while 328 patients (14\%) had interrupted it. Of these, 185 had resumed treatment before data collection and 143 had not and were eligible as cases. Of the 143, 27 could not be traced and 11 declined to participate. Thus, 105 cases and 210 controls were included and interviewed.

The results of this study conclude some factors influence defaulting of TB treatment. These factors included socio-demographic factors such as: residential locality (rural area), patients moving or changing address, and absence of family support and occupation (blue collar work); Disease- and treatment-related factors such as: not being on a DOTS programme, having side-effects from treatment, and having a history of TB (relapse, multidrug-resistant TB or treatment failure); Patient knowledge and behavioral factors such as: "had never heard about TB before had it", lack of knowledge on when to stop TB medication, less support by families, friends and colleagues, too many patients when visiting the TB center, and lack of counseling about TB and its treatment.

In chapter 6 we reported the barriers Leading to Treatment Default among Tuberculosis Patients in Khartoum State, Sudan: The findings were obtained by 
conducting a qualitative research using the technique of Focus Group Discussion (FGD) during the period from $1^{\text {st }}$ of May 2011 to $15^{\text {th }}$ of July 2011. Six FGD were conducted ( 3 for defaulted patients and 3 for health personnel). Overall, 27 TB defaulted patients and 24 health care providers were randomly selected. The objective of this study is to provide health authorities and patients with insight into the perceived factors affecting TB treatment default.

The Participants included in this study reported several barriers leading to TB treatment default such as: lack of knowledge about TB, high cost of transportation, difficulty for making a daily visit to health facilities for DOT programme due to distance of the facilities from their residences, rural residency, social circumstances, TB-related stigma, lack of family support, patient movement or giving wrong address, seeking traditional healers and treatment-related factors such as side-effects of drugs, the attitude of health care providers, the long delay in obtaining medications, and weakness and challenges facing defaulter tracing teams. There were consistent findings from interviews among patients and health care providers. In chapter 7 we reported the use of Mobile health to improve adherence to tuberculosis treatment in Khartoum State, Sudan. The findings were obtained by conduticng a controlled intervention pilot study during the period from 1th of May 2017 to 31th of March 2018, in eight TB treatment units in Khartoum state. Short message services (SMS) reminder were sent to the intervention group. The aim of this study was to evaluate the potential use of cell phones for lowering treatment default. However, it's impact on treatment outcome in Sudan has not yet been evaluated before.

There was 148 TB patients enrolled in this study, seventy-four patients in each group. The patients in the intervention group had a lower default rate(6.8\%), higher documented cure rate(78.4\%), better knowledge compared to control group.SMS 
reminder was useful and facilitated good interaction between patients and health personnel.

The findings presented in chapter 3,4,5,6 and 7 constitutes the first in-depth study conducted in Khartoum State and Sudan to explore the factors associated with TB default related to patients, their families and community. We identified more variables associated with TB treatment default than those identified in our systematic review (which included the results of 53 articles). Our research included three types of study design (observational, focus group discussion and intervention), in contrast to the single study designs of the research included in the systematic review. Moreover, our findings across the three studies were similar and consistent, and confirmed the findings of the previous studies conducted in developed and developing countries.

In summary, we believe that our studies have identified the important factors associated with TB default. With this knowledge, more focus can be placed on helping patients most at risk of treatment default adhere to their treatment plan. Our findings are applicable not only to the current situation regarding TB management and control in Sudan, but also to those in a similar situation in other developing countries.

In chapter 8 we presented a discussion of our research findings reported in the previous chapters, which focus on the predictors of TB treatment default. Also we discussed future implications of these findings on the TB patient care and health care providers. In addition, we identified the research needs and priority areas for enhancing adherence of TB treatment and strengthening activities, strategies and policies of the national TB control programme (NTP) in Khartoum State, Sudan and communities with similar settings. 
Appendices 
Appendix 1 


\section{QUESTIONNAIRE \\ TUBRCULOSIS TREATMENT DEFAULTER STUDY}

The questions will be answer by the clients

Date:

locality: health area:

area: interviewer:

Patient File No Patient Telephone No

We wish to learn about your opinion regarding tuberculosis treatment (TB) as well as determinant factors for TB treatment defaulting. The information you provide will be used to improve TB treatment.

Your answers will not be released to anyone and will remain anonymous. Your name will not be written on the questionnaire or be kept in any other records. Your participation is voluntary and you may choose to stop the interview at any time.

Thank you for your assistance.

Interviewer: Please write the answer number in the box of selected answer(s). Do not read responses unless the directions indicate.

1. Study Serial No:

2. Patient status

1. Defaulter

2. Complaint

A- Socio- demographic questions:

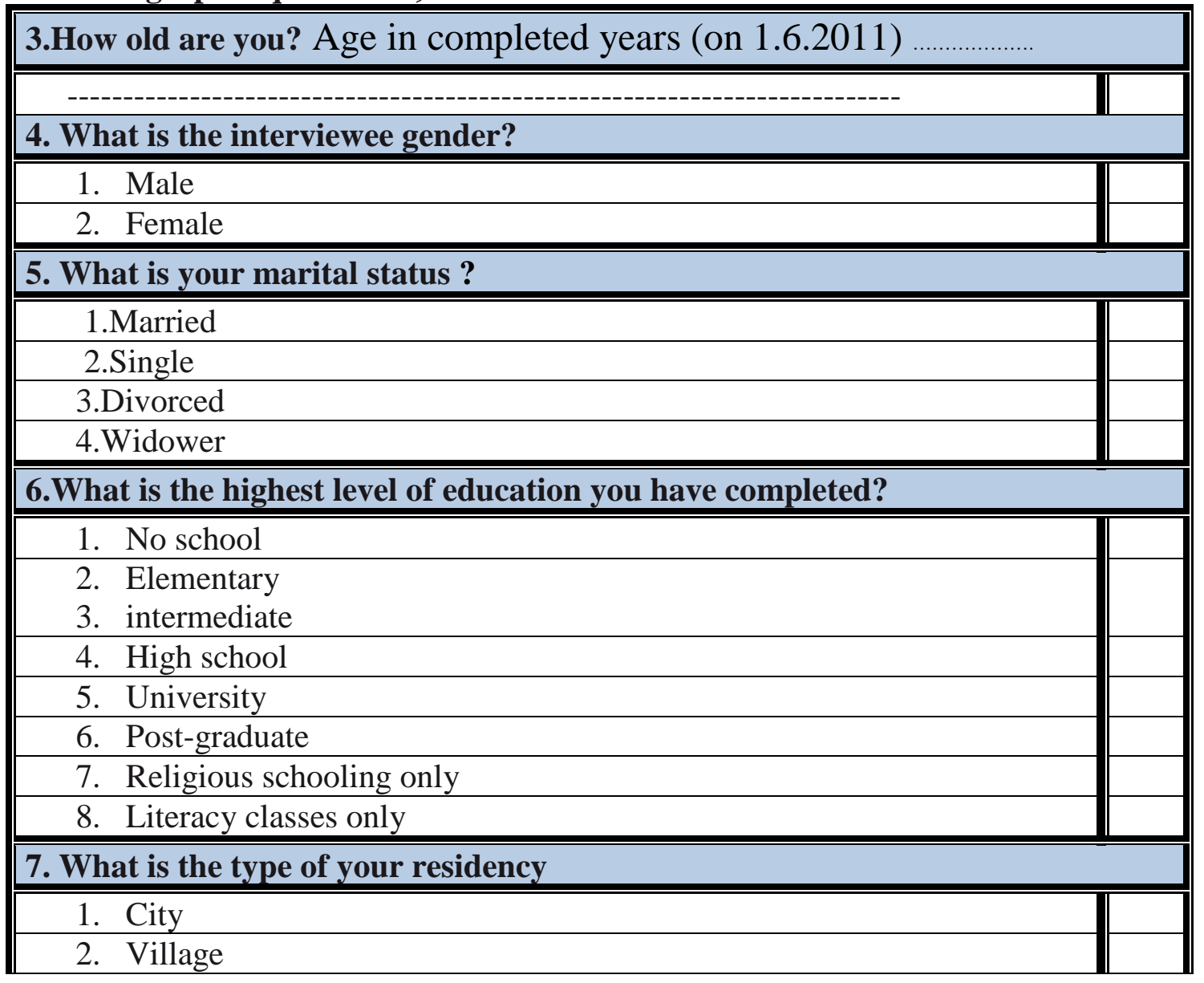




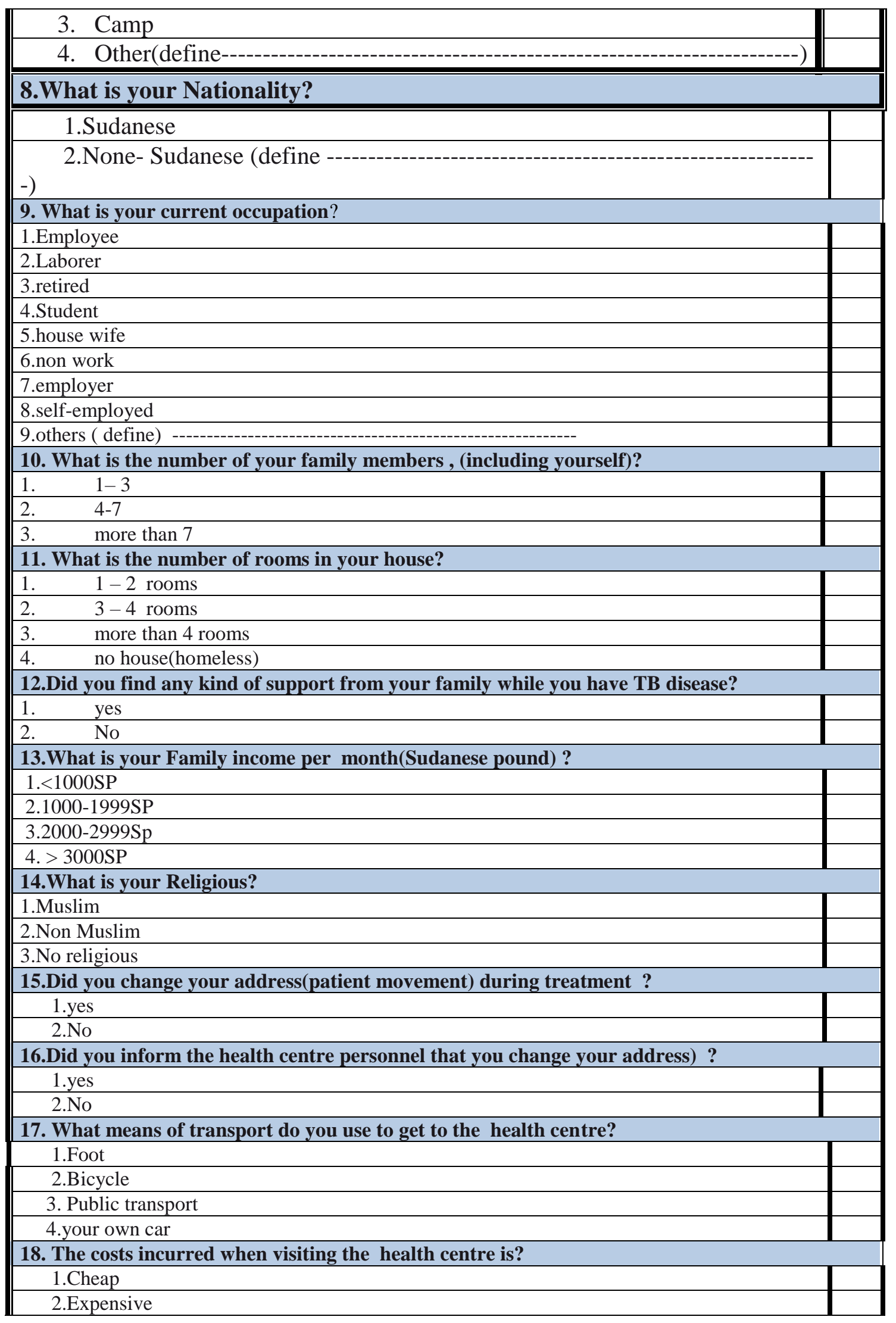


3. Reasonable

3. No money spent to reach the health centre

19. How far do you live from the nearest health clinic or hospital(Tuberculosis treatment clinic)?

Less than $2 \mathrm{~km}$ (kilometers)

2. $3-5 \mathrm{~km}$

3. $6-10 \mathrm{~km}$

4. More than $10 \mathrm{~km}$

20. How long does it take to reach the nearest health clinic or hospital(Tuberculosis treatment clinic)?

\section{B-TB knowledge and awareness}

\section{Do you hear about TB before you had it?}

1.Yes

2.No

22. In your opinion, what you expect if you stop TB treatment? (Please check all that are relevant)

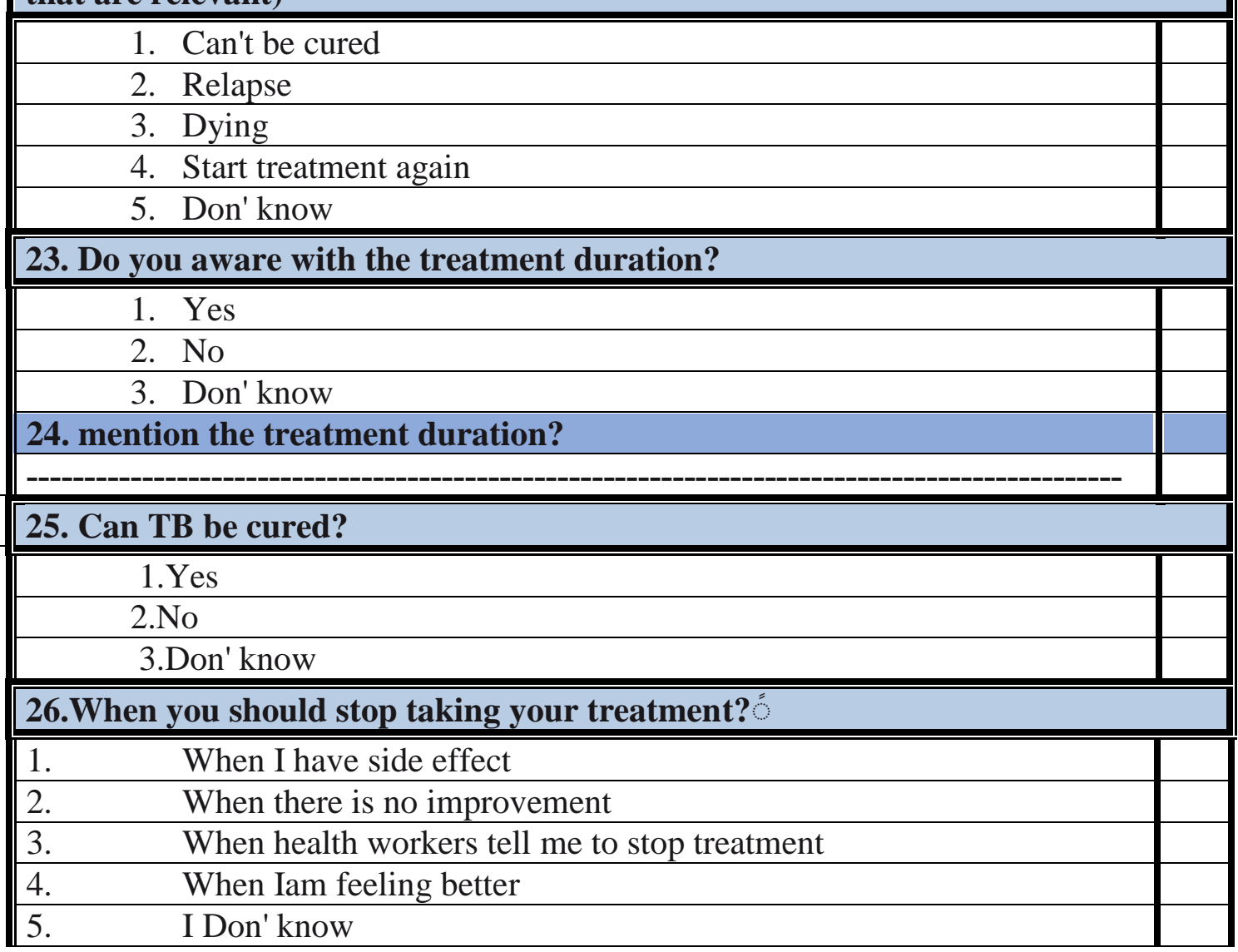

\section{Disease and Treatment related Factors:}

\begin{tabular}{|l||}
\hline 27. Did you receive BCG vaccination against TB? \\
\hline \hline 1.yes \\
\hline 2.No \\
\hline \hline 28.What was the result of sputum smear at the beginning of the disease ? \\
\hline
\end{tabular}




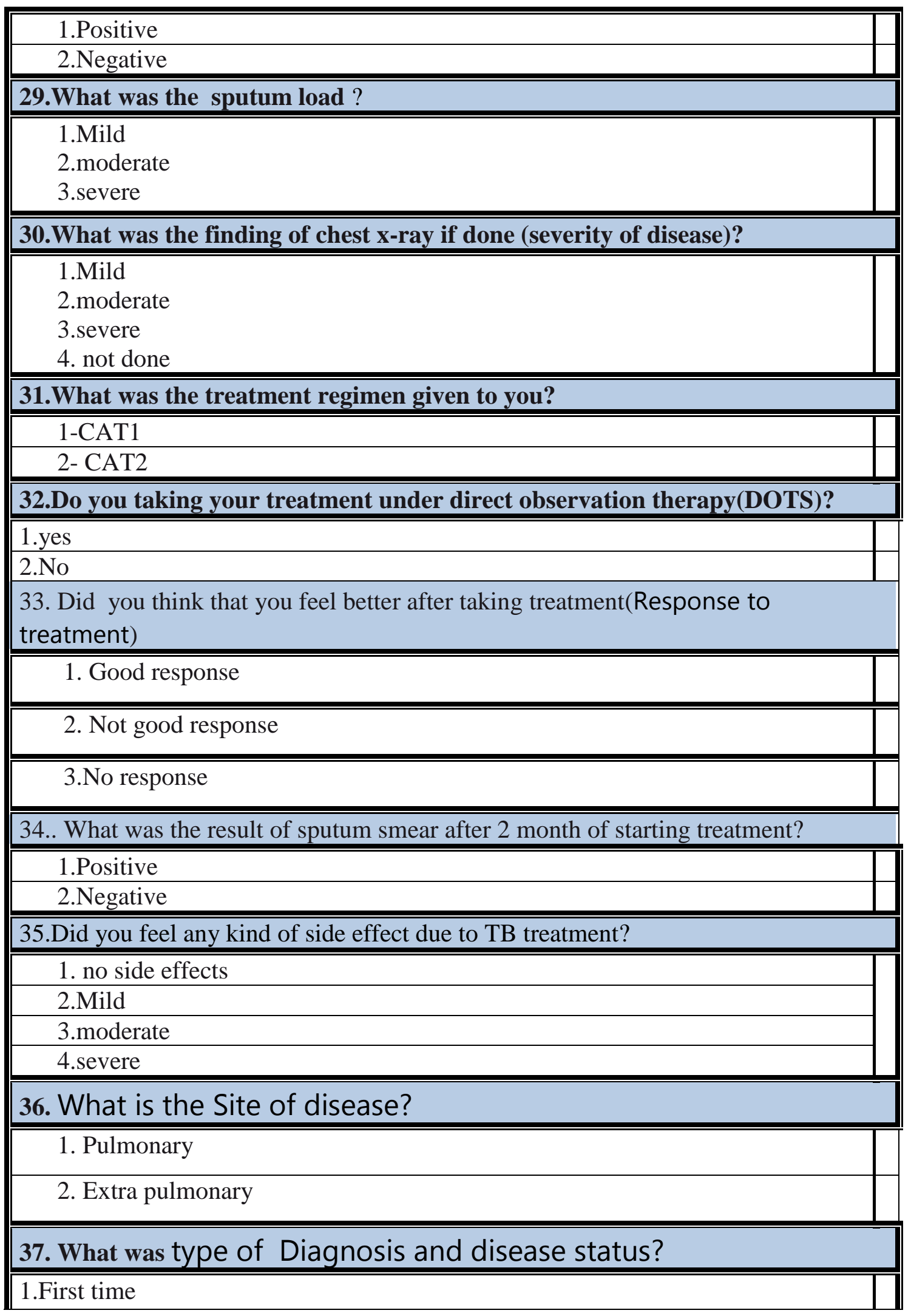




\begin{tabular}{|l|l||}
\hline 2. Relapsing disease & \\
\hline 3. MDRTB & \\
\hline 4.Treatment Failure & \\
\hline \hline 38.Do you have Chronic disease ? & \\
\hline \hline 1.yes & \\
\hline 2.No & \\
\hline 39.If yes define & \\
\hline \hline 1- DM & \\
3- Cardiac Diseases & \\
4- Renal diseases & Cancer \\
6- Other(define) ------------------------------------------------------- & \\
\hline \hline 40.During your course illness Did you receive any kind of treatment other than anti \\
tuberculosis drugs?
\end{tabular}

\section{D:Behavioral Factors:}

\begin{tabular}{||l|l|}
\hline 42. Do you smokes? & \\
\hline \hline 1.yes & \\
\hline 2.No & \\
\hline 43.Do you use Alcohol? & \\
\hline 1.yes & \\
\hline 2.No & \\
\hline 44.Do you have HIV (+ve ) disease? & \\
\hline 1.yes & \\
\hline 2.No & \\
\hline 45.Do you use intravenous drugs(IVDU)? & \\
\hline 1.yes & \\
\hline 2.No & \\
\hline 46.Do you use any other types of drugs? & \\
\hline 1.yes & \\
\hline 2.No & \\
\hline 47.If yes specify the type of drug? & \\
\hline 1.Cannbis & \\
\hline 2.benzene \\
\hline 3. Spirit \\
\hline 4.others (mention) \\
\hline
\end{tabular}


E. Stigma:

\begin{tabular}{|l|l|}
\hline 48. Do you feel shame to have TB? & \\
\hline 1. Yes, why ( & \\
\hline 2. No why ( & \\
\hline 3. I don't know & \\
\hline 49. Do you try to hide your TB disease from the others? & \\
\hline 1.Yes & \\
\hline 2.No & \\
\hline 3. don't know & \\
\hline $\begin{array}{l}\text { 50. Did some of your family, friends and colleagues treat you different when they } \\
\text { found out that you have TB? }\end{array}$ & \\
\hline 1.Yes & \\
\hline 2.No & \\
\hline 51.If yes specify & \\
\hline 1- Friends & \\
\hline 2- Family members & \\
\hline 3- colleagues & \\
\hline 52. How do you fell about being observed taking treatment? & \\
\hline 1.I Do not mind & \\
\hline 2.Feel embarrassed & \\
\hline
\end{tabular}

F:Patients Opinion about TB services:

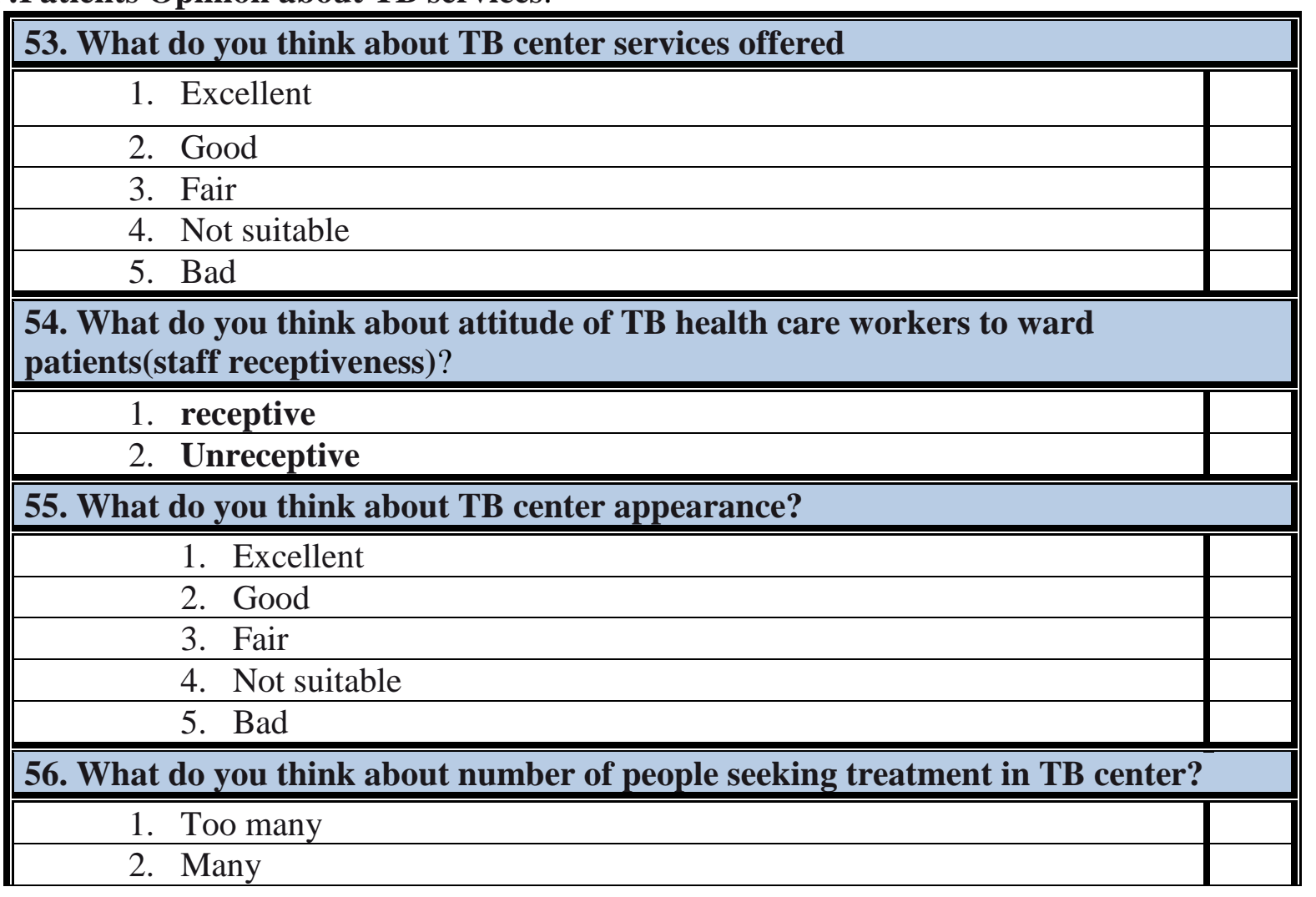




\begin{tabular}{||l|l||}
\hline 3. Suitable & \\
\hline 4. Few & \\
\hline 5. Very few & \\
\hline \hline 57. What do you think about your waiting time in TB center ? & \\
\hline \hline $1 . \quad<15$ minutes & \\
\hline $2 . \quad 15-30$ minutes & \\
\hline 3. $30-1$ hour $1-2$ hours & \\
\hline 5. more than 2 hours & \\
\hline 58.Do you satisfy with TB treatment given ? & \\
\hline \hline 1.yes & \\
\hline 2.No & \\
\hline 59.Were you given information on the dangers of interrupting treatment ? \\
\hline 1.yes
\end{tabular}

Name of interviewer:

Designation \& Health Center:

Thank you very much for you answer 
Appendix 2 


\section{QUESTIONNAIRE}

Use of Mobile health to improve adherence to TB treatment

The questions will be answer by the clients

Date: ___ __ $\quad \begin{aligned} & \text { locality: } \\ & \text { area: }\end{aligned}$

We wish to learn about your opinion regarding tuberculosis treatment (TB), the information you provide will be used to improve TB treatment.

Your answers will not be released to anyone and will remain anonymous. Your participation is voluntary and you may choose to stop the interview at any time.

Thank you for your assistance.

Interviewer: Place an $\mathrm{X}$ in the box of the selected answer(s).Do not read responses unless the directions indicate.

1. Study Serial No:

2. Patient status

1. Owner mobile phone

2. Do not have mobile phone

A- Socio- demographic questions:

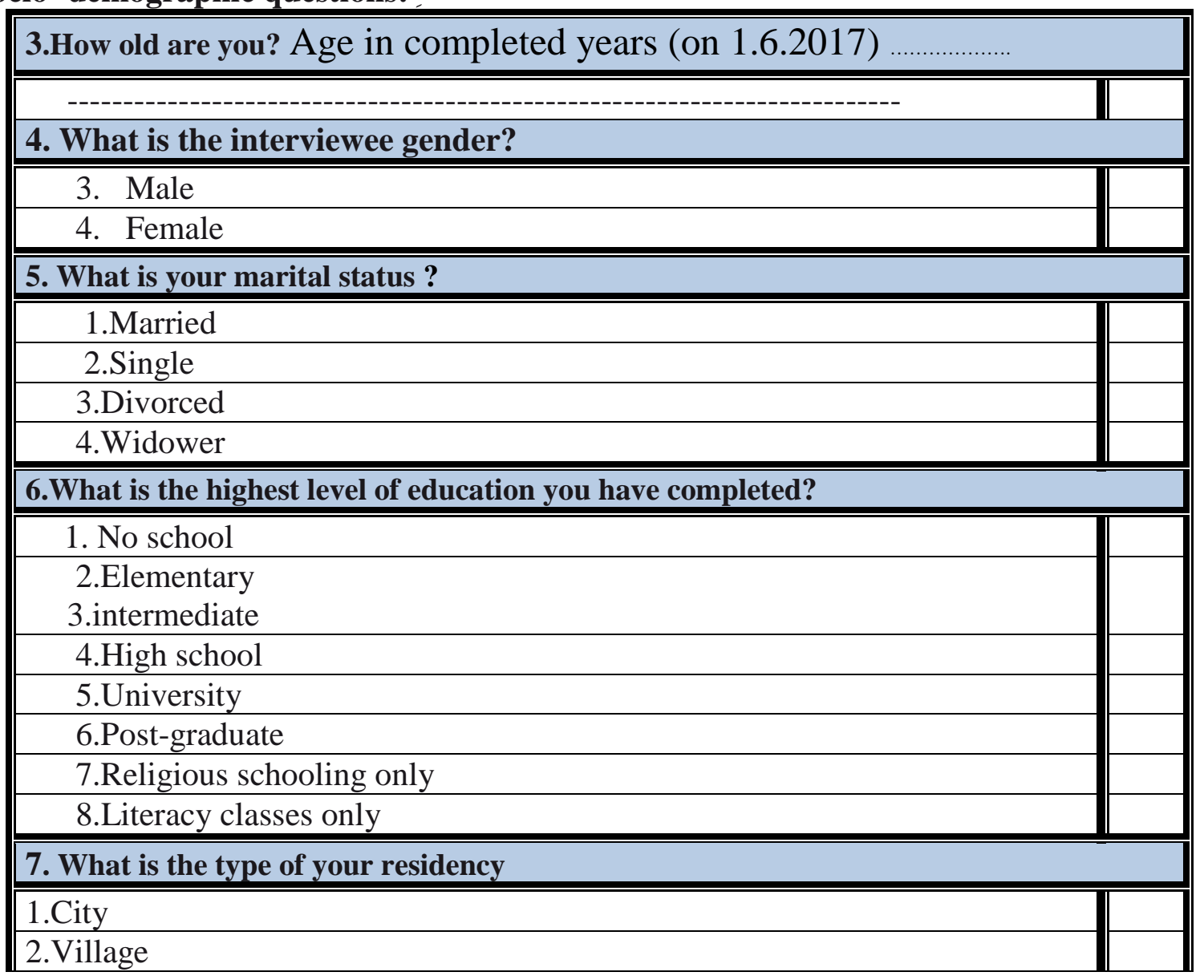




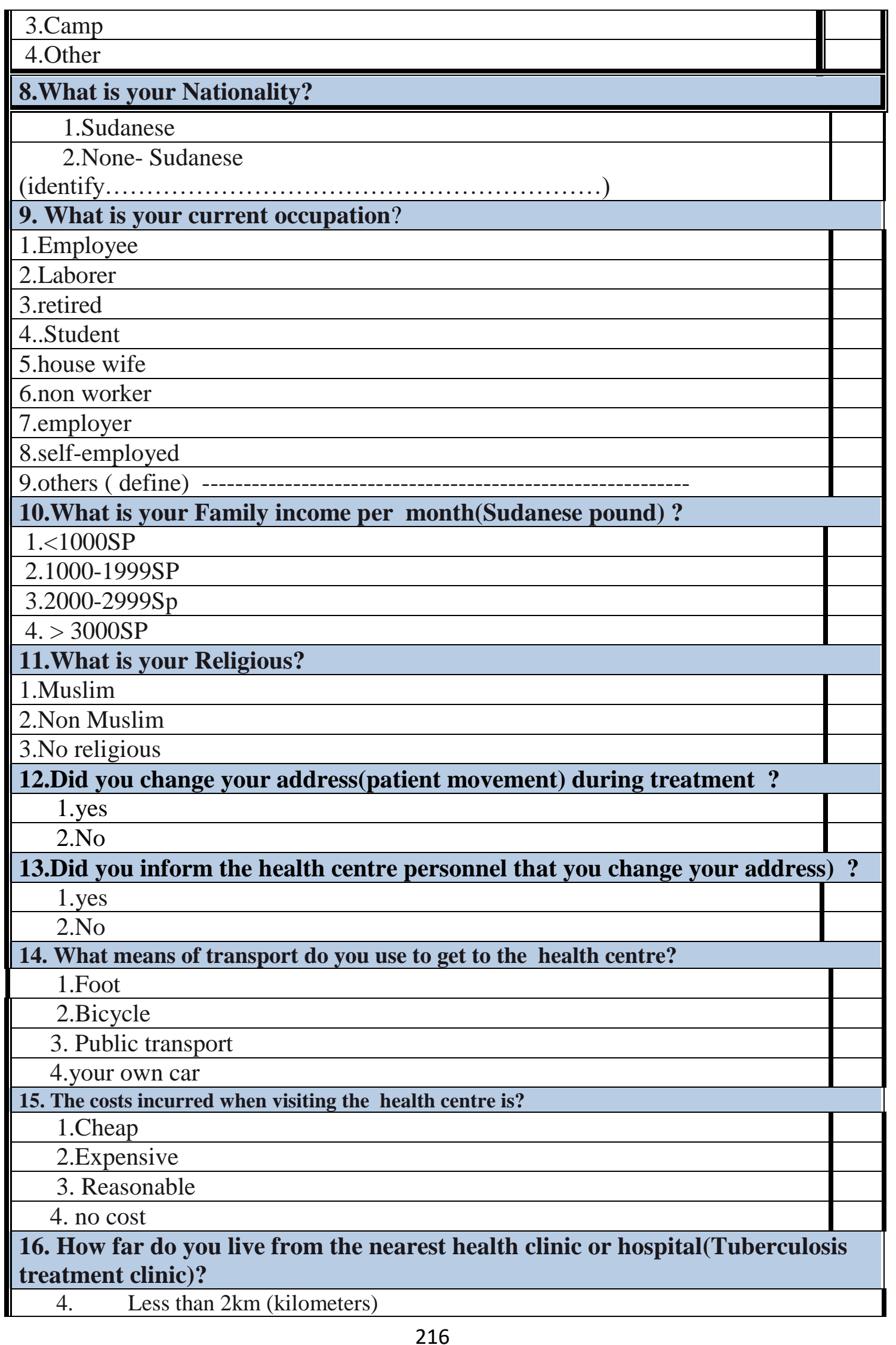




\begin{tabular}{|c|c|}
\hline 5. & $3-5 \mathrm{~km}$ \\
\hline $6 . \quad 6-10 \mathrm{~km}$ \\
\hline $4 . \quad$ More than $10 \mathrm{~km}$ \\
\hline $\begin{array}{l}\text { 17. How long does it take to get to the nearest health unit or hospital to be } \\
\text { treated (a treatment unit for TB patients) }\end{array}$ \\
\hline
\end{tabular}

\section{B-TB knowledge and awareness}

\begin{tabular}{|l||l|}
\hline 18.Do you hear about TB before you had it? \\
\hline \hline 1.Yes & \\
\hline 2.No & \\
\hline
\end{tabular}

19. In your opinion, what you expect if you stop TB treatment? (Please check all that are relevant)

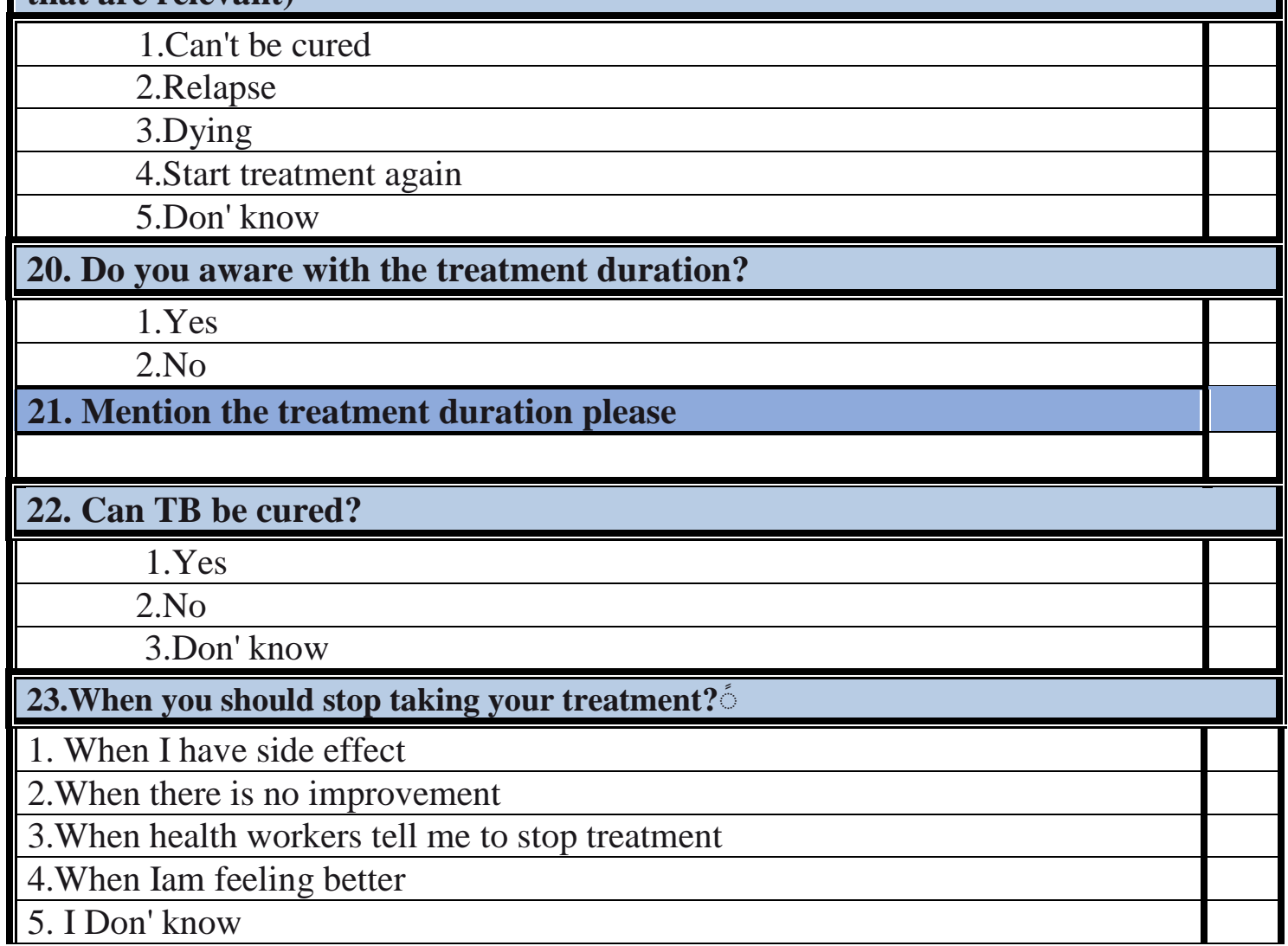

\section{Disease and Treatment related Factors:}

\begin{tabular}{||l||}
\hline 24. What was the result of sputum smear at the beginning of the disease ? \\
\hline 1.Positive \\
\hline 2.Negative \\
$\begin{array}{l}\text { 25. Did you think that you feel better after taking treatment(Response to } \\
\text { treatment) }\end{array}$ \\
\hline \hline 1. Good response
\end{tabular}




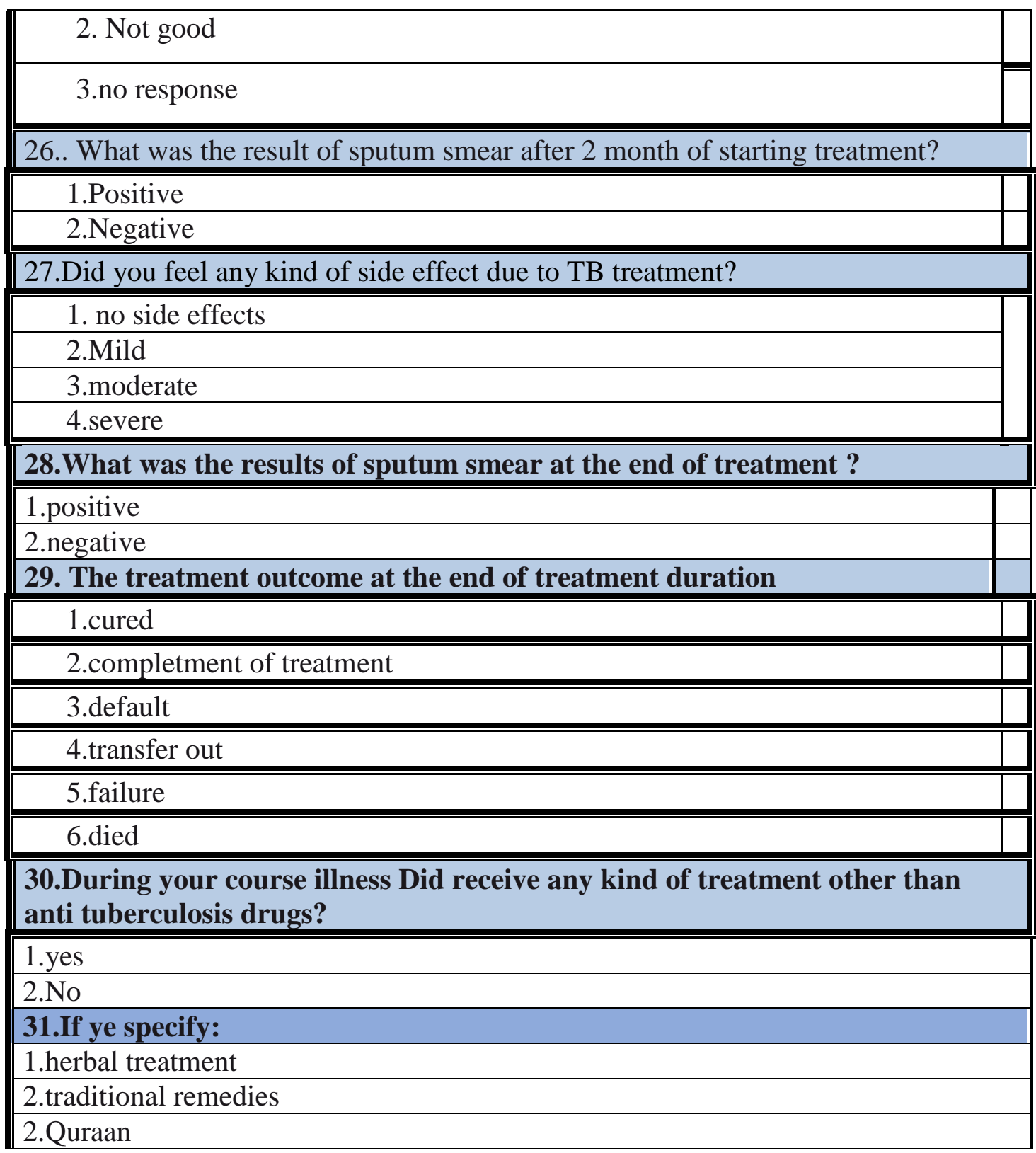

\section{D:Behavioral Factors:}

\begin{tabular}{|l|l|}
\hline 32. Do you smokes? & \\
\hline 1 .yes & \\
\hline 2.No & \\
\hline 33.Do you use Alcohol? & \\
\hline 1.yes & \\
\hline 2.No & \\
\hline 34.Do have HIV (+ve ) disease? & \\
\hline 1.yes & \multicolumn{2}{|l|}{} \\
\hline 2.No & \\
\hline
\end{tabular}




\begin{tabular}{||l|l|}
\hline 35.Do you use intravenous drugs(IVDU)? & \\
\hline 1.yes & \\
\hline 2.No & \\
\hline 36.Do you use any other types of drugs? & \\
\hline 1.yes & \\
\hline 2.No & \\
\hline 37.If yes specify the type of drug? & \\
\hline 1.Cannbis & \\
\hline 2.benzene & \\
\hline 3. Spirit & \\
\hline 4.others & \\
\hline
\end{tabular}

\section{E. Stigma:}

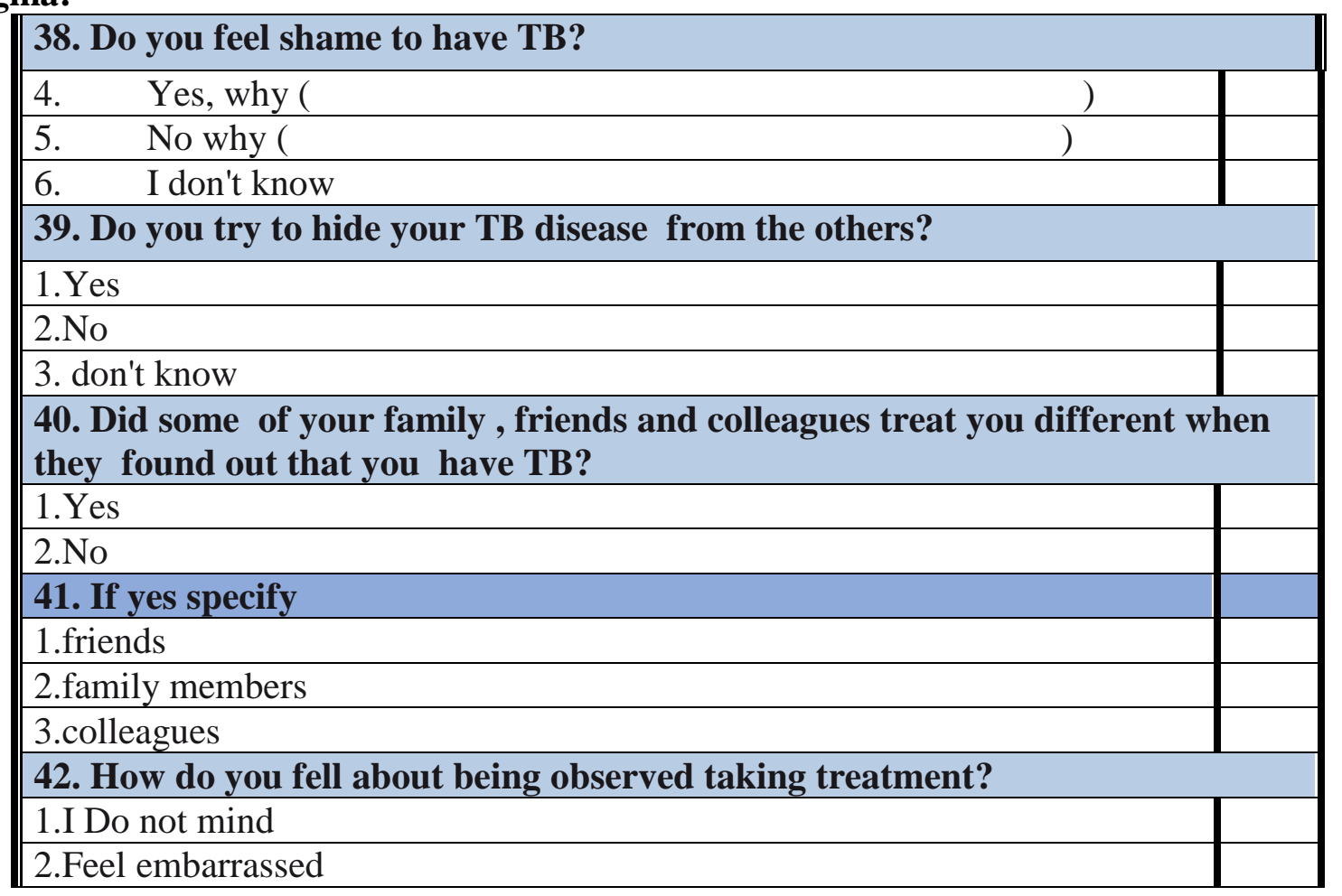

F:Satisfaction about TB services:

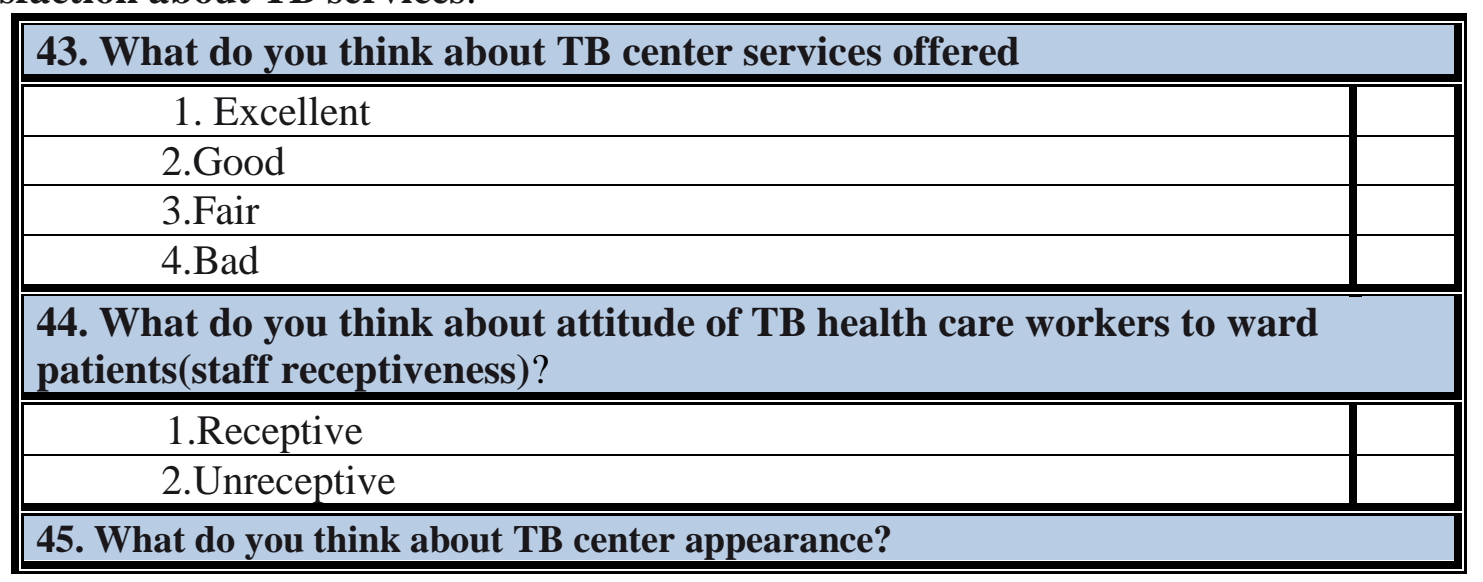




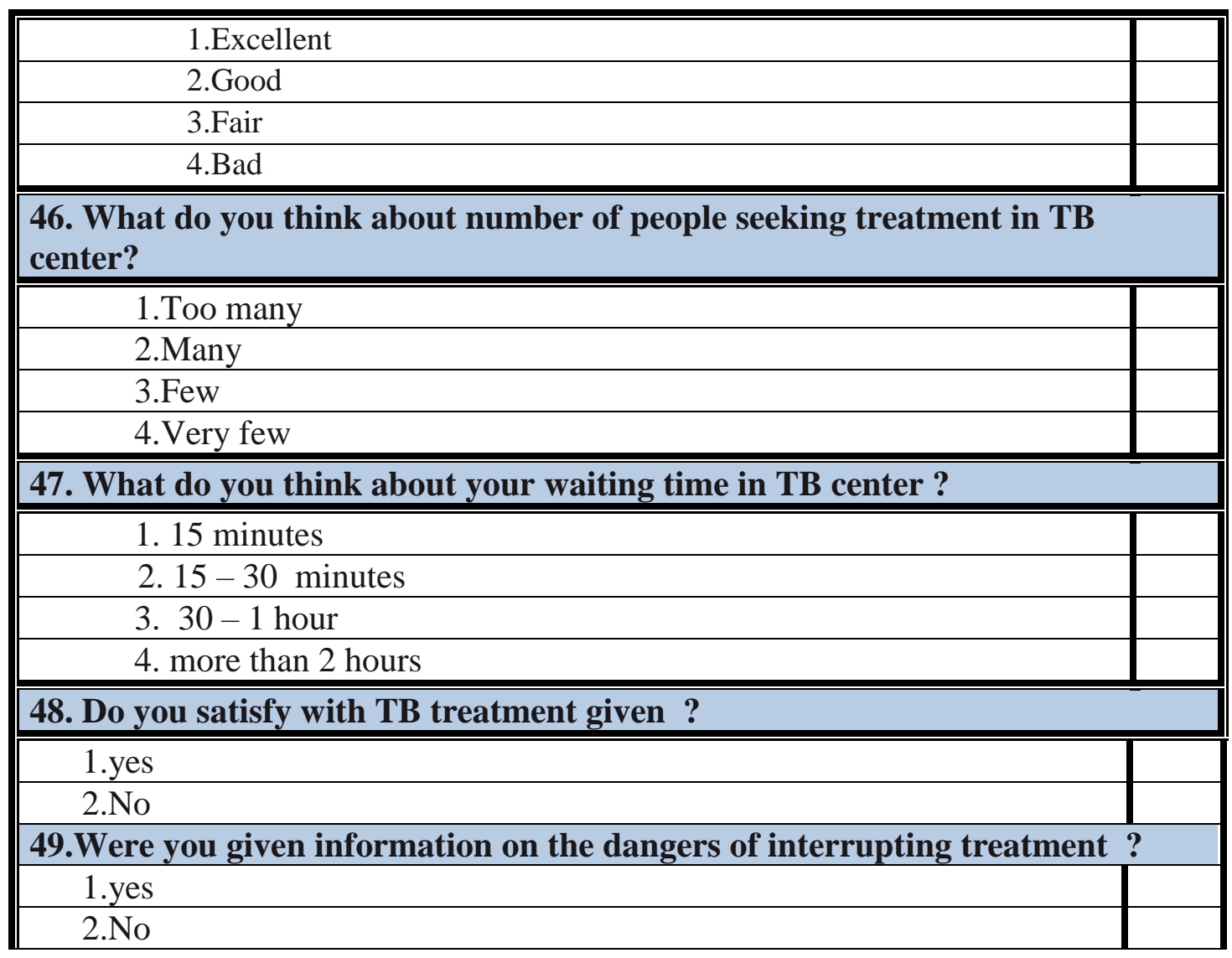

Name of interviewer:

Designation \& Health Center:

Thank you very much for you answer 


\section{Acknowledgements}

I would like to express my deepest gratitude to my supervisor Professor Martin Hendrik Prins. I cannot have sufficient words to thank you for your wide knowledge, dedicated and strong support, instant feedback, patience, and friendliness. Despite his tight schedule, Prof. Prins always made time to discuss problems and offered valuable advices. Your understanding, advice, logical way of thinking have been of great value for me, gave me confidence to work independently to think critically. Your continuous support and guidance encourage me to complete this thesis in proper and smart way.

I wish to express my sincere appreciation to staff of Epidemiology department, Faculty of Health, Medicine and Life Sciences, University of Maastricht for their support, warm hospitality and provided services.

I am thankful to my colleagues and staff at ministry of health, Khartoum state for their support throughout this work, Also I would like to thank the staff of National Tuberculosis Control Programme at different levels in in Khartoum State for all-rounded support, cooperation, and great help in data collection. I am grateful to all the patients and participants from all over Khartoum State who took part in the study.

My Family was virtually always with me at home and in abroad throughout this study. Always my family is the source of inspiration and the reason of success in my life. Thank you for your care and support to enable me to continue and complete this thesis. 


\section{Samenvatting ( Curriculum Vitae)}

\section{About the author}

Ahmed Osman was born on January 01, 1965 in Gezira, Sudan. He received his Bachelor of Medicine and Surgery (MBBS) from University of Gezira in 1993. During the period 1993 to1995, he fulfilled an internship at Medani teaching Hospital. Then he served as medical officer at Medani Teaching Hospital, Sudan from 1995 to 1997. A Key achievement he made during the period was to lead the efforts of introducing renal dialysis services for the first time in the hospital. In 1998, he completed a Master in Public health from University Malaya, Malaysia. In 1999, he received a Master degree in Epidemiology from University Malaya, Malaysia.

From 1999 to 2002, Ahmed worked as a Public Health and Epidemiology Specialist at Ministry of Health, Khartoum State, Sudan. His main Task to implement the surveillance programme of infectious diseases; capacity building included the staff training, awareness raising, knowledge, and improvement of skills and capability with respect to control and prevention of infectious diseases, as well as early detection of infectious diseases, outbreak investigation, environmental sanitation and vector control, vaccination campaign. He contributed to development of manuals and protocols at state and national level. In addition, he participated in training of health care professionals. During this period, he guided expansion implementation of epidemiology programmes including TB programme in Khartoum State. Moreover, he attended many seminars and workshops related to infectious disease surveillance, surveys and researches. In 2000, he received a Fellowship degree in Community Medicine.

In the period from 2002 to 2009, he joined the Ministry of Education in Riyadh, Saudi Arabia, to work as public health specialist at General Directorate of School Health. 
From 2009, onward Ahmed started working as a public health and epidemiology specialist at Ministry of Health in Riyadh, Saudi Arabia. He served the General Directorate of Infectious Diseases Control at different capacities, including Tuberculosis Control programme. During this period, he participated in the implementation of Tuberculosis programme strategies, training of health care professional, surveys and writing of protocols and notification forms for these programmes beside the update of these protocols and forms. Moreover, he is currently supervising the implementing of Tuberculosis programme by health facilities in district and provinces, which include case detection, notification of cases, epidemiological investigation, lab investigation, case treatment, contacts tracing and other epidemiological interventions. In addition, he participates in National TB control programme efforts to achieve the aims of END TB Strategy. 